Aus der Abteilung Hals-Nasen-Ohrenheilkunde

(Prof. Dr. med. C. Matthias)

im Zentrum Augenheilkunde und Hals-Nasen-Ohrenheilkunde der Medizinischen Fakultät der Universität Göttingen

\title{
Auditory Steady-State Responses (ASSR) und transiente auditorische Hirnstammpotenziale: \\ Evaluation und Hörschwellenvergleich an Mausmodellen der sensorineuralen Schwerhörigkeit
}

\author{
INAUGURAL - DISSERTATION \\ zur Erlangung des Doktorgrades \\ der Medizinischen Fakultät \\ der Georg-August-Universität zu Göttingen
}

\author{
vorgelegt von \\ Dania Pauli-Magnus \\ aus \\ Frankfurt am Main
}

Göttingen 2010 
Dekan: $\quad$ Prof. Dr. med. Frömmel

I. Berichterstatter: Prof. Dr. med. Moser

II. Berichterstatter/ in: Prof. Dr. rer. nat. Dr. med. Schild

III. Berichterstatter/ in: Prof. Dr. med. Paulus

Tag der mündlichen Prüfung: $\quad$ 01.03.2011 


\section{Inhaltsverzeichnis}

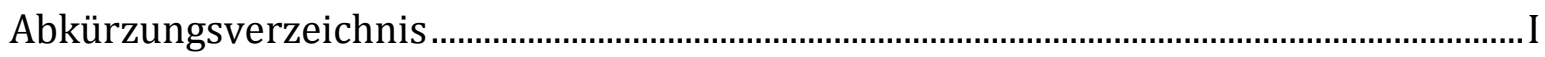

Abbildungsverzeichnis ..................................................................................................................II

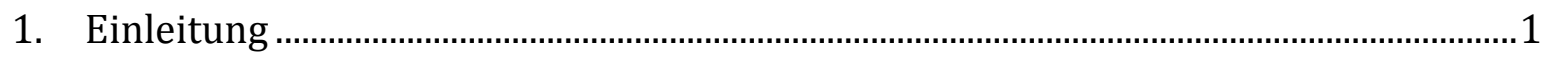

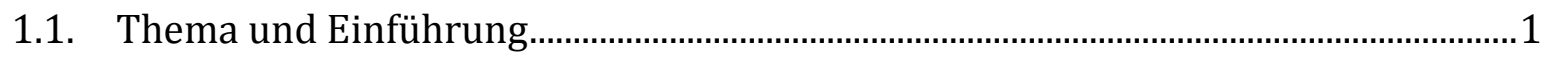

1.2. Anatomie und Hörfunktion..............................................................................................

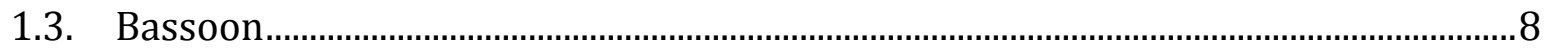

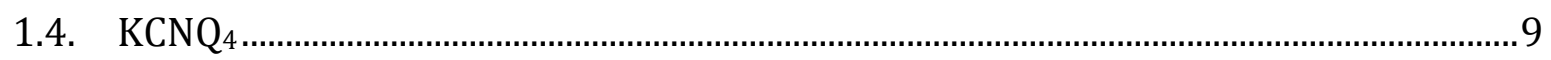

1.5. Akustisch evozierte Potenziale - AEP ……………………………………………….... 11

1.5.1. Grundlagen der AEP ........................................................................................... 11

1.5.2. Brainstem Evoked Response Audiometry- BERA....................................................13

1.5.3. Auditory Steady-State Responses - ASSR................................................................. 15

1.5.4. Otoakustische Emissionen - OAEs .......................................................................... 20

1.6. Entstehung und Ziel der Arbeit ................................................................................2.

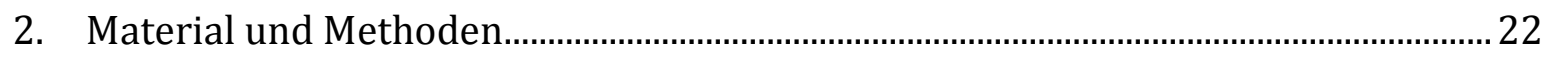

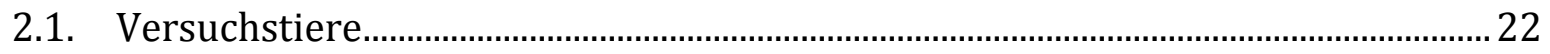

2.1.1. Technischer Aufbau.................................................................................................... 23

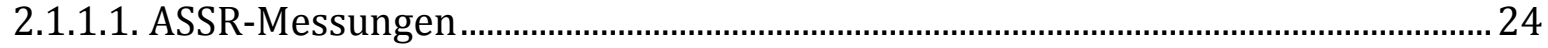

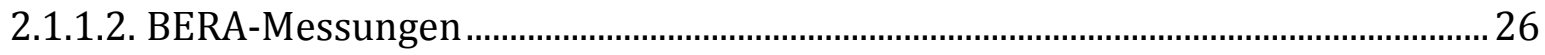

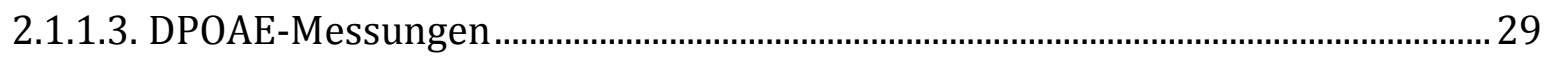

2.2. Datenanalyse und statistische Auswertung ................................................................. 30 
3. Ergebnisse.

3.1. Normalhörende Tiere

3.1.1. Modulation Transfer Function (MTF) und optimale Messdauer 31

3.1.2. ASSR-Amplitudenwachstum bei normalhörenden Tieren. 34

3.1.3. Hörschwellenbestimmung mittels ASSR und BERA .................................................. 35

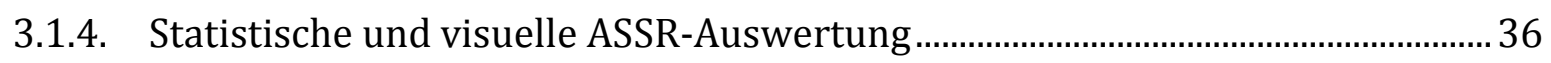

3.1.5. ASSR bei experimenteller Schallleitungsschwerhörigkeit.......................................39

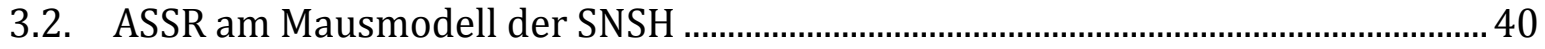

3.2.1. Modulation Transfer Function bei SNSH ................................................................... 40

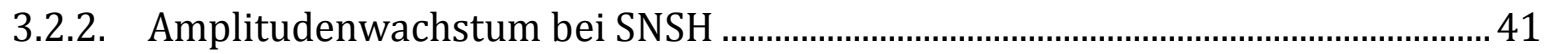

3.2.3. Hörschwellenvergleich mit ASSR und BERA bei SNSH .......................................... 42

3.3. ASSR, Tb-BERA und DPOAEs zur Differentialdiagnose der SNSH .......................... 45

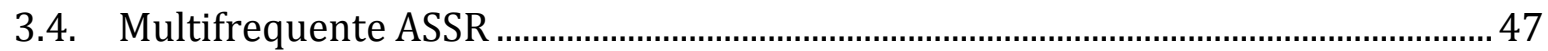

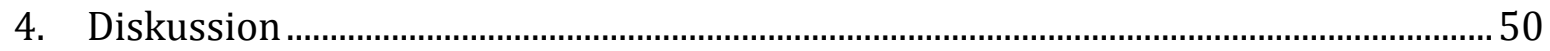

4.1. Nutzen der ASSR zur audiologischen Untersuchung der Maus ................................50

4.2. Etablierung der ASSR-Messungen mit dem TDT-III-System .................................... 51

4.3. Vergleich der Hörschwellenmessungen der Maus mit dem TDT-III-System ........53

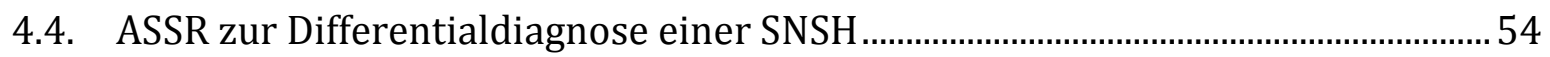

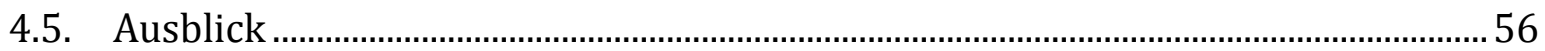

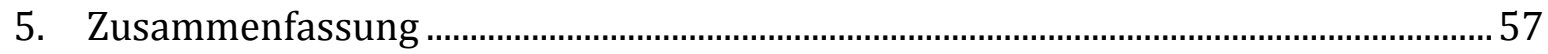

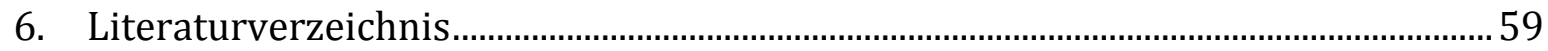




\section{Abkürzungsverzeichnis}

\begin{tabular}{|c|c|}
\hline Abb. & Abbildung \\
\hline A/ D & Analog/ Digital \\
\hline AEP & Akustisch Evozierte Potenziale \\
\hline ÄHZ & äußere Haarzellen \\
\hline ASSR & Auditory Steady-State Responses \\
\hline BERA & Brainstem Evoked Response Audiometry \\
\hline BK & "big conductance" Kalium Kanal \\
\hline Bsn & Bassoon \\
\hline CMV & Cytomegalie-Virus \\
\hline $\mathrm{D} / \mathrm{A}$ & Digital/ Analog \\
\hline DNA & Desoxyribonukleinsäure \\
\hline $\mathrm{dB}$ & Dezibel \\
\hline dB SPL & Dezibel Schalldruckpegel (engl.: Sound Pressure Level) \\
\hline $\mathrm{dB} H \mathrm{H}$ & Dezibel Hearing Level \\
\hline $\mathrm{DP}$ & Distorsionsprodukt \\
\hline DPOAE & Distortionsprodukt Otoakustische Emissionen \\
\hline EEG & Elektroenzephalogramm \\
\hline EKG & Elektrokardiogramm \\
\hline f & Frequenz \\
\hline FAEP & Frühe Akustisch Evozierte Potenziale \\
\hline FFT & Fast Fourier Transformation \\
\hline $\mathrm{Hz}$ & Hertz \\
\hline $\mathrm{IHZ}$ & innere Haarzellen \\
\hline $\mathrm{J}$ & Jewett \\
\hline $\mathrm{kDa}$ & kilo Dalton \\
\hline KO & Knock-out \\
\hline $\mathrm{L}$ & Lautstärkepegel \\
\hline MAEP & Mittlere Akustisch Evozierte Potenziale \\
\hline $\mathrm{mM}$ & Millimol \\
\hline MTF & Modulation Transfer Function \\
\hline
\end{tabular}




$\begin{array}{ll}\text { MF } & \text { Modulationsfrequenz } \\ \text { MT } & \text { Modulationstiefe } \\ \mathrm{n} & \text { Stichprobengröße } \\ \mathrm{Ncl} & \text { Nucleus } \\ \mathrm{p} & \text { Signifikanzniveau } \\ \text { PCR } & \text { Polymerasekettenreaktion } \\ \text { RP } & \text { Real-Time Prozessor } \\ \text { SAM-Ton } & \text { Sinusförmig Amplitudenmodulierter Ton } \\ \text { SLS } & \text { Schallleitungsstörung } \\ \text { SNSH } & \text { Sensorineurale Schwerhörigkeit } \\ \text { SGN } & \text { Spiralganglienneurone } \\ \text { SE } & \text { Standardfehler } \\ \text { SD } & \text { Standardabweichung } \\ \text { Tb } & \text { Tonburst } \\ \text { TDT } & \text { Tucker-Davis Technologies } \\ \text { TF } & \text { Trägerfrequenz } \\ \text { WHO } & \text { World Health Organisation } \\ \text { WT } & \text { Wildtyp }\end{array}$




\section{Abbildungsverzeichnis}

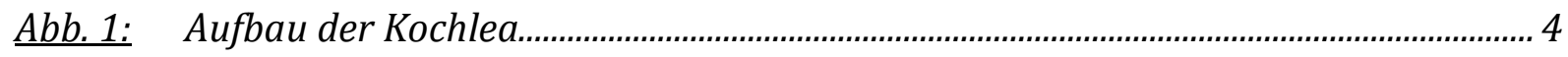

Abb. 2: $\quad$ Aufbau der IHZ und des synaptischen Bandes ......................................................... 9

Abb. 3: $\quad$ Darstellung der AEP nach ihrer Latenz ....................................................................13

Abb. 4: $\quad$ Vergleich der transienten und stationären AEP-Stimuli.............................................19

Abb. 5: Gedankenmodell zur Entstehung der DPOAEs.........................................................21

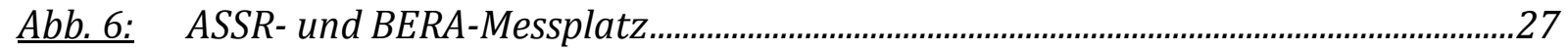

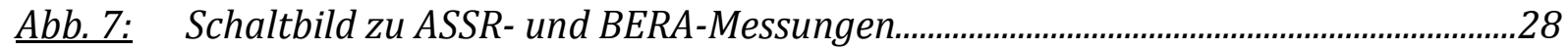

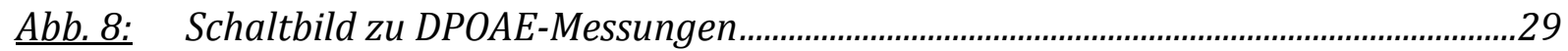

Abb. 9: $\quad$ Einfluss der Messdauer auf ASSR-Hörschwelle und ASSR-Amplitude........................32

Abb. 10: Modulation Transfer Function (MTF) .....................................................................33

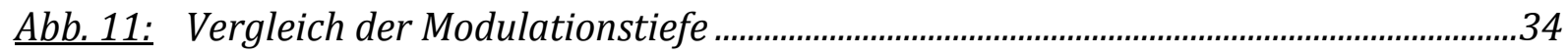

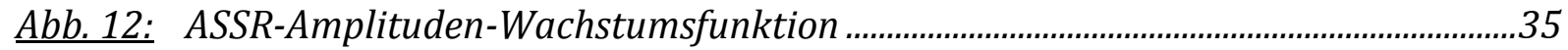

Abb. 13: Box-Plots der ASSR- und Tb-BERA Hörschwellen der WT-Tiere .................................36

Abb. 14: Box-Plots und Korrelationsdiagramme der statistischen und visuellen ASSR-

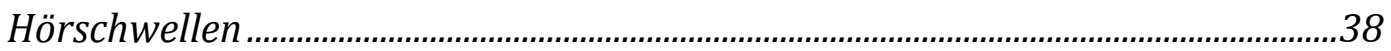

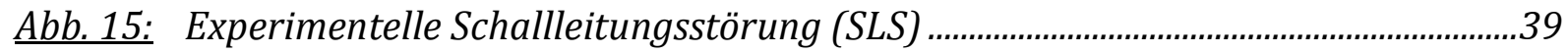

Abb. 16: Modulation Transfer Function (MTF) der KO-Tiere...................................................41

Abb. 17: ASSR-Amplituden-Wachstumsfunktion der SNSH-Tiere ............................................42

Abb. 18: Box-Plots und Korrelationsdiagramme der ASSR- und BERA-Hörschwellen der

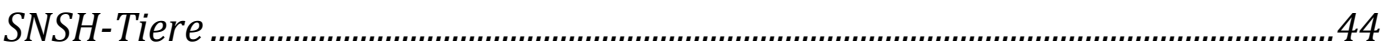

Abb. 19: Profil der sensorineuralen Schwerhörigkeit (SNSH)..................................................46

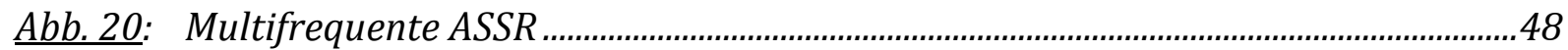

Abb.21: Amplitudenwachstum bei multifrequenter ASSR ….....................................................48 


\section{Einleitung}

\subsection{Thema und Einführung}

Schwerhörigkeit spielt, als die häufigste Erkrankung der sensorischen Wahrnehmung des Menschen (Kalatzis und Petit 1998), in der Gesellschaft eine wichtige Rolle und stellt für Betroffene jeden Lebensalters eine schwere Einschränkung der Wahrnehmung, Kommunikation und Lebensqualität dar. Der WHO nach litten 2005 weltweit 278 Millionen Menschen an einem mittel- bis schwerwiegendem Hörverlust beider Ohren (http://www.who.int/mediacentre/factsheets/fs300/en/index.html). Das Deutsche Zentralregister für kindliche Hörstörungen berichtet von etwa 20000- 35000 in Deutschland lebenden Kindern und Jugendlichen mit einer Hörstörung von mehr als $40 \mathrm{~dB}$ auf dem besser hörenden Ohr (Gross et al. 1999). Einer allgemeinmedizinischen Untersuchung nach wird geschätzt, dass bereits $19 \%$ der deutschen Bevölkerung über dem 14. Lebensjahr hörgeschädigt sind (Sohn 2001).

Schwerhörigkeit kann nach verschiedenen Aspekten eingeteilt und beschrieben werden. Je nach anatomischer Lokalisation des Defekts können unterschiedliche klinische Krankheitsbilder differenziert werden. Die häufigste Form der Schwerhörigkeit mit $70 \%$ ist die sensorineurale Schwerhörigkeit (SNSH). Hierunter versteht man eine Schallempfindungsstörung, welche sowohl durch Defekte der Sinneszellen im Innenohr (kochleärer Typ) als auch durch Defekte der Nervenfasern des Hörnervs entstehen kann (retrokochleärer Typ). Defekte des kochleären Verstärkersystems, hervorgerufen durch den Funktionsverlust der äußeren Haarzellen (ÄHZ), führen zu einem mittelgradigen Hörverlust mit positivem Recruitmentphänomen. Defekte an der Synapse führen durch eine gestörte Reizweiterleitung zu einer fehlenden zeitgetreuen Wahrnehmung des Gehörten, was als auditorische Synaptopathie bezeichnet wird (Übersicht in Strenzke et al. 2008). Die SNSH wird von der konduktiven (schallleitungsbedingten), der kombinierten und der zentralen Schwerhörigkeit (Kalatzis und Petit 1998) abgegrenzt. Weiterhin wird die angeborene von der erworbenen Schwerhörigkeit unterschieden. Eine angeborene Schwerhörigkeit tritt als Folge von pränatalen Infekten (z.B. Röteln, Toxoplasmose, CMV) oder nach medikamentös-toxischer Exposition während der Schwangerschaft auf. Die Prävalenz angeborener Hörstörungen wird weltweit auf 1- 6/ 1000 Neugeborenen geschätzt (Morton 1991). In Deutschland liegt die Prävalenz etwa bei 1,2/ 1000 (Deutsches Zentralregister für kindliche Hörstörungen, Gross et al. 1999). 
Schätzungsweise $35 \%$ der angeborenen Schwerhörigkeit sind nach dem deutschen Zentralregister für kindliche Hörstörungen genetisch bedingt (Gross et al. 2001). Diese wird in syndromale (assoziiert mit Symptomen anderer Organsysteme) und nichtsyndromale Schwerhörigkeit unterteilt. $70 \%$ der genetisch bedingten Schwerhörigkeiten sind nicht-syndromal (Kalatzis und Petit 1998). Nicht-syndromale Schwerhörigkeit kann X-chromosomal, autosomal-dominant, autosomal-rezessiv oder mitochondrial vererbt werden. Etwa 15 \% der nicht-syndromalen Schwerhörigkeit folgt einem autosomal-dominanten Erbgang (Kalatzis und Petit 1998) und wird als DFNA bezeichnet.

Schwerhörigkeit ist eine der heterogensten Erkrankungen des Menschen überhaupt. Vermutlich infolge phänotypischer Variationen eines bekannten Pathomechanismus und durch eine komplexe Pathologie der Krankheitsbilder selbst ist eine SNSH selten aufgrund eines einzigen Krankheitsmechanismus erklärbar (Review in Ohlemiller, 2006). Ausnahmen bilden seltene monogenetische, hereditäre Formen der SNSH (Petit et al. 2001, Steel und Kros 2001). Eine große Anzahl von Genen wird für die Entstehung der nicht-syndromalen Schwerhörigkeit verantwortlich gemacht. Bis heute sind 55 Gene und 117 Loci bekannt. Eine ausführliche Darstellung zum aktuellen Stand ist auf der „Hereditary Hearing Loss Homepage“ einzusehen (http://webh01.ua.ac.be/hhh/).

Schwerhörigkeit kann auch nach dem Zeitpunkt ihrer Manifestation unterschieden werden. Tritt sie innerhalb der ersten zwei Lebensjahre, vor dem Erwerb der Sprachfähigkeit auf, wird sie als prälinguale Schwerhörigkeit bezeichnet, danach als postlinguale Schwerhörigkeit.

Je nach Ausprägung wird die Schwerhörigkeit in eine milde $(<40 \mathrm{~dB}$ Hörverlust), mittelgradige (41-55 dB Hörverlust), hochgradige (56-70 dB Hörverlust) schwerwiegende (71-90 dB Hörverlust), oder profunde (>91 dB Hörverlust) Form eingeteilt (Kalatzis und Petit 1998).

Die Manifestation und Prognose der Schwerhörigkeit eines Patienten hängen entscheidend von ihren zugrundeliegenden Krankheitsmechanismen ab. Insbesondere bei Säuglingen und Kleinkindern ist eine rasche Diagnosestellung und Rehabilitation unabdingbar für eine optimale Entwicklung der sprachlich-kommunikativen Fähigkeiten. Trotz eines beträchtlichen Fortschritts der psychoakustischen und physiologischen Untersuchungsmöglichkeiten sind wir noch weit entfernt von einer zuverlässigen klinischen Identifikation der Krankheitsursachen eines SNSH-Patienten. 
Mausmodelle einer humanen SNSH (Steel und Kros 2001) bieten wertvolle Möglichkeiten zur Entwicklung audiologischer Untersuchungsprotokolle für die Entschlüsselung von vorherrschenden Krankheitsmechanismen. So zeigen Modelle eine selektive Einschränkung kochleärer Prozesse an den hörphysiologisch wichtigen funktionellen Untereinheiten, wie z.B. der Endolymphproduktion, der Ionenhomöostase (Review in Jentsch 2000, Wangemann 2006), der elektromechanischen Transduktion (Review in Steel und Kros 2001) oder der Verstärkerfunktion der ÄHZ (Liberman et al. 2002, Cheatham et al. 2005). Andere Mausmodelle ergründen die synaptische Transmission an den IHZ (Khimich et al. 2005, Roux et al. 2006) oder die Generierung der Aktionspotenziale im Hörnerv (z.B. Zhou et al. 1995, Parkinson et al. 2001, Lacas-Gervais et al. 2004, Delmaghani et al. 2006).

Das Arbeiten mit Mausmutanten und ihren gesunden Wurfgeschwistern vermeidet einige Quellen der Variabilität, welche die Diagnostik der SNSH erschweren kann. Besonders wichtig erscheint jedoch, dass die auditorischen Defekte zu ihren funktionellen Einschränkungen und morphologischen Veränderungen auf zellulärer Ebene korreliert werden können. Dies erlaubt eine exakte Aufklärung der Rolle der beteiligten Proteine und die Indentifizierung der Krankheitsmechanismen (z.B. Kharkovets et al. 2006, Roux et al. 2006).

Hörstörungen der Maus wurden bisher meist mit der Hirnstammaudiometrie (Brainstem Evoked Response Audiometry- BERA) und den Otoakustischen Emissionen (OAE) untersucht. Die BERA stellt dabei sowohl im tierexperimentellen als auch im klinischen Bereich den diagnostischen Goldstandard zur objektiven Hörschwellenbestimmung dar. In dieser Arbeit werden erstmals die frequenzspezifischen Auditory Steady-State Responses (ASSR) der Maus charakterisiert. Sie werden dann zur Hörschwellenbestimmung an normalhörenden Mäusen, an Mäusen mit einer SNSH sowie an Mäusen mit einer Schallleitungsstörung genutzt und dabei mit der BERA verglichen.

\subsection{Anatomie und Hörfunktion}

Der Mensch ist in der Lage, Töne in einem Frequenzbereich zwischen 0,02 kHz und $20 \mathrm{kHz}$ wahrzunehmen, das Hauptfrequenzspektrum liegt bei 2-4 kHz. Die Maus erkennt Töne in einer bis zu fünffach höheren Frequenz (1 kHz bis $100 \mathrm{kHz}$ ). Trotz des hochfrequenten Hörspektrums, ist die Maus ein wichtiger Teil der neurobiologischen 
Forschung, da der anatomische Aufbau des Mäuseinnenohres dem des Menschen sehr nahe ist. Es wird von vergleichbaren neurobiologischen Mechanismen der Transduktion und Schallkodierung eines Aktionspotenzials ausgegangen.

Der Schall wird vom äußeren Ohr aufgenommen, durch den Gehörgang, über die Gehörknöchelchenkette (Amboss, Hammer und Steigbügel) und durch das Mittelohr zum ovalen Fenster in das Innenohr fortgeleitet. Hier pflanzt sich der Schall als hydrodynamische Wanderwelle entlang der Kochlea fort und wird durch das CortiOrgan, ein hochkomplexes Organ, welches für die Sinnesfunktion Hören verantwortlich ist, in elektrische Signale umgewandelt. Bei der Maus wird der Schall auf einer Kochlealänge von etwa $5 \mathrm{~mm}$ (Müller et al. 2005), beim Menschen im Vergleich auf $35 \mathrm{~mm}$, von den IHZ transduziert und die Informationen an den Haarzellsynapsen in ein neuronales Entladungsmuster kodiert.

A

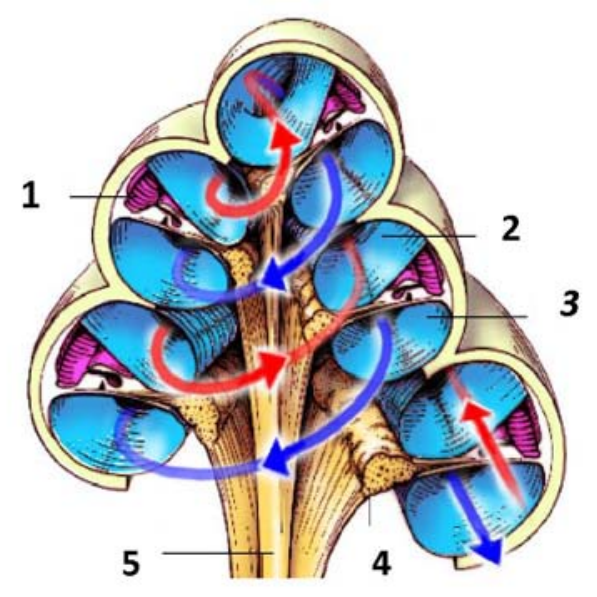

B

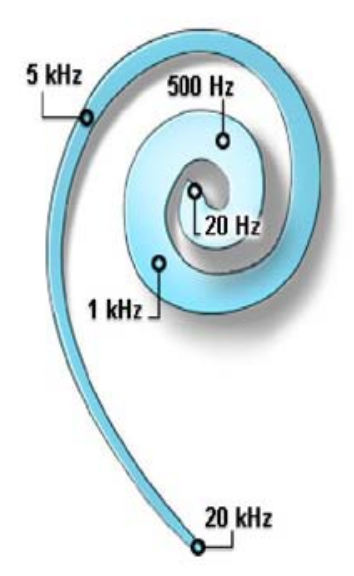

Abb. 1: Aufbau der Kochlea

(A) Schema der Kochlea im Querschnitt. (1) Scala media (2) Scala vestibuli (3) Scala tympani (4) Spiralganglion (5) Auditorische Fasern des VII. Hirnnervs. Schallinduzierte Wellen wandern vom ovalen Fenster entlang der Kochlea aufwärts in der Scala vestibuli (roter Pfeil) und abwärts in der Scala tympani (blauer Pfeil) zum runden Fenster. (B) Schematische Darstellung der Frequenzzerlegung von basal nach apikal der menschlichen Kochlea.

(Quelle: www.iurc.monpt.inserm.fr/cric51/audition/english/cochlea/cochlea.htm) 
Die schneckenförmige Kochlea ist aus drei, um eine knöcherne Achse (der Modiolus) gewundenen, Röhrensystemen aufgebaut (Abb.1A). Scala vestibuli und Scala tympani enthalten Perilymphe und sind über das Helikotrema an der Kochleaspitze miteinander verbunden. Zwischen ihnen liegt die mit Endolymphe gefüllte Scala media. Die Endolymphe wird von zwei elastischen Strukturen abgegrenzt, der Reissner Membran und der Basilarmembran. Die Flüssigkeiten Endo- und Perilymphe unterscheiden sich in ihrer Elektrolytzusammensetzung und im Potenzial. Während die Perilymphe sich in ihrer Zusammensetzung der extrazellulären Flüssigkeit (kaliumarm (6 mM) und natriumreich (140 mM)) ähnelt, zeichnet sich die Endolymphe durch ihren hohen Kaliumgehalt (157 mM) aus.

Das Corti-Organ liegt, überdeckt von der Tektorialmembran, auf der Basilarmembran. Auf ihm sind eine Reihe innerer Haarzellen (IHZ) und drei Reihen äußerer Haarzellen (ÄHZ), umgeben von Stützzellen, angeordnet. Die ca. 3500 IHZ stellen die primären Sinneszellen dar, welche über Bändersynapsen mit den Hörnervenfasern in Verbindung stehen und den Botenstoff Glutamat freisetzen. Die ca. 12000 ÄHZ üben eine Verstärkung der schallinduzierten Wellen aus (Hudspeth 1997), indem sie Änderungen des Membranpotenzials in mikroskopisch kleine Veränderungen ihrer Zelllänge umsetzen. Das Motorprotein Prestin (Zheng et al. 2000) an der lateralen Seite der ÄHZ, vermittelt über Konformationsänderungen diese Elektromotilität und gibt den ÄHZ ihre Bezeichnung als „kochleäres Verstärkersystem“. Durch genetische Deletion des Motorproteins und selektiven Verlust der ÄHZ im Tierexperiment (Liberman et al. 2002; Ryan und Dallos 1975) ist bekannt, dass die ÄHZ den eintreffenden Schall um maximal 45- $50 \mathrm{~dB}$ verstärken können.

Die apikale Membran der Haarzellen erstreckt sich in die Endolymphe, während die basale Seite Kontakt zur Perilymphe hat. Jede Haarzelle ist an ihrer apikalen Seite mit einem Bündel von etwa 50-300 Stereozilien ausgestattet. Die Stereozilien liegen ihrer Größe nach abgestuft, abneural liegen die längsten. Untereinander sind die Stereozilien an ihren Spitzen über Tip-Links, einer feinen filamentösen Struktur, mit ihren benachbarten größeren und kleineren Stereozilien verbunden (Pickles und Corey 1992). Der Sinnesvorgang Hören wird durch die eintreffende Schallwelle am ovalen Fenster eingeleitet, indem diese durch eine Steigbügelbewegung die Perilymphe „anstößt“. Durch die nicht-kompressive Eigenschaft von Flüssigkeiten kommt es zur Ausbildung einer Wanderwelle entlang der Scala media. Die Amplitude der Welle steigt zunächst 
konstant an, um an einem jeweilig frequenzspezifischen Ort ein Amplitudenmaximum $\mathrm{zu}$ erreichen und anschließend rapide abzufallen. Die Theorie der Wanderwelle nach von Békésy (1928) beschreibt dieses Phänomen der Frequenzzerlegung. Jeder Frequenz ist somit ein Ort auf der Basilarmembran mit einem spezifischen Amplitudenmaximum zuzuordnen und führt so $\mathrm{zu}$ einer Frequenzselektivität für hohe Frequenzen an der Basis der Kochlea bzw. für niedrige Frequenzen in der Nähe des Helikotremas (Abb. 1B). Da die Basilarmembran von der Basis zum Apex breiter und elastischer wird, nimmt ebenfalls die Ausbreitungsgeschwindigkeit der Wanderwelle zum Apex hin ab. Ein weiterer Mechanismus des Ohres, Frequenzen zu kodieren, ist die Eigenschaft, dass Aktionspotenziale phasengekoppelt zur Basilarmembranschwingung entstehen.

Ausgelöst durch die Wanderwelle führt eine passive Auf- und Abbewegung der Basilarmembran zu einer pendelnden Scherbewegung der Stereozilien relativ zur starren Tektorialmembran. Die Stereozilien der IHZ werden vermutlich durch die radiären Strömungen der Endolymphe in Bewegung versetzt. Zug an den Tip-Links in Richtung der größten Stereozilie führt zur Öffnung von nicht-selektiven Kationenkanälen an der apikalen Spitze der Stereozilien. Die ungewöhnlich hohe Potenzialdifferenz $(\sim+150 \mathrm{mV})$ zwischen Endolymphe und Intrazellulärraum der Haarzelle dient als Treibspannung für einen $\mathrm{K}^{+}$-Einstrom durch die Transduktionskanäle, welcher so die Zelldepolarisation initiiert. Werden die Stereozilien in die gegenläufige Richtung bewegt, schließen sich die Transduktionskanäle und es kommt zur Hyperpolarisation (Hudspeth und Corey 1997). Haarzellen verfügen über die morphologische Besonderheit sowohl für die sehr schnelle als auch für die kontinuierlich anhaltende Transmitterfreisetzung ausgelegt zu sein, was durch Bändersynapsen an der aktiven Zone ermöglicht wird. Unter der aktiven Zone versteht man ein spezialisiertes Netzwerk von Proteinen (z.B. Bassoon, Piccolo, RIMund Munc-13 Proteine) (Übersicht in Schoch und Gundelfinger 2006) an der präsynaptischen Membran, welches als die Zytomatrix der aktiven Zone bezeichnet wird. Hier wird die Exozytose von synaptischen, transmittergefüllten Vesikeln räumlich und zeitlich organisiert. Das synaptische Band (engl. „ribbon synapse“) bildet die zentrale Struktur der Bändersynapsen (Sterling und Matthews 2005). Es ist eine runde bis länglich-ovale Struktur, welche molekularbiologisch hauptsächlich aus dem Protein RIBEYE besteht (Schmitz et al. 2000). Das synaptische Band ist von etwa 100-200 glutamatgefüllten synaptischen Vesikeln umlagert (Khimich et al. 2005, 
Nouvian et al. 2006), welche über filamentöse Strukturen am Band angeheftet sind (Lenzi et al. 1999). Die Anzahl der Bänder pro Zelle variiert von Spezies zu Spezies, die IHZ der Maus enthält etwa 10-20 Bänder pro Zelle (Khimich et al. 2005, Meyer et al. 2009). Ein Teil der synaptischen Vesikel befindet sich in einem „,angedockten“ Zustand an der Membran und stellt den „readily releasable pool (RRP)“ dar, welcher nach Stimulation schnell zuerst freigesetzt wird (Moser und Beutner 2000). Weitere freie Vesikel umgeben die Bändersynapse (Abb. 2). Ein bis zwei Bänder übertragen die Erregung auf ein afferentes Neuron, welches über das Spiralganglionneuron in den auditorischen Hirnstamm projiziert (Glowatzki und Fuchs 2002).

Die Depolarisierung der Haarzellmembran aktiviert spannungsgesteuerte basolaterale L-Typ-Ca 1.3 Kanäle an der aktiven Zone (Platzer et al. 2000; Brandt et al. 2005) und löst über einen $\mathrm{Ca}^{2+}$-Einstrom die Exozytose von bis zu 1000 transmittergefüllten Vesikeln pro Sekunde in den synaptischen Spalt aus (Moser und Beutner 2000, Brandt et al. 2003, Griesinger et al. 2005). Postsynaptisch aktiviert der Transmitter Gluatamat die AMPA-Rezeptoren der Axone der peripheren Spiralganglien (Glowatzki und Fuchs 2002) und führt zur Bildung eines exzitatorischen Aktionspotenzials. Typ-ISpiralganglienneurone (SGN), welche 90-95\% der SGN ausmachen, innervieren die IHZ. Eine Haarzelle steht in Kontakt mit 5-30 Nervenfasern von SGN, jedoch bildet jede Nervenfaser der SGN nur eine Synapse mit einer IHZ. Typ-II-Fasern stehen in Verbindung mit den ÄHZ.

Die über L-Typ-Ca ${ }_{v} 1.3$ Kanäle einströmenden $\mathrm{Ca}^{2+-}$ Ionen aktivieren einen $\mathrm{K}^{+}$-Kanal (KCNMA) mit hoher Leitfähigkeit vom Typ BK (big conductance), welcher so eine schnelle Repolarisation der Haarzellbasis garantiert (Kros et al. 1998). An der Basis der ÄHZ und IHZ wird der $\mathrm{K}^{+}$-Kanal $\mathrm{KCNQ}_{4}$ exprimiert, welcher vermutlich ebenfalls durch einen $\mathrm{K}^{+}$-Ausstrom an der Zellrepolarisation beteiligt ist (Kubisch et al. 1999, Kharkovets et al. 2000). Aus der Perilymphe wird das $\mathrm{K}^{+}$von Fibrozyten des Ligamentum spirale aufgenommen. Aufrechterhalten wird dieser Kreislauf durch Gap junctions und aktiven Ionentransport in der Stria vaskularis, ein mehrschichtiges sekretorisches Epithel an der Außenwand der Scala media. Aktive Pumpen (Kir4.1 Kanal) (Marcus et al. 2002), Na-K-Cl Co-Transporter ( NKCC $_{1}$ ) und Na-K-ATPasen transportieren das $\mathrm{K}^{+}$durch die Zellen der Stria vascularis. Über den $\mathrm{K}^{+}-\mathrm{Kanal}$ $\mathrm{KCNQ}_{1} / \mathrm{KCNE}_{1}$ (Shen et al. 1997) wird das $\mathrm{K}^{+}$aus den Marginalzellen der Stria vascularis 
in die Endolymphe resezerniert, und so wird diese ungewöhliche Ionenkonzentration aufrechterhalten.

\subsection{Bassoon}

Bassoon ist ein $420 \mathrm{kDa}$ großes Protein (tom Dieck et al. 1998), welches am Strukturaufbau der aktiven Zone beteiligt ist. Es ist an der basalen Seite der synaptischen Bänder lokalisiert. Die primäre Rolle von Bassoon besteht in der Verankerung des synaptischen Bandes an der präsynaptischen aktiven Zone (Khimich et al. 2005). Neben der Lokalisation in sensorischen IHZ der Kochlea (Khimich et al. 2005) und Photozellen der Retina (Dick et al. 2003), ist Bassoon in verschiedenen Regionen des Gehirns nachgewiesen. Bassoon kommt sowohl an exzitatorischen und inhibitorischen glutamatergen Synapsen des Kortex und Hippokampus vor (tom Dieck et al. 1998; Richter et al. 1999). Neuroendokrine Pinealozyten verfügen ebenfalls über Bassoon verankerte synaptische Bänder (Spiwoks-Becker et al. 2009).

Genetische Deletion der Exone 4 und 5 des Bassoon-Gens auf Chromosom 9F führt zu Bassoon-Mutanten, welche ein defektes und verkürztes Bassoon-Protein (180 kDa) exprimieren. Elekronenmikroskopisch sind deformierte und frei im Zytosol schwimmende Bänder erkennbar (Khimich et al. 2005). Die Verankerung des synaptischen Bandes an der präsynaptischen Membran fehlt. Der RRP ist reduziert und führt zu einer synchronen, abgeschwächtenTransmitterfreisetzung. Die Folge ist eine erschwerte Übertragung der mechanischen Schwingung in ein neuronales Signal. Audiologisch lässt sich eine verkleinerte Jewett-Welle I mit einer verlängerten Latenz darstellen (Khimich et al. 2005). Dieser Pathomechanismus der Bassoon Mutante steht für das Krankheitsbild der auditorischen Synaptopathie mit vorhandenen OAEs und pathologischen Hirnstammpotenzialen (Strenzke et al. 2008).

Die Deletion von funktionellem Bassoon führt im Hippokampus zu einer reduzierten exzitatorischen Aktivität und einer erhöhten Anzahl von funktionell stillen Synapsen. Stukturell unterscheiden sie sich jedoch nicht von den aktiven Synapsen (Altrock et al. 2003). Dennoch leiden Bassoon Mutanten phänoptypisch an einer exzitatorischen Hyperaktivität im Sinne von spontanen epileptischen Anfällen, was eine hohe Mortalität der Bassoon-Mutanten erklärt (Altrock et al. 2003). Im MRT wurden vergrößerte Hippokampi und Kortex Regionen sowie metabolische Veränderungen nachgewiesen (Angenstein et al. 2008). Zusammen spricht dies für ein Ungleichgewicht 
zwischen exzitatorischer und inhibitorischer neuronaler Regulation, so dass Bassoon auch als Modell zur Erforschung der Epilepsie dient (Ghiglieri et al. 2009).

In der Retina führt ein Verlust von Bassoon zu einer fehlenden Verankerung des synaptischen Bandes in der Photorezeptorzelle und zu einer Einschränkung der visuellen Funktion (Dick et al. 2003).

Das humane Bassoon-Gen ist auf Chromosom 3p21 lokalisiert (Winter et al. 1999), jedoch ist kein entsprechender Gendefekt bekannt, welcher eine auditorische Synaptopathie hervorruft.

A

B

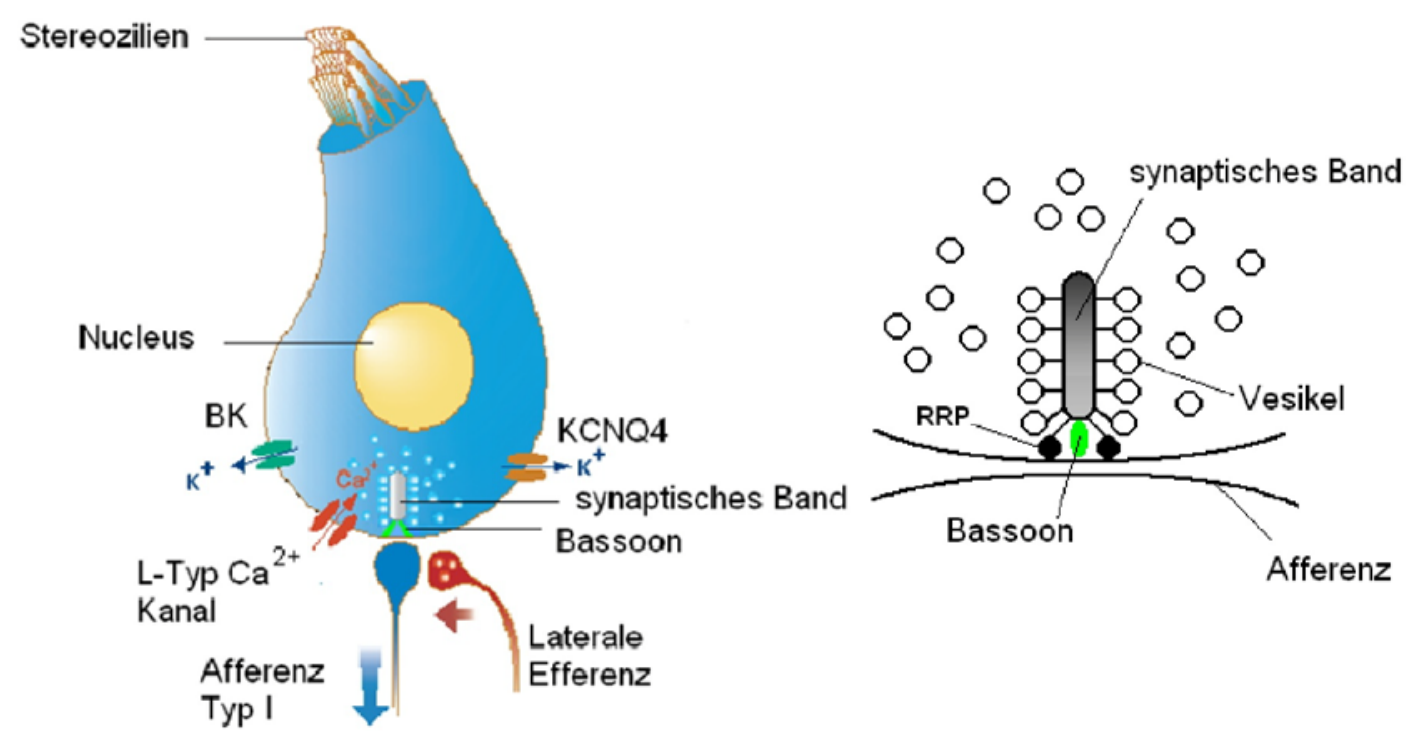

Abb. 2: Aufbau der IHZ und des synaptischen Bandes

(A) Schematische Darstellung einer IHZ. Das synaptische Band liegt an der basalen Zellseite der präsynaptischen aktiven Zone und formt eine Synapse mit Typ-I-Afferenzen der Spiralganglienzellen. (Darstellung nach Nouvian 2005) (B) vergrößerte Darstellung eines synaptischen Bandes mit angedockten (RRP), angehefteten und umgebenen freien Vesikeln. Bassoon als Ankerprotein ist grün dargestellt (eigene Darstellung).

\section{4. $\mathrm{KCNQ}_{4}$}

Ionengradienten und -ströme über die Zellmembran sind essentiell zur Aufrechterhaltung und Steuerung von physiologischen Zellfunktionen. Mittels 
Ionenpumpen oder Ionenkanälen werden Ionenkonzentrationsgradienten aufrechterhalten und zu Signalprozessen genutzt. $\mathrm{KCNQ}_{4}$ ist ein spannungsgesteuerter Kaliumkanal der KCNQ-Familie. Depolarisation über der Membran führt zu einer Konformationsänderung und lässt die Pore des Kanals öffnen. Aktuell sind fünf KCNQSubtypen bekannt, vier von ihnen sind in verschiedenartigen Erbkrankheiten verändert (Jentsch et al 2000).

Das humane $\mathrm{KCNQ}_{4}-\mathrm{Gen}$ ist auf dem Chromosom 1p34 lokalisiert (Kubisch et al. 1999). Hier liegt der Lokus für DFNA2 (Coucke et al. 1994), einer Form der hereditären nonsyndromalen Schwerhörigkeit. Mutationen des KCNQ 4 -Gens führen zu DFNA2, (Kubisch et al. 1999). Aktuell sind 13 Mutationen des $\mathrm{KCNQ}_{4}-\mathrm{Gens}$ bekannt (Nie et al. 2008; Hildebrand et al. 2008).

$\mathrm{KCNQ}_{4}$ bildet homomere Kanäle, die bei Depolarisation aktiviert werden (Kubisch et al. 1999). Möglicherweise kann $\mathrm{KCNQ}_{4}$ auch heteromere $\mathrm{K}^{+}$-Känale mit KCNQ3 formen. Der $\mathrm{KCNQ}_{4}$-Kanal scheint funktionsgleich mit dem für ÄHZ charakteristischen $\mathrm{K}^{+}$-Strom $\mathrm{I}_{\mathrm{k}, \mathrm{n}}$ zu sein, der eine hohe Leitfähigkeit in der Nähe des Ruhemenbranpotenzials aufweist (Marcotti und Kros 1999) und durch muskarinerge M1-Azetylcholinrezeptoren inhibiert wird (Selyanko et al. 2000). Pharmakologisch lassen sich sowohl $\mathrm{KCNQ}_{4}$ als auch $\mathrm{I}_{\mathrm{k}, \mathrm{n}}$ durch Linopirdin blockieren (Oliver et al. 2003). Eine Deletion von $\mathrm{KCNQ}_{4}$ resultiert in einem Verlust von $\mathrm{I}_{\mathrm{k}, \mathrm{n}}$ der ÄHZ (Kharkovets et al. 2006).

Im Innenohr wird $\mathrm{KCNQ}_{4}$ an der basalen Seite der ÄHZ exprimiert. Funktionell wird möglicherweise der $\mathrm{K}^{+}$-Ausstrom an der basalen Zellseite durch $\mathrm{KCNQ}_{4}$ vermittelt (Kubisch et al. 1999, Kharkovets et al. 2000). Entlang der Kochlea nimmt die KCNQ 4 Dichte von basal nach apikal ab. Weiterhin ist es in Typ-I- und Typ-II-Vestibularzellen (Kubisch et al. 1999, Kharkovets et al. 2000, Rocha-Sanchez et al.2007) sowie im Nucleus cochlearis, Lemniscus lateralis und im Colliculus inferior entlang der zentralen Hörbahn beschrieben (Kharkovets et al. 2000, Oliver et al. 2003). Beisel et al. (2000) zeigten auch eine Expression von $\mathrm{KCNQ}_{4}$ an den IHZ.

Die Klinik der $\mathrm{KCNQ}_{4}$-Mutation zeigt sich ab der zweiten bis dritten Lebensdekade. Es kommt, beginnend bei hohen Frequenzen, zu einem progressiven Hörverlust. Innerhalb von 10 Jahren nimmt die Ertaubung etwa um 60 dB zu (Coucke et al. 1994, De Leenheer et al. 2002). Die langsame Progression der Erkrankung hat zu der Hypothese geführt, dass $\mathrm{KCNQ}_{4}$ für den aktiven Hörprozess nicht essentiell ist, sondern dass eine 
chronische $\mathrm{K}^{+}$-Überladung zur Zelldegeneration führt (Jentsch 2000, Kharkovets et al. 2006). Die Ausprägung der Schwerhörigkeit der DFNA2 lässt sich nicht allein durch den Untergang der ÄHZ erklären, da bekannt ist, dass der selektive Verlust der ÄHZ zu einem Hörverlust von etwa 40-50 dB führt (Ryan und Dallos 1975). Möglicherweise spielen additive Effekte einer Altersschwerhörigkeit eine Rolle. Zudem treten bei DFNA2 Patienten keine vestibulären Manifestationen auf (Coucke et al. 1999). Im Mausmodell führt eine Deletion der Exone 6-8 zu KCNQ ${ }_{4}$ defizienten KO Tieren mit normaler vestibulärer Funktion. Die IHZ zeigen keine synaptischen Defekte. Ab der zweiten Lebenswoche kommt es zu einem zunehmend signifikanten Hörverlust in der Klick-BERA (Kharkovets et al. 2006).

\subsection{Akustisch evozierte Potenziale - AEP}

\subsubsection{Grundlagen der AEP}

Unter akustischer Reizung des Hörsystems entstehen physiologische sinnesspezifische Potenzialschwankungen, welche über die Kopfhaut in Form eines Elektroenzephalogramms (EEG) ableitbar sind und unter dem Begriff der akustisch evozierten Potenziale (AEP) beschrieben werden. Sie stellen eine Antwort auf den akustischen Stimulus und dessen Verarbeitung entlang der Hörbahn zum auditorischen Kortex dar. Als grundlegende Eigenschaft tritt das Antwortsignal, im Gegensatz zu der sonstigen elektrischen Aktivität, im zeitlichen Zusammenhang zum Stimulus auf. Ein Mitteln der Messabschnitte hebt die Antwort aus der Hintergrundaktivität hervor.

Es werden stationäre von transienten Potenzialen unterschieden. Transiente Potenziale entstehen durch zeitlich begrenzte kurze Stimuli, welche eine ebenfalls zeitlich begrenzte Antwort erzeugen. Durch stimulusgetriggerte Aufzeichnung für einen definierten Zeitabschnitt und bei einer geeigneten Verstärkung, werden die Potenziale sichtbar. Durch Mittelwertbildung stellt sich die gewünschte Antwort mit steigender Anzahl der Zeitabschnitte immer deutlicher heraus, da die nicht stimulussynchronen Potenziale rausgemittelt werden. $\mathrm{Zu}$ den transienten Potenzialen werden die frühen AEP (FAEP) gezählt, welche mit der Hirnstammaudiometrie (Brainstem evoked response audiometry- BERA), als ein Verfahren der Elekrischen Reaktionsaudiometrie, detektiert werden. Transiente Potenziale werden visuell-subjektiv im Zeitfenster detektiert und nach ihrer Latenz und Amplitudengröße beschreiben. 
Stationäre Potenziale treten auf, wenn ein Stimulus mit ausreichend hoher Wiederholungsrate dazu führt, dass eine Antwort überlappend auf die vorherige auftritt. Im Unterschied zu den transienten Potenzialen entsteht auf der Basilarmembran ein eingeschwungener Dauerzustand während der Reizapplikation. So sind stationäre Potenziale definiert als evozierte Potenziale, deren eigenständige Frequenzkomponente in Amplitude und Phase über einen unendlichen Zeitraum erhalten bleiben (Regan 1989). Während des akustischen Reizes sind sie dauerhaft nachweisbar und folgen der zeitlichen Struktur ihres Reizes, im engeren Sinn folgen sie jedoch der Modulationsrate (Hoke und Hoke 1997). Picton et al. (2003) beschrieben die ASSR-Stimuli auch als Stimuli, die durch periodische Reizdarbietung die elektrische Aktivität des Gehirns lenken.

Weiter lassen sich die Steady-State Potenziale nach Amplitudengröße und Phasenbezug beurteilen. Eine statistische Detektion (Dobie und Wilson 1996, Stürzebecher et al. 1996, Aoyagi et al. 1999) ermöglicht so eine objektive Analyse.

Von Regan (1966) wurden erstmals stationäre Potenziale durch amplitudenmoduliertes Licht beschrieben und als Steady-State Evoked Potential (SSEP) benannt. 1981 wurden die ASSR erstmalig beim Menschen als auditorisches $40 \mathrm{~Hz}$ Potenzial von Galambos et al. beschrieben. Bekannt geworden sind die ASSR in den 80er Jahren als neuronale Potenziale, welche der Einhüllenden des Signals folgen, der Envelope Following Response (EFR) (Kuwada et al. 1986). Später wurden sie in der Literatur auch als Frequency Following Response (FFR) (Batra et al. 1986, Glaser et al. 1976) oder als Amplitude Modulation Following Response (AMFR) benannt (Griffiths und Chambers 1991, Aoyagi et al. 1994, Kuwada et al. 2002). 


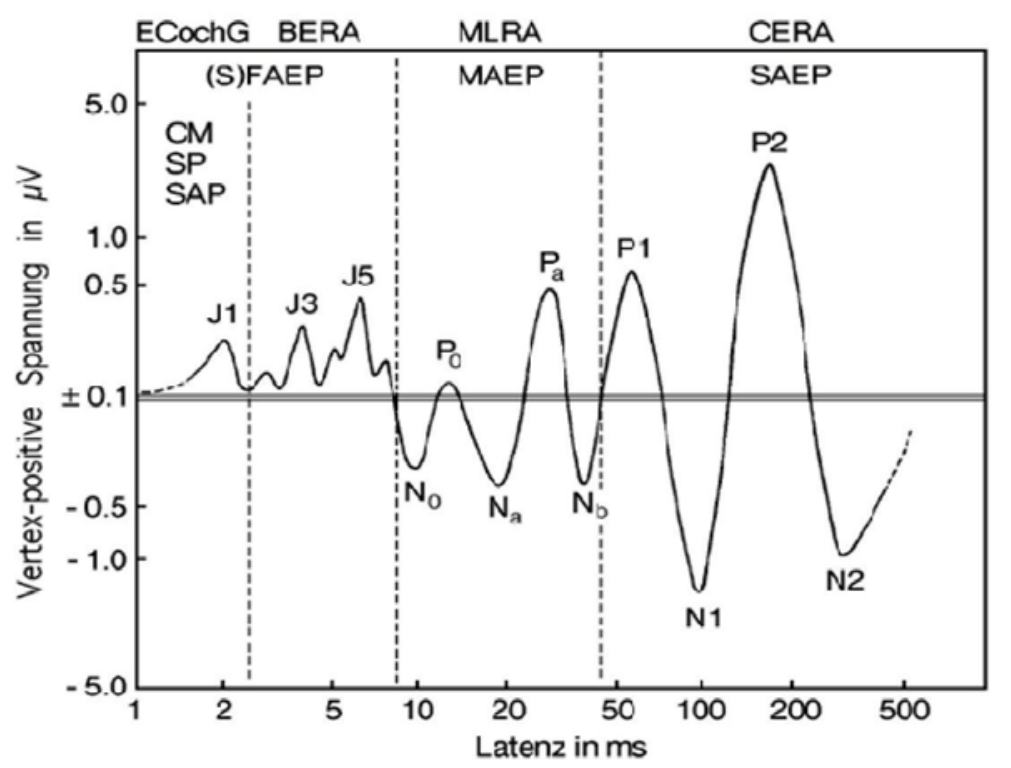

Abb. 3: Darstellung der AEP nach ihrer Latenz (Picton et al. 1974, Seite 181)

\subsubsection{Brainstem Evoked Response Audiometry- BERA}

Die AEP lassen sich nach ihrer Latenz in sehr frühe (SFAEP), frühe (FAEP, 2-10 ms Latenz), mittlere (MAEP, 10- $50 \mathrm{~ms}$ Latenz) und späte Potenziale (SAEP, $50 \mathrm{~ms}-1 \mathrm{~s}$ Latenz) einteilen (Picton et al. 1974). Die in der heutigen Form bekannten FAEP wurden erstmals 1970 durch Jewett und Williston beschrieben, nach Jewett erfolgt die Bezeichnung der Potenziale Jewett I-V (Abb.3).

Die FAEP werden mit der Hirnstammaudiometrie (BERA- Brainstem Evoked Response Audiometry) registriert und treten mit einer Latenz von 2-10 ms auf. Anhand der Hörschwelle, der Amplitudengröße und der Latenz lassen sich die Potenziale topographisch den reizverarbeitenden Strukturen im Hirnstamm zuordnen und erlauben so eine Aussage über die Integrität der Hörbahn. Ein Potenzial spiegelt die synchrone Entladung einer großen Zahl von Einzelneuronen wieder. Mit Studien detaillierter intrakranieller und oberflächlicher EEG-Ableitungen wurde versucht, den einzelnen Potenzialen nähere Hirnstammgebiete zuzuordnen. Anhand gezielt gesetzter chirurgischer Läsionen oder Injektionen neurotoxischer Medikamente im Tierversuch (Fullerton et al. 1990, Melcher und Kiang 1996, Melcher et al. 1996a-b) sowie durch Ableitungen bei Patienten mit lokalisierbaren pathologischen Veränderungen des Hirnstamms wie Apoplex, Tumore oder Multiple Sklerose (Levine et al. 1993) erfolgten Lokalisationsanalysen. 
Eine topographische Zuordnung der Potenziale wurde in mehreren Studien zur Quellenlokalisation im Tierexperiment oder anhand ausführlicher EEG-Untersuchungen dargestellt. Intrakranielle Ableitungen konnten erstmals den Ursprung der Welle I distalen Anteilen des VIII. Hirnnervs und somit noch dem peripheren Nervensystem zugeordnen (Möller et al. 1981, Buchwald und Huang 1975, Scherg und von Cramon 1985a, Scherg und von Cramon 1985b). Starr und Zooroor (1990) ordneten JII proximalen Anteilen des VIII. Hirnnervs, wenn der Nerv in den Hirnstamm eintritt, als auch dem Nucleus cochlearis zu. 1996 zeigten Melcher et al. in einer Schlüsselarbeit anhand von detaillierten Läsionen durch Kainsäureinjektionen in den Nucleus cochlearis und in den oberen Olivenkomplex der Katze, dass JI als frühestes Potenzial aus Zellen des Spiralganglions stammt und JII aus Zellen des Nucleus cochlearis. Bereits 1983 konnten Starr et al. zeigen, dass chirurgische Läsionen des kontralateralen oberen Olivenkomplexes zu einer Supression von JIII führen. Später wurde JIII Zellen des Nucleus cochlearis und Zellen der kontralateralen Nuclei des Corpus trapezoideum zugeordnet, JIV Zellen dem ipsi- und kontralateralen Nucleus olivaris superior. JV stammt aus Zellen des lateralen Lemniscus lateralis und/ oder des Colliculus inferior (Melcher und Kiang 1996, Melcher et al. 1996 a, Melcher et al. 1996 b).

Zur Auslösung der Jewett-Potenziale I-V werden Klicks und Tonburst-Impulse verwendet. Tonburst-Impulse sind Sinusschwingungen, die mit einer Cosinusquadrat An- und Abstiegsflanke beginnen und enden. Der mittlere Plateauanteil enthält die maximalen Amplituden der Schwingung (Abb. 6A). Die Einhüllende des Sinustons kann weiterhin als Tonpip oder Gaußreiz variiert werden (Picton et al. 1979, Klieny 1981). Daneben gibt es noch andere Stimuli wie z.B. Chirps (Dau et al. 2000). Im Spektrum konzentriert sich die Energie des Tonbursts um seine Frequenz und ist umgeben von Seitenbändern (Abb. 5C). In dieser Studie verwendeten wir vorwiegend rechteckige Klickimpluse mit einer Frequenz von 30-100/ Sekunde als Stimulus. Klicks ermöglichen durch eine hohe Flankensteilheit und ein breites Frequenzspektrum (Finneran et al. 2007) eine synchrone Erregung einer Vielzahl von Haarzellen auf der Basilarmembran (Stapells und Oats 1997). In der klinischen Anwendung liegt der Hauptfrequenzgehalt des verwendeten Klicks im Bereich von 2-4 kHz. Allgemein gilt: je kürzer die Anstiegszeit der Hüllkurve eines Stimulus, desto größer ist die Potenzialamplitude, aber desto geringer die Frequenzspezifität (Sininger et al. 1997). 
In der klinischen Praxis stellt die BERA den diagnostischen Goldstandard zur objektiven Hörschwellenbestimmung sowie zur Erfassung kochleärer und retrokochleärer Hörstörungen bei Mensch und Tier dar. Über die Bestimmung der Peaklatenzen werden Weiterleitungsstörungen wie Multiple Sklerose oder Akustikusneurinome diagnostiziert (Japaridze et al. 2002). Fachfremd finden sich Einsätze der BERA in der Anästhesiologie zum Monitoring der Narkosetiefe (Schmidt et al. 2008).

\subsubsection{Auditory Steady-State Responses - ASSR}

Die stationären Auditory Steady-State Responses (ASSR) sind Potenziale, welche sich in ihren Eigenschaften grundlegend von den transient-evozierten Hirnstammpotenzialen unterscheiden. Die ASSR sind gekennzeichnet durch einen sehr frequenzspezifischen Stimulus und der Möglichkeit einer objektiven, statistischen Erkennung des Antwortpotenzials sowie einer multifrequenten Stimulation (MASTER Technik) (Herdman et al. 2002, Picton et al. 2003), welche einen reduzierten Zeitbedarf gegenüber den FAEP erfordert.

Der Reizton der ASSR ist ein sinusoidal amplitudenmodulierter (SAM) Ton. Im Unterschied zu den transienten und kurzen Tonburst Stimuli der BERA besteht der SAM-Ton aus einem kontinuierlichen Sinuston einer Trägerfrequenz (TF) [kHz]. Die Amplitude des Sinus wird mit einer Modulationsfrequenz (MF) [Hz] sinusförmig moduliert (Abb. 5B). Die zu prüfende Frequenz entspricht der Trägerfrequenz. Die Modulationstiefe (MT) [\%] beschreibt das Verhältnis von maximaler zu minimaler Amplitude (Picton et al. 2003). Darstellbar werden die ASSR nach Verstärkung der abgeleiteten Spannungsdifferenz zwischen Vertex und Mastoid, Filterung und Registrierung von aufeinander folgenden EEG-Abschnitten. Beruhend auf der Annahme, dass das EEG aus einer Vielzahl von Einzelfrequenzen besteht, wird ein EEG-Abschnitt mit der schnellen Fourrier Transformation (Fast Fourrier Transformation- FFT) im Frequenzspektrum dargestellt. Mit verschiedenen statistischen Tests kann eine objektive Entscheidungsbasis zur Definition eines vorhandenen Antwortsignals festgelegt werden. In der FFT wird hierzu die Größe des Antwortsignals mit den Amplituden der benachbarten Frequenzen verglichen. Oft verwendet werden der F-Test und der $\mathrm{T}^{2}$ Test (Dobie und Wilson, 1996). Weiterhin können Amplitude und Phase im Polardiagramm dargestellt werden. Nach Picton et al. (2001) wird die Phasenkohärenz 
berechnet, basierend auf der Annahme, dass die Phase über einen konstanten Zeitraum unverändert bleibt (Regan 1989).

Nicht nur im zeitlichen Verlauf, sondern auch in der Spektralanalyse lassen sich ASSRund BERA-Stimuli voneinander unterscheiden. Transiente Tonburst-Stimuli (ohne zusätzliche Maskierungen) zeigen in der Spektralanalyse ein breiteres Frequenzspektrum (Abb. 5C). Der SAM-Ton zeigt in der Spektralanalyse ein sehr schmales Energiespektrum in Form von drei Spektrallinien. Das zentrale Hauptband stellt die TF dar, umgeben von je zwei Nebenbändern, welche je um die Modulationsfrequenz erhöht oder erniedrigt liegen (Abb. 5D). In der Kochlea wird nur ein selektives Areal der Membran an der Frequenz der TF \pm die MF angeregt. Hieraus resultiert die für die Hörschwellenbestimmung wichtige Frequenzspezifität der ASSR.

Ebenso können die ASSR durch frequenzmodulierte SAM-Töne (John et al. 2001), Kombinationen aus amplituden- und frequenzmodulierten Tönen (Dimitrijevic et al. 2001) oder durch multifrequente SAM-Töne erzeugt werden (Lins and Picton 1995, John et al. 1998, Herdman et al. 2002). Eine Übersicht über die verschiedenen Stimuli gibt Picton 2003. Des Weiteren ist die ASSR-Erzeugung auch durch Klicks (Galambos et al. 1981) oder gaussförmigen Tonbursts (Pantev et al. 1986, Glaser et al. 1976) möglich.

Die multifrequente Stimulation stellt eine besonders zeitsparende Methode der objektiven Hörschwellenbestimmung dar (Herdman et al. 2002). Die simultane Präsentation mehrerer Trägerfrequenzen setzt voraus, dass jede Frequenz mit einer individuellen Modulationsfrequenz moduliert wird. Ähnlich wie bei der monofrequenten Stimulation sind die applizierten Modulationsfrequenzen im Frequenzspektrum wiederzufinden (John et al. 1998). Um eine gegenseitige Beeinflussung der ASSR-Amplituden zu vermeiden, sollten die Trägerfrequenzen mehr als eine halbe Oktave auseinander liegen. Eine zunehmende Testdauer erhöht die Messgenauigkeit (Luts et al. 2004). Die monaurale oder binaurale simultane Präsentation von mono- sowie multifrequenten Stimuli hat keinen Einfluss auf die Hörschwellenbestimmung (Herdman et al. 2001).

Ein sicherer Nachweis der ASSR hängt entscheidend von der Wahl der Modulationsfrequenz ab. Für die Hörschwellenbestimmung beim Mensch werden sowohl bei Normalhörenden als auch bei Hörgeschädigten Modulationsfrequenzen im Bereich von $40 \mathrm{~Hz}$ (Galambos et al. 1981, Kuwada et al. 1986, Stapells et al. 1987) und 
$80 \mathrm{~Hz}$ (Levi at al. 1993, Aoyagi et al. 1994, , Lins 1995) verwendet. Die schnelleren 80$110 \mathrm{~Hz}$ Potenziale sind weniger störanfällig durch Schlaf und Narkotika (Cohen et al. 1991, Dobie et al. 1998), zeigen aber eine größere Variabilität (Lins und Picton 1995). ASSR mit niedrigen MF (40 Hz) werden im Schlaf deutlich kleiner (Galambos et al. 1981, Jerger er al. 1986, Cohen et al. 1991) und sind vom zerebralen Reifegrad abhängig (Aoyagi et al. 1993). Daher erscheinen die 80-110 Hz Potenziale zuverlässiger für die Anwendung bei Kindern (Herdman und Stapells 2001). Weiterhin sind die ASSRAmplituden modulationsfrequenzabhängig. Beim Menschen werden für $40 \mathrm{~Hz}$ ASSR kleine Antworten bei ansteigenden Modulationsfrequenzen beschrieben (Galambos et al. 1981, Picton et al. 1987 ). Modulationsfrequenzen um $80 \mathrm{~Hz}$ generieren größere ASSR (John et al. 2001).

Als neuere Methode zur objektiven Hörschwellenbestimmung eignen sich die ASSR daher insbesondere bei unkooperativen Patienten wie Neugeborenen und Kindern, wenn keine aktive Mitarbeit wie beim Tonaudiogramm möglich ist. Eine Reihe von Studien weisen auf eine sichere Darstellung bei normalhörenden und schwerhörigen Kindern, als auch bei Erwachsenen hin (Lins et al. 1996, Cone-Wesson et al. 2002, Herdman und Stapells 2003, Luts und Wouters 2004, Vander Werff und Brown 2006, Scherf et al. 2006, van der Reijden et al. 2006). Ebenso ist eine gute Korrelation zur BERA als auch zum Tonaudiogramm (Dimitijevic et al. 2002, Canale et al. 2006, Swanepoel et al. 2007) beschrieben. Im Speziellen ist der Einsatz der ASSR zur Diagnostik des Verlaufs der frequenzspezifischen Hörschwelle bei Kindern, z.B. zur Hörgeräteanpassung oder präoperativ vor Anlage eines Kochleaimplantats interessant (Yang et al. 2008).

Im tierexperimentellen Bereich sind die ASSR bei Katzen (Mäkelä et al. 1990, Kiren et al. 1994), mongolischen Wüstenrennmäusen (Dolphin und Mountain 1992, Behrend et al. 2002), Chinchillas (Arnold und Burkhard 2002, Szalda und Burkard 2005), Meerschweinchen (Jeng et al. 2008) und Delfinen (Finneran et al. 2007) beschrieben. Jedoch wurden sie nicht in erster Linie als audiologische Methode zur Hörschwellenmessung verwendet, sondern zur Erforschung der ASSR-Generatoren mit Hilfe artifiziell gesetzter intrazerebraler Läsionen.

Anhand von Phasenmessungen [Grad] kann die berechnete „apparent latency“ indirekt einen Rückschluss über die Latenz der Potenziale geben (Regan 1966, Picton et al. 2003). Diese wird über die lineare Regression der Phasenantwort als Funktion der MF in 
Frequenzbereichen mit stetiger Wachstumsfunktion über die Formel Latenz $=(\Delta$ Phase $/ \Delta \mathrm{MF}) / 360^{\circ}$ berechnet. Die „apparent latency“ variiert entscheidend mit der Modulations- und Trägerfrequenz (Rickards und Clark 1984). Es konnte gezeigt werden, dass Modulationsfrequenzen um $40 \mathrm{~Hz}$ eine Antwort nach 31-37 Millisekunden erzeugen (Kuwada et al. 1986). Die schnelleren Potenziale um $80 \mathrm{~Hz}$ zeigen Latenzen um 19-25 Sekunden (Lins et al. 1995, John und Picton 2000, John et al. 2001).

Bisher sind keine genauen Urspungsorte der ASSR bekannt. Diskutiert werden sowohl der Kortex als auch der Hirnstamm. Aufgrund der Latenzbestimmungen werden die schnelleren $80 \mathrm{~Hz}$ Potenziale dem Hirnstamm zugeordnet und die $40 \mathrm{~Hz}$ Potenziale dem Kortex. Nuklearmedizinische PET-Analysen (Reyes et al. 2005) und MRT-Studien (Schoonhoven et al. 2001) sind experimentelle Möglichkeiten zur Quellenanalyse. Magnetoenzephalographisch konnte eine starke kortikale Aktivität Applikation der $40 \mathrm{~Hz}$ Potenziale gezeigt werden (Ross et al. 2003). Ein Abschwächung der $40 \mathrm{~Hz}$ Potenziale unter Narkose (Plourde et al. 2008, Szalda und Burkard 2005) spricht weiterhin für überwiegende Quellen im Kortex und Subkortex. Die meisten Autoren gehen heute von einem Zusammenspiel von kortikalen und im Hirnstamm liegenden Generatoren aus (Maurer und Döring 1999, Herdman et al. 2002, Schoonhoven et al. 2001, Kuwada et al. 2002, Reyes et al. 2005, Plourde et al. 2008).

Bei Hunden (Markessis et al. 2006) und Affen (Burton et al. 1992) wurden die ASSR bereits als Methode zur Hörschwellenbestimmung beschrieben. Hier wurden Modulationsfrequenzen bis $310 \mathrm{~Hz}$ verwendet. Bei der Maus wurden die ASSR bisher nicht beschrieben, wären aber zur frequenzspezifischen Untersuchung der Hörfunktion genetisch veränderter Mäuse in der audiologischen Forschung wertvoll. 
A

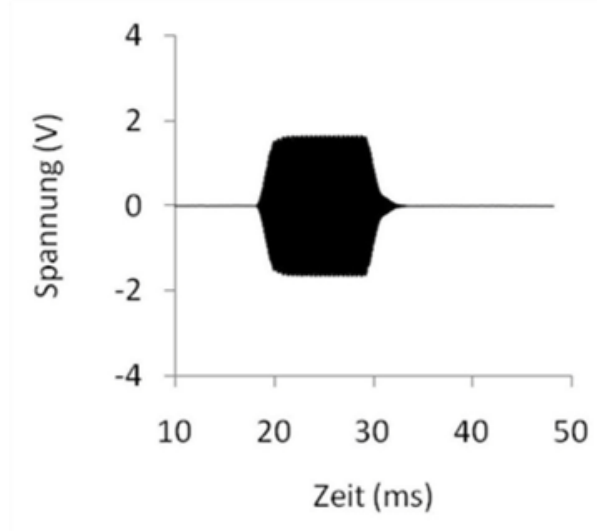

C

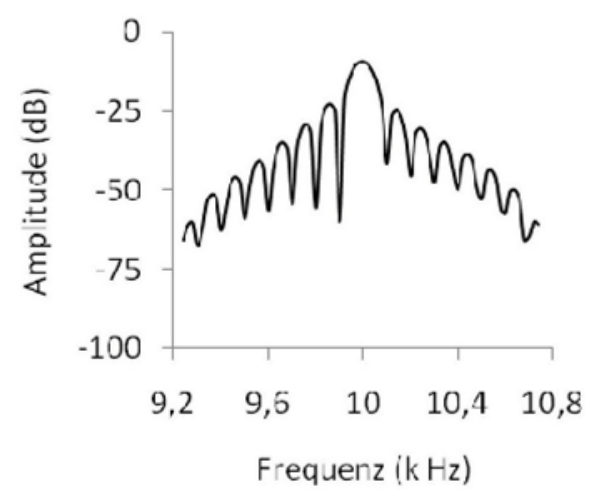

E

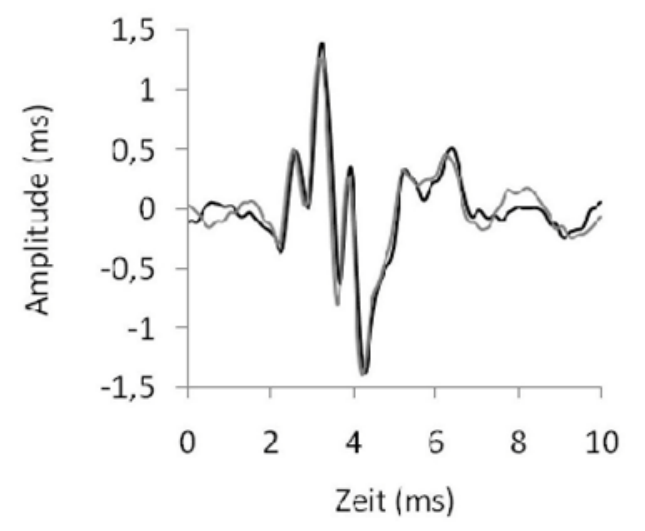

B

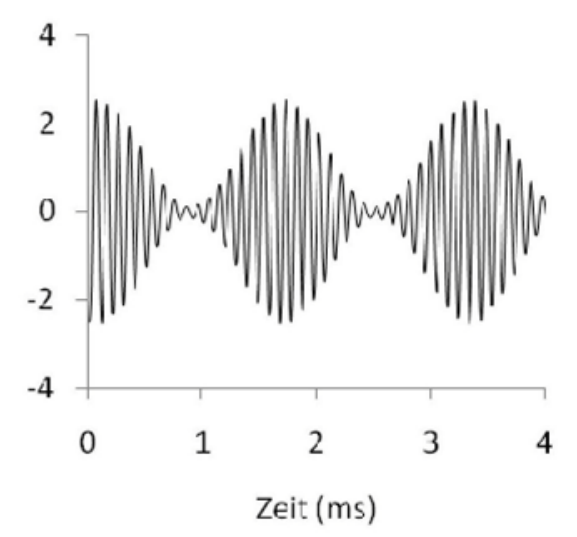

D

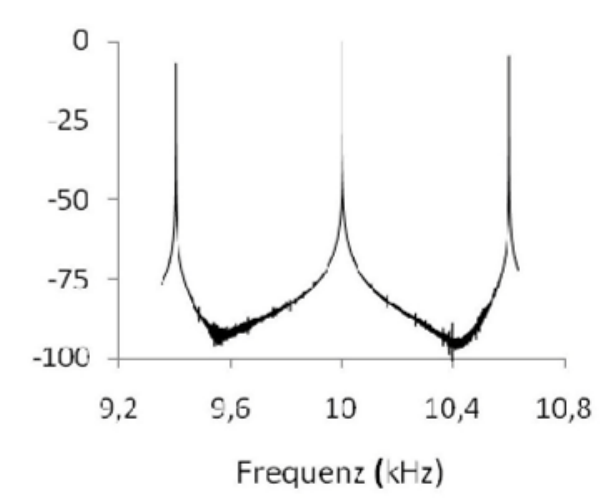

$F(1)$

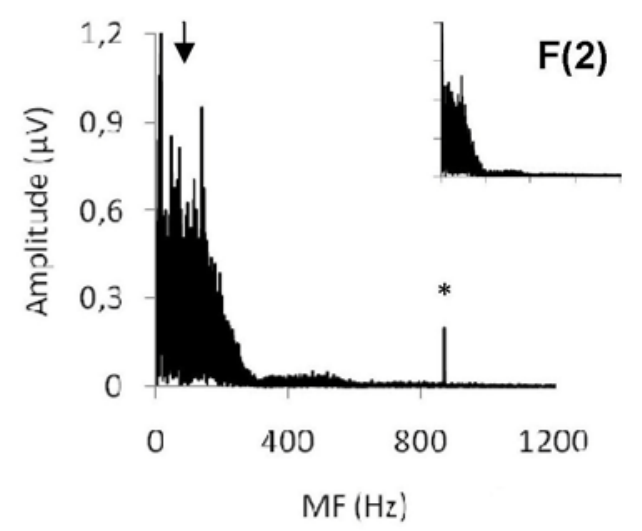

Abb. 4: Vergleich der transienten und stationären AEP-Stimuli

(A) BERA-Stimulus: $10 \mathrm{kHz}$ Tonburst, $80 \mathrm{~dB}$ SPL (10 ms Plateau, $\cos ^{2}$ An- und Abstieg) (B) ASSR-Stimulus: Ausschnitt eines $80 \mathrm{~dB}$ SPL, $10 \mathrm{kHz}$ SAM-Tons (moduliert mit $600 \mathrm{~Hz}$ und 100\% Modulationstiefe). Die Signale wurden mit einem Sennheiser MKE-2-P-Mikrofon im Freifeld gemessen. (C) FFT des Tonbursts (D) FFT des ASSR-Stimulus (E) zwei Mittelwertkurven (jeweils 1000 Sweeps) als Antwort auf den Stimulus (A) einer 8 Wochen alten C57BL/6 Maus. F (1) Antwort auf einen ASSR-Stimulus $(10 \mathrm{kHz}, \mathrm{MF} 869 \mathrm{~Hz}$, $80 \mathrm{~dB} S P L)$ einer repräsentativen 8 Wochen alten C57BL/6 Maus. Der Pfeil markiert die Haupthintergrundaktivität des EEGs. $\boldsymbol{F ( 2 )}$ zeigt im Hintergrund eine Leermessung ohne Stimulus beim gleichen Tier. 


\subsubsection{Otoakustische Emissionen - OAEs}

Otoakustische Emissionen entstehen als spontane, oder durch akustische Beschallung, evozierte Schallreflexionen während des physiologischen Hörvorganges im Innenohr. Sie wurden bereits 1978 durch Kemp et al. als auf der Basilarmembran gebildete Schwingungen beschrieben, die als Schallabstrahlungen im äußeren Gehörgang messbar werden.

Die passive Übertragung der Schallwellen über die Gehörknöchelchenkette führt zur Ausbildung einer Wanderwelle entlang der Basilarmembran mit freqenzspezifischen Schwingungsmaxima (von Békésy 1960). Die auf der Basilarmembran sitzenden ÄHZ werden durch die passive Auslenkung der Basilarmembran $\mathrm{zu}$ einer eigenen Schwingung angeregt. Diese Verstärkerfunktion ist nichtlinear ausgebildet (starke Verstärkung schwacher Intensitäten und zunehmend schwächere Verstärkung höherer Intensitäten) und bildet die Grundlage für die Entstehung der OAEs. Somit spiegeln die OAEs in erster Linie die Funktion der kochleären Verstärkerfunktion der äußeren Haarzellen wieder.

Evozierte OAEs werden durch breitfrequente Klickreize (transitorische OAEs) oder zwei Sinustöne erzeugt. Die Stimulation der ÄHZ mit zwei Sinustönen $f_{1}$ und $f_{2}$ der Intensitäten $\mathrm{L}_{1}$ und $\mathrm{L}_{2}$ führt zur Ausbildung zweier passiver Wanderwellen, welche dicht aneinander liegende Maxima besitzen. Es entsteht ein überlappender Bereich (ÜB), in welchem Haarzellen von beiden Wellen angeregt werden. Bedingt durch die nichtlineare Verstärkereigenschaft der Basilarmembran werden durch den kochleären Verstärkermechanismus weitere Schwingungen an verschiedenen Frequenzen $\left(2 \mathrm{f}_{1}-\mathrm{f}_{2}\right.$ oder $f_{2}-f_{1}$ ) als Antwort gebildet. Diese im Überlappungsbereich entstehenden Schwingungen erzeugen eine in Richtung Schneckenspitze laufende Wanderwelle. Am Ort ihrer maximalen Wellenbildung werden sie über die IHZ wahrgenommen. Über seine retrograde Schallaussendung sind diese zusätzlich entstandenen Töne durch empfindliche Mikrofone im Gehörgang messbar und durch eine FFT im Frequenzspektrum darstellbar. Neben $f_{1}$ und $f_{2}$ ist an der Frequenz $2 f_{1}-f_{2}$ das Distortionsprodukt (DPOAE), auch das Verzerrungsprodukt genannt, der Otoakustischen Emissionen sichtbar (Abb. 6). Klinische Anwendung findet nur die Messung der DPOAEs der Frequenz $2 \mathrm{f}_{1}-\mathrm{f}_{2}$.

Die Amplitudengröße der DPOAEs ist abhängig vom Frequenzverhältnis und dem Pegelunterschied der Primärtöne. Zur Erzeugung möglichst großer Emissionen sind als 
Richtwert Frequenzverhältnisse von $2 \mathrm{f}_{1}-\mathrm{f}_{2}$ und Intensitätsverhältnisse von $\mathrm{L}_{1}-\mathrm{L}_{2}=10 \mathrm{~dB}$ üblich (Janssen 2001).

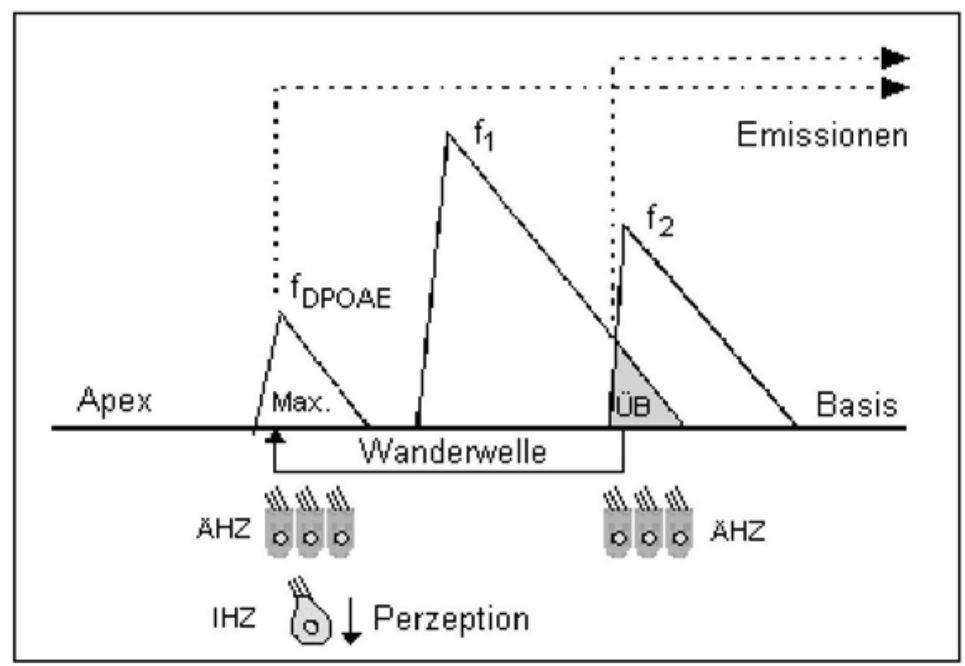

Abb. 5: Gedankenmodell zur Entstehung der DPOAEs

ÜB: Überlappender Bereich (Quelle: Lehnhardt und Laszig, 2001. Seite 83)

\subsection{Entstehung und Ziel der Arbeit}

Während die ASSR eine schon oft beschriebene Methode zur objektiven frequenzspezifischen Hörschwellenbestimmung beim Mensch ist, werden in dieser Arbeit neue Erkenntnisse über die Potenziale bei der Maus gewonnen. Ein erstes Ziel war die Etablierung und Charakterisierung der nötigen ASSR-Stimulusparameter für das hochfrequente Hörspektrum der Maus, da bis heute noch keine Erkenntnisse über diese Potenziale bei der Maus vorliegen. Nachfolgend wurden ASSR- und BERA-Hörschwellen bei gesunden und schwerhörigen Mäusen anhand von zwei definierten Mausmodellen einer sensorineuralen Schwerhörigkeit (Bassoon und $\mathrm{KCNQ}_{4}$ ) verglichen. Durch die Anwendung der ASSR, BERA und DPOAEs gelang es, ein audiologisches Profil der sensorineuralen Schwerhörigkeit zu erstellen. 


\section{Material und Methoden}

\subsection{Versuchstiere}

19 C57/BL6, 6 Bassoon-Mutanten, $6 \mathrm{KCNQ}_{4}$ Knockout (KO)-Tiere und ihre gesunden Wurfgeschwister (7 Bassoon-WT und $7 \mathrm{KCNQ}_{4}-\mathrm{WT}$ ) im Alter von 6-8 Wochen wurden in der Arbeit untersucht. 10 der C57BL/6 Tiere wurden für Vorversuche verwendet. Die Bassoon Mäuse stammten aus dem Max-Planck-Institut für Hirnforschung in Frankfurt am Main sowie aus der Zentralen Tierexperimentellen Einrichtung (ZTE) der Universitätsmedizin Göttingen. Es bestanden Defekte der Exone 4 und 5 der Bassoon DNA (Altrock et al. 2003). Die Mäuse für das $\mathrm{KCNQ}_{4}$-Modell stammten aus dem Zentrum für Molekulare Neurobiologie Hamburg. Eine Deletion der Exone 6-8 auf dem Chromosom 1p34 führt zu KCNQ 4 defizienten Mäuse (Kharkovets et al. 2005). Die C57/BL6 Mäuse stammten aus der ZTE der Universitätsmedizin Göttingen und wurden zur Bildung einer gesunden Vergleichsgruppe verwendet.

Die Tiere wurden intraperitoneal mit einer Mischung aus Ketamin (125 mg/kg) (Inresa Arzneimittel GmbH Freiburg) und Xylazin (2,5 mg/kg) (Bayer Vital GmbH) anästhesiert. Die Narkose wurde kontinuierlich über eine intraperitoneal liegende 24 G (Gauge) Butterfly Kanüle (Braun) aufrechterhalten (0,5- 1,25 ml/h). Subkutane Elektroden zur Ableitung des EEGs wurden am Vertex, beidseitig am Mastoid und in Schwanznähe (Erdelektrode) positioniert, bevor die Maus auf einen speziell angefertigten Untersuchungstisch gelegt wurde. Zur Steuerung der Narkose erfolgte eine Videoüberwachung sowie ein fortlaufendes Monitoring der Herzfrequenz im EEG per Oszilloskop (HM 208, HAMEG, Frankfurt am Main). Die Körperkerntemperatur wurde mit einer Rektalsonde gemessen und über eine temperaturregulierende Heizmatte (Hugo Sachs Elektronik, Harvard Apparatus GmbH, March-Hugstetten, Deutschland) konstant auf $37^{\circ} \mathrm{C}$ gehalten (Abb.6). Am Ende der Versuche wurden die Tiere durch intrapulmonale Injektion von 0,5 ml Embutramid (T61, Intervet GesmbH, Österreich) getötet. Der Genotyp der Tiere wurde post mortem durch PCR Analysen verifiziert.

Eine experimentelle Schallleitungsschwerhörigkeit wurde durch beidseitiges Versiegeln des äußeren Gehörgangs mit einem selbst hergestellten Gemisch aus Elektrodengel (NuPrep, EEG Skin Gel) und Wasser induziert. 
Alle tierexperimentellen Untersuchungen erfüllten die Nationalen Tierversuchsrichtlinien und wurden durch die Tierschutzkommission des Landes Niedersachsen genehmigt.

\subsubsection{Technischer Aufbau}

Zur Stimulusgeneration, Datenaufnahme und -speicherung wurde die computergestützte Messstation Tucker-Davis-Technologies (TDT, Ft. Lauderdale, FL, USA) System-III (für BERA- und ASSR-Messungen) und System-II (für DPOAEMessungen) verwendet. Steuerbar war das System über eine Software (BioSig32, TDT) des Hardwareanbieters für die BERA-Messungen sowie über eine eigens für die Arbeit programmierte MATLAB (The Mathworks Inc., Natick, MA, USA Version, 7.0.1) Routine für die ASSR-Messungen. DPOAE-Messungen wurden mit der Software Sound Forge (Sony Creative Software Inc., Version 7.0) durchgeführt.

Auf der Homepage der Abteilung liegen die MATLAB Dateien zur ASSR-Erzeugung unter http://www.innerearlab.uni-goettingen.de/materials/materials.htm bereit.

Das TDT-III-System ist ein Messsystem zur Echtzeit Stimulusgeneration und Messdatenerfassung. Es bestand aus einer modularen Plattform, das Kernstück waren drei digitale System Prozessoren (Zwei RP2.1 Real-Time Prozessore und eine RA16BA Medusa Base Station), welche von weiteren Modulen umgeben waren. Die RP2.1 Prozessoren generierten und wandelten die digitalen Stimuli mit einem 24-Bit D/A Wandler (sampling Rate 24,41 kHz) in analoge Signale um. Nach der Generation wurden die Signale zu einem programmierbaren Abschwächer (programmable attenuator, PA5, TDT) geleitet, welcher anhand eines Testtons kontrolliert die Amplitude auf den gewünschten Schalldruckpegel abschwächte. Die Abschwächleistung reichte von 0- $120 \mathrm{~dB}$ in 0,1 dB Schritten, welche durch MATLAB angesteuert und automatisch eingestellt wurde. Über ein Leistungsverstärkersystem (HeadBuffer System (power amplifier) HB6, TDT) wurden die Stimuli nachfolgend zum Lautsprecher (JBL GmbH \& Co., Neuhofen, Deutschland) geleitet.

Die abgeleiteten Potenziale wurden mit einem Headstage Vorverstärker verstärkt (RA4LI, Medusa Low impedance headstage Verstärker, TDT) und digitalisiert (RA4PA Medusa PreAmplifier, TDT). Anschließend wurden sie über einen Lichtwellenleiter zur Medusa Base Station (RA16BA) geleitet und gefiltert (Hochpass Filter zur Eliminierung der $50 \mathrm{~Hz}$ Störfrequenz). Im letzten Schritt wurde die Antwort 
störsicher über ein Verbindungsmodul (Fiber-Link Modul), welches die jeweiligen Bestandteile des Messsystems ansteuert, sowie per Lichtwellenleiter zum PC zurückgeleitet und in BioSig oder MATLAB dargestellt. Multifrequente Stimuli entstanden durch analoges Aufmischen von je vier SAM-Tönen mit einem weighted summer (SM3, TDT).

Die Schalldruckpegel L sind in Dezibel (dB) SPL (Sound Pressure Level) RMS (Root Mean Square) für tonale Stimuli oder in Dezibel SPL "peak äquivalent" (PE) für Klicks angegeben. Der Schalldruckpegel (dB SPL) stellt als logarithmisches Maß das Verhältnis zwischen dem gemessenen Schalldruckpegel $\left(\mathrm{p}_{\mathrm{x}}\right)$ und dem Bezugsschalldruck $\left(\mathrm{p}_{0}=2 \cdot 10^{-5}\right.$ Pascal) dar und wird nach der Formel $\mathrm{L}[\mathrm{dB} S \mathrm{SP}]=20 \cdot \log 10\left(\mathrm{p}_{\mathrm{x}} / \mathrm{p}_{0}\right)$ berechnet. Die Kalibration erfolgte mit einem 1/4“ Brüel \& Kjaer Mikrophon (D 4039, Brüel \& Kjaer GmbH, Bremen, Deutschland).

Tonburst und ASSR-Stimuli zur Darstellung im Frequenzspektrum (Abb. 4C und D) wurden durch Messung bei $80 \mathrm{~dB}$ SPL Intensität über ein Sennheiser Mikrophon (MKE 2 P-C) aufgenommen.

ASSR- und BERA-Stimuli wurden den Tieren monaural in $7 \mathrm{~cm}$ Abstand zum ipsilateral positionierten Lautsprecher (JBL GmbH \& Co., Neuhofen, Deutschland) im Freifeld präsentiert. Die Impedanzdifferenz zwischen den Elektroden wurde um $1 \mathrm{k} \Omega$ gehalten und vor jeder Messung an einen eingebauten Impedanztester des RA4Li Headstager Moduls (TDT) getestet.

ASSR- und BERA-Messungen wurden in einer schallisolierten Untersuchungsbox (1,2 m x 1,0 m x 1,2 m Soundblocker; Desone GmbH, Berlin, Deutschland) durchgeführt. Alle Messungen erfolgten nach dem gleichen Versuchsaufbau im Innenohrlabor der Abteilung für Hals-Nasen-Ohrenheilkunde der Georg-August Universität Göttingen.

\subsubsection{ASSR-Messungen}

Sinusförmig amplitudenmodulierte (SAM) Töne (Abb. 4B) wurden durch das TDT-IIISystem generiert. Es wurden Frequenzen von 4 kHz, 7 kHz, 8 kHz, 10 kHz, 12 kHz und $16 \mathrm{kHz}$ erzeugt, welche mit einer Frequenz von 100-1400 Hz amplitudenmoduliert wurden. Die Modulationstiefe betrug in allen Versuchen 100\%.

Das abgeleitete EEG-Potenzial wurde in der schallisolierten Untersuchungsbox verstärkt (20fach, RA4Li, Low impedance, Headstage Verstärker, TDT), digitalisiert (RA4PA, 
Medusa PreAmplifier, 16-Bit, sampling Rate 24,41 Hz), über einen Lichtwellenleiter zur Medusa Base Station geleitet und gefiltert ( $50 \mathrm{~Hz}$ Kerbfilter und $60 \mathrm{~Hz}$ Hochpassfilter für alle Versuche zur Reduktion der initialen niedrigfrequenten Peaks). Es wurden Zeitabschnitte (Sweeps) von je 4 Sekunden gespeichert. Durch schnelle FourierTransformation (engl.: fast Fourier-Transformation, FFT) erfolgte die Umwandlung der ASSR aus dem Zeitfenster in das Frequenzspektrum mit einer Auflösung von 0,016 Hz. Es wurde kein Artefaktverwurf verwendet. Einen Überblick zum Versuchsaufbau geben Abb. 6 und 7.

Vor jeder Messreihe wurden Testmessungen mit Modulationsfrequenzen beginnend bei $100 \mathrm{~Hz}$, aufsteigend in $29 \mathrm{~Hz}$ Schritten bis $1400 \mathrm{~Hz}$ durchgeführt. Es wurde überschwellig stimuliert (80 dB SPL bei WT-Tieren, $90 \mathrm{~dB}$ SPL bei KO-Tieren) und die Messdauer betrug 16 Sekunden pro MF. Die Amplituden der ASSR und des Hintergrundes jeder Einzelmessung wurden automatisch durch MATLAB als Funktion aufgetragen und in Form einer Modulation Transfer Function (MTF) dargestellt (Abb.11A). Dies ermöglichte die Darstellung von individuellen Modulationsfrequenzbereichen zur optimalen ASSR-Erzeugung. Während der MTF war eine FFT des EEGs, eine online-MTF und ein online-EEG sichtbar.

In Anschluss wurden die Hörschwellen bei individuell ermittelten Modulationsfrequenzen gemessen und sowohl visuell als auch statistisch mit $10 \mathrm{~dB}$ SPL Genauigkeit ausgewertet. Gemessen wurde abwärts, begonnen bei 80 dB SPL bei WTTieren und bei $90 \mathrm{~dB}$ SPL bei Mutanten. Die Messdauer betrug eine Minute pro Intensität. Während der ASSR-Messung war die FFT des EEGs, ein vergrößerter Ausschnitt $( \pm 10 \mathrm{~Hz}$ ) der ASSR in der FFT sowie ein online EEG sichtbar.

Als Hörschwelle wurde die niedrigste Intensität festgelegt, bei der eine statistisch signifikante ASSR-Amplitude vorhanden war. Dies war als ein Peak definiert, welcher an der applizierten MF mindestens um die zweifache Standardabweichung größer war, als die mittlere Hintergrundaktivität der benachbarten $\pm 10 \mathrm{~Hz}$ um den Peak herum. Die Amplitudengrößen wurden in der Arbeit als hintergrundkorrigierte Amplituden dargestellt, sofern nicht anders angegeben. Hierzu wurde die mittlere Hintergrundaktivität $( \pm 10 \mathrm{~Hz}$ um den Peak) von der absoluten ASSR-Amplitude abgezogen.

Die visuell bestimmten Hörschwellen wurden subjektiv in der FFT der ASSR bestimmt. 


\subsubsection{BERA-Messungen}

BERA-Stimuli wurden durch die Software SigGen in einer Konfigurationsdatei generiert, durch BioSig wurden die Potenziale aufgezeichnet und ausgewertet. Die technische Generation und Datenspeicherung erfolgte ebenfalls durch das TDT-III-System. Der akustische Stimulus für die Tb-BERA war ein 12 ms langer Impuls ( $\cos ^{2}$ Anstiegs- und Abfallzeit je $1 \mathrm{~ms} ; 10 \mathrm{~ms}$ Plateau) (Abb. 4A), welcher mit einer Reizwiederholungsrate von $20 \mathrm{~Hz}$ und bei Frequenzen von $4 \mathrm{kHz}, 7 \mathrm{kHz}, 8 \mathrm{kHz}, 10 \mathrm{kHz}, 12 \mathrm{kHz}$ und $16 \mathrm{kHz}$ präsentiert wurde.

Die gemessene Potenzialdifferenz wurde in der schallisolierten Untersuchungsbox vorverstärkt (20fach, RA4Li, Low impedance, Headstage Verstärker, TDT), digitalisiert (RA4PA, Medusa PreAmplifier, 16-Bit, sampling Rate 24,41 $\mathrm{Hz}$ ), über einen Lichtwellenleiter zur Medusa Base Station (TDT) geleitet und gefiltert $(0,4 \mathrm{kHz}$ Hochpass und $4 \mathrm{kHz}$ Tiefpass). Anschließend wurde die Antwort stimulusgetriggert aufgezeichnet und über 2000 Sweeps (Zeiteinheiten) gemittelt als eine Spur dargestellt. Es wurden zwei Spuren (à 2000 Sweeps) pro Intensität aufgezeichnet, was die visuelle Auswertung vereinfacht und optimiert (Abb. 4E). Die Stimulusantwort wurde für eine Dauer von 20 ms nach Stimulusinput aufgezeichnet.

Rechteckige Klick-Impulse (0,03 ms Dauer) als Stimuli für die Klick-BERA wurden mit einer Reizwiederholungsrate von $20 \mathrm{~Hz}$ appliziert und nach den gleichen Verfahren verstärkt, gefiltert, gemittelt und aufgezeichnet.

Zeitabschnitte mit vielen Artefakten (Muskelartefakte, EKG-Potenziale) wurden durch einen automatischen Artefaktverwurf von BioSig32 von der Mittelung ausgeschlossen. Als Hörschwelle wurde die niedrigste Intensität festgelegt, welche noch reproduzierbare Potenzialantworten in beiden Spuren sowie im Vergleich zur nächsthöheren Intensität erkennen ließ. Es wurden die Jewett-Wellen I-V aufgesucht, insbesondere wurden die Jewett-Wellen III und V zur Hörschwellenbestimmung herangezogen, da diese von der Morphologie am konstantesten zu erkennen waren. Die Amplituden wurden von der Amplitudenspitze zum Amplitudental im $\mu \mathrm{V}$ ausgemessen. Es wurde darauf geachtet, dass der Artefaktanteil nicht über $10 \%$ lag. Gemessen wurde in $10 \mathrm{~dB}$ Schritten abwärts. Begonnen wurde bei 80 dB SPL und bei 90 dB SPL in den Gruppen der KOTiere. Bei überschwelliger Stimulation und klar erkennbaren Jewett-Wellen wurde bereits benutzerdefiniert nach mindestens 2 gemittelten Spuren à 1000 Sweeps abgebrochen. 


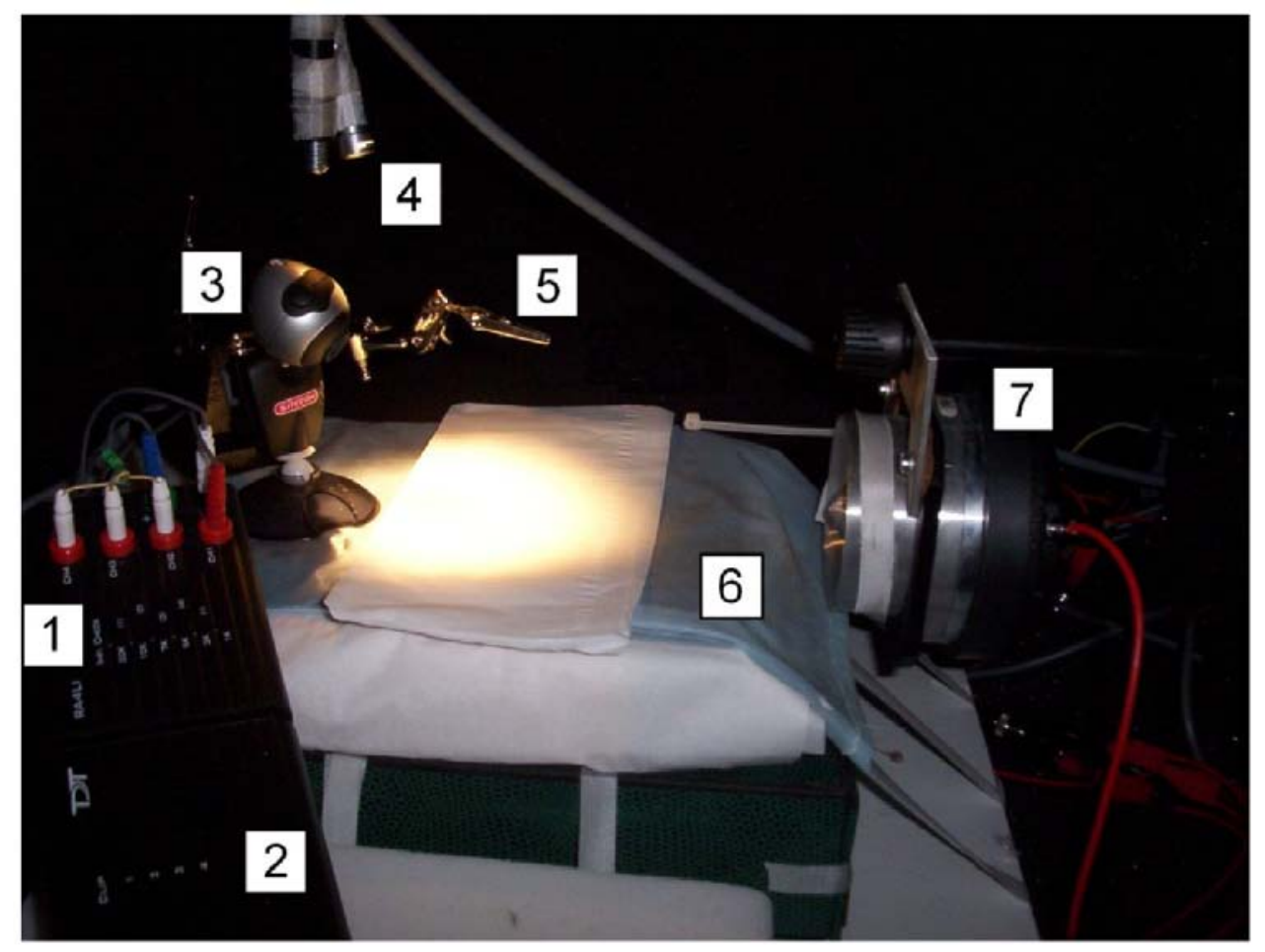

Abb. 6: ASSR- und BERA-Messplatz

(1) RA4Li, Medusa Low impedance headstage Verstärker, TDT; (2) RA4PA, Medusa PreAmplifier, TDT; (3) USB Kamera; (4) Lichtquelle; (5) Elektrodenhalterung; (6) Heizmatte; (7) Lautsprecher 
BERA

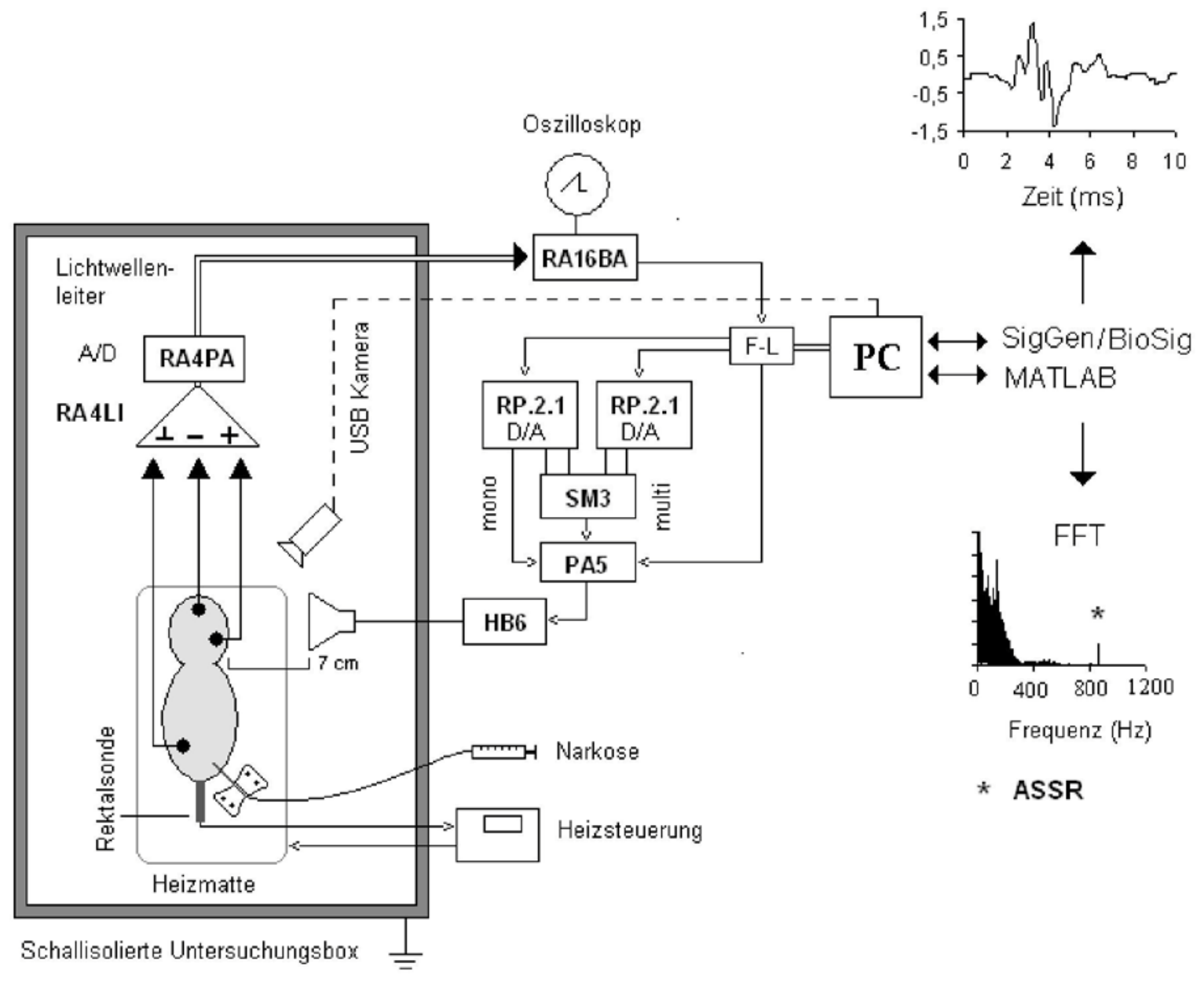

Abb. 7: Schaltbild zu ASSR- und BERA-Messungen

Der PC ist über ein $\boldsymbol{F - L}$ (Fiber-Link) Verbindungsmodul mit den jeweiligen nachgeschalteten Systemmodulen verbunden und steuert über MATLAB zwei RP.2.1 (digitale Systemprozessoren mit 24-Bit D/A Wandler), den PA5 (programmable attenuator TDT), sowie die Medusa Base Station an. HB6 (Head Buffer System, TDT); SM3 (weighted summer, TDT; zur Generation mulitfrequenter Töne). RA4LI: Low impedance headstage Verstärker, TDT; RA4PA: Medusa 16-Bit A/D Wandler, RA16BA: Medusa Base Station, TDT. Über SigGen werden die BERA-Stimuli generiert, über BioSig werden die digitalen Systemprozessoren angesteuert sowie die Antworten dargestellt und analysiert. 


\subsubsection{DPOAE-Messungen}

Zur Erzeugung der DPOAEs wurden zwei Sinustöne $\left(f_{1}\right.$ und $f_{2}$ ) im Verhältnis von $\mathrm{f}_{2} / \mathrm{f}_{1}=1,2\left(\right.$ mit $_{1}=10 \mathrm{kHz}$ und $\mathrm{f}_{2}=12 \mathrm{kHz}$ ) über einen programmierbaren Abschwächer (PA4, TDT) generiert und mit und einem ED1/ EC1 Lautsprechersystem (Tucker-Davis Technologies, System-II) präsentiert. Die Intensitäten von $\mathrm{L}_{1}$ und $\mathrm{L}_{2}$ bei $\mathrm{f}_{1}$ und $\mathrm{f}_{2}$ betrugen je $60 \mathrm{~dB}$ SPL. Über eine Sonde (Eigenbau) wurden die Primärtöne in den Ohrkanal möglichst nah an das Trommelfell geleitet. Über ein an der Spitze des Sondensystems liegendes MKE-2-P Mikrofon (Sennheiser, Hannover, Deutschland) wurden die empfangenen OAE Signale aufgenommen. Anschließend wurden die OAEs über einen Dual Microphone Preamplifier (DMP3, MIDIMAN) verstärkt, mit einer 24-Bit Soundkarte (Firma Terratec, DMX, $96 \mathrm{kHz}$ ) aufgenommen und anhand von Sound Forge (Version 7.0) ausgewertet. Hier erfolgte durch eine FFT die Umwandlung in das Frequenzspektrum. Die Auswertung auf das Vorhandensein von den charakteristischen Peaks wurde mit der Software IgorPro durchgeführt. Die DPOAE-Messungen erfolgten in einem schallisolierten Untersuchungsraum.

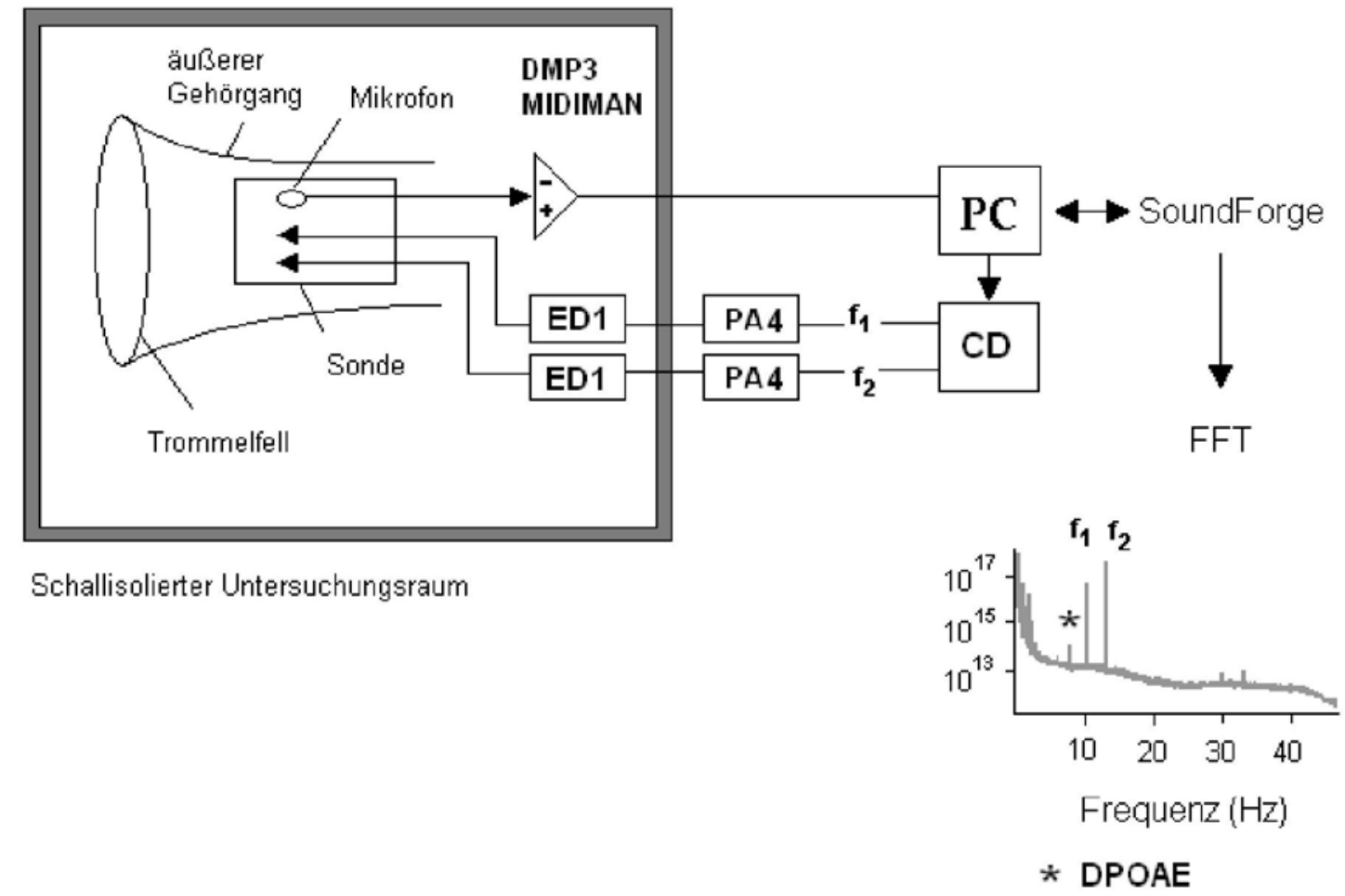

Abb. 8: Schaltbild zu DPOAE-Messungen

Die Soundkarte des PCs gibt über einen CD-Player die beiden Primärtöne $f_{1}$ und $f_{2}$ zu je zwei PA4: programmable attenuator, TDT; ED: electronic speaker device, TDT; DMP3 MIDIMAN: Verstärker, TDT. 


\subsection{Datenanalyse und statistische Auswertung}

Offline Analysen der ASSR-Daten erfolgten mit MATLAB (Version 7.0.1; The Mathworks, Natick, MA, USA), Microsoft Excel, Microsoft Access und Igor Pro (Wavemetrics, Eugene, OR, USA).

Die Analyse der BERA-Daten erfolgte mit BioSig32, Microsoft Excel und IgorPro. Die Analyse der OAE Daten wurde MATLAB und IgorPro durchgeführt. Die Box-Plots wurden mit Statistica 8 dargestellt.

Die Hörschwellen sind im Box-Plot mit dem arithmetischen Mittelwert, dem Standardfehler $( \pm$ SE) und der Standardabweichung $( \pm$ SD) dargestellt. Dabei stellt der zentrale Punkt den Mittelwert dar und die obere bzw. untere Grenze der Rahmen markiert den Standardfehler. Die von hier ausgehenden Linien zeigen die Standardabweichung an. Im Text ist, wenn nicht anders angegeben, der Standardfehler angegeben.

Der Spearman's Rangkorrelationskoeffizient $r_{s}$ (für nichtparametrische Daten), als Maß für die Ausprägung des linearen Zusammenhangs, wurde zur Prüfung der Korrelation verwendet. Je näher $r_{s}$ an 1 liegt, desto enger verteilen sich die Messwerte um die eingezeichnete Regressionsgrade.

Für den Vergleich der Mittelwerte zweier Gruppen wurde der Student's t-Test verwendet. Der gepaarte t-Test wurde verwendet, wenn Ergebnisse innerhalb der gleichen Maus verglichen wurden. Der Wilcoxon-Rangsummmentest für verbundene Stichproben wurde zum Testen von ordinalskalierten, nichtparametrischen Merkmalen, basierend auf einer Rangbildung, verwendet. 


\section{Ergebnisse}

\subsection{Normalhörende Tiere}

\subsubsection{Modulation Transfer Function (MTF) und optimale Messdauer}

Im Frequenzspektrum des EEGs der Maus in Narkose ohne akustische Stimulation war ein großer niedrigfrequenter Peak bei Frequenzen unter $200 \mathrm{~Hz} \mathrm{zu}$ erkennen (Abb. 4F (2)). Dies ließ während der Vorversuche eine eingeschränkte Verwendung der sehr niedrigen Modulationsfrequenzen vermuten. ASSR konnten mit $40 \mathrm{~Hz}$ und $80 \mathrm{~Hz}$ Modulationsfrequenz erzeugt werden, jedoch waren die Hintergrundamplituden verhältnismäßig groß (Abb. 10A). Daher wurde zunächst nach geeigneten Modulationsfrequenzen für ASSR Messungen bei der Maus gesucht. Hierzu wurden die absoluten ASSR- und Hintergrundamplituden aller getesteten Modulationsfrequenzen $(100-1400 \mathrm{~Hz})$ als Modulation Transfer Function (MTF) aufgetragen (Abb. 10B). Weiterhin stellte sich die Frage nach der optimalen Messdauer für MTF- und ASSRMessungen, weil ASSR Amplituden und Hörschwellen von der Messdauer abhängig sind (Luts et al. 2004, Picton et al. 2005).

ASSR Messungen mit 1,875-60 Sekunden Messdauer zeigten, dass unter 15 Sekunden Messdauer die Amplitudengröße abnahm (Abb. 9B). Bei einer Messdauer von 60 Sekunden waren die Hörschwellen niedriger (Abb. 9A), es zeigte sich aber kein signifikanter Unterschied im Vergleich zu 30 Sekunden Messdauer $(p=0,72)$. Als Messdauer für jede Intensität zur Hörschwellenbestimmung wurde 1 Minute definiert. Für jede Frequenz in der MTF wurde 16 Sekunden (4 Sweeps) Messdauer definiert.

Die MTF zeigte, dass sowohl die Hintergrundamplituden, als auch die ASSR-Amplituden von der Modulationsfrequenz abhängig waren (Abb. 10B). Es waren drei Maxima sichtbar (Abb. 10C). Nach einem Maximum bei $180 \mathrm{~Hz}$ erfolgte ein Abfall der Amplituden auf ein Minimum um $430 \mathrm{~Hz}$. Anschließend folgte ein weiterer Amplitudenanstieg bis Frequenzen um $600 \mathrm{~Hz}$. Oft war noch ein weiteres Maximum um $900 \mathrm{~Hz}$ erkennbar. Trotz kleiner Amplituden waren ASSR statistisch bis Modulationsfrequenzen von $1400 \mathrm{~Hz}$ nachweisbar. Basierend auf diesen Ergebnissen wurden für die folgenden Untersuchungen niedrig- $(<200 \mathrm{~Hz})$, mittel- (200-600 Hz) und hochfrequente (> $600 \mathrm{~Hz}$ ) MF-Gruppen gebildet und näher untersucht. 
Der Verlauf der MTF war von der TF abhängig (Abb. 10D). Bei 4 kHz zeigte sich eine gering ausgeprägte MTF Kurve ohne deutliche Maxima. Nach ausgeprägten ASSRAmplituden im niedrigfrequenten Bereich war bei allen Trägerfrequenzen ein Amplitudenminimum um $430 \mathrm{~Hz}$ vorhanden. Bei Frequenzen von $7 \mathrm{kHz}, 10 \mathrm{kHz}$ und $15 \mathrm{kHz}$ war ein weiterer Anstieg der Amplitudengrößen bei Modulationsfrequenzen um $630 \mathrm{~Hz} \mathrm{zu}$ verzeichnen. Wiederholungen der MTF am gleichen Tier zeigten eine zeitliche Verschiebung der ASSR-Maxima mit zunehmender Untersuchungsdauer in niedrigere MF-Bereiche (Abb. 10E). Nach der ersten Untersuchungsstunde kam es zu einer mittleren Verschiebung des ASSR-Amplitudenminimums um -103,6 $\pm 25,6 \mathrm{~Hz}$ (n=3 C57/BL6 Tiere). Hieraus wurde die Konsequenz gezogen, für jede ASSR-Messung Modulationsfrequenzen zu verwenden, welche aus einer maximal 45 Minuten alten MTF stammten.

Es wurde kein Unterschied zwischen ASSR-Amplituden mit 80\% und 100\% Modulationstiefe gefunden (Abb.11). Für alle folgenden Messungen wurde eine Modulationstiefe von $100 \%$ verwendet.

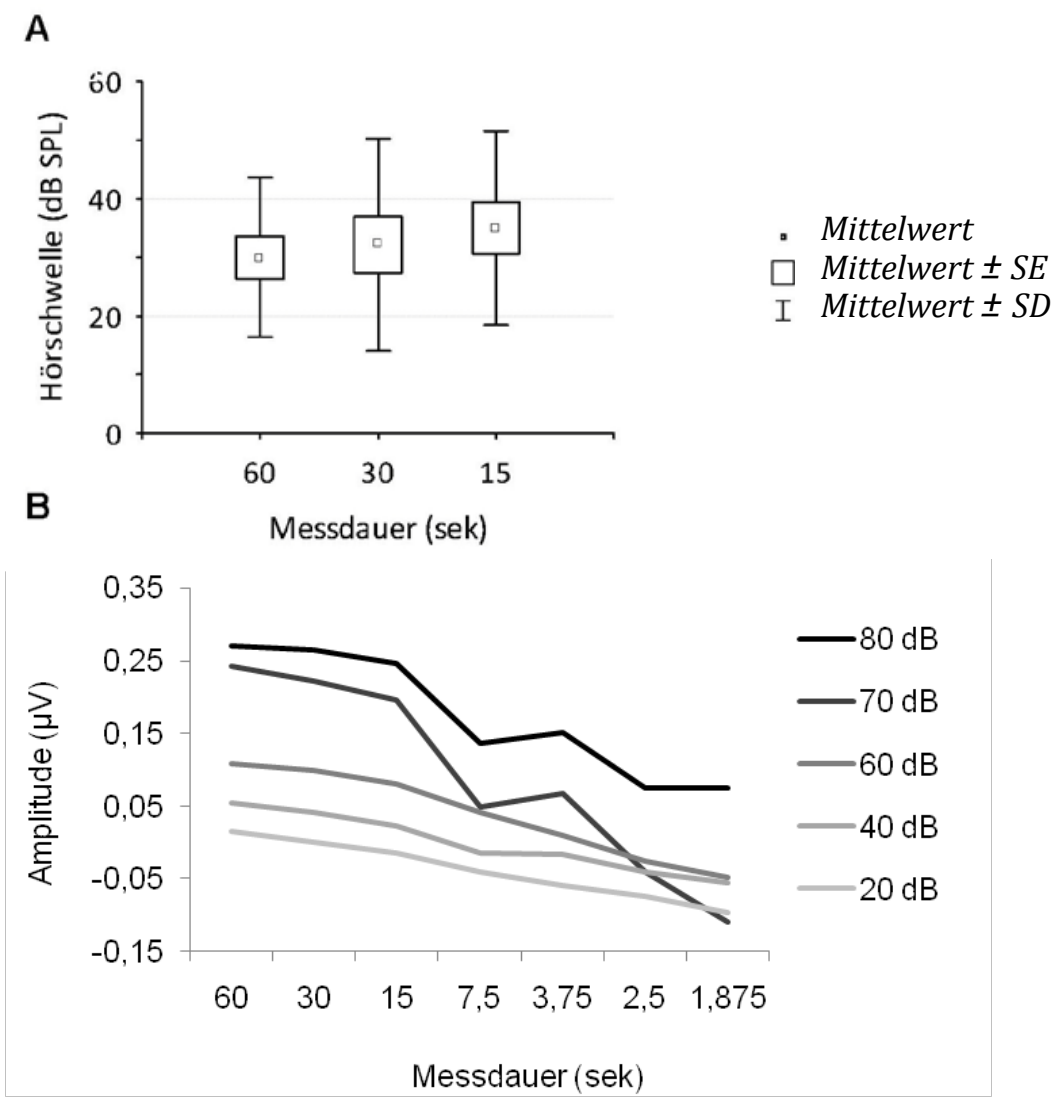

Abb.9: Einfluss der Messdauer auf ASSR-Hörschwelle und ASSR-Amplitude (A) $n=14$ Ohren von 7 C57/BL6 Tieren (B) $n=20$ Ohren von 10 C57/BL6 Tieren 

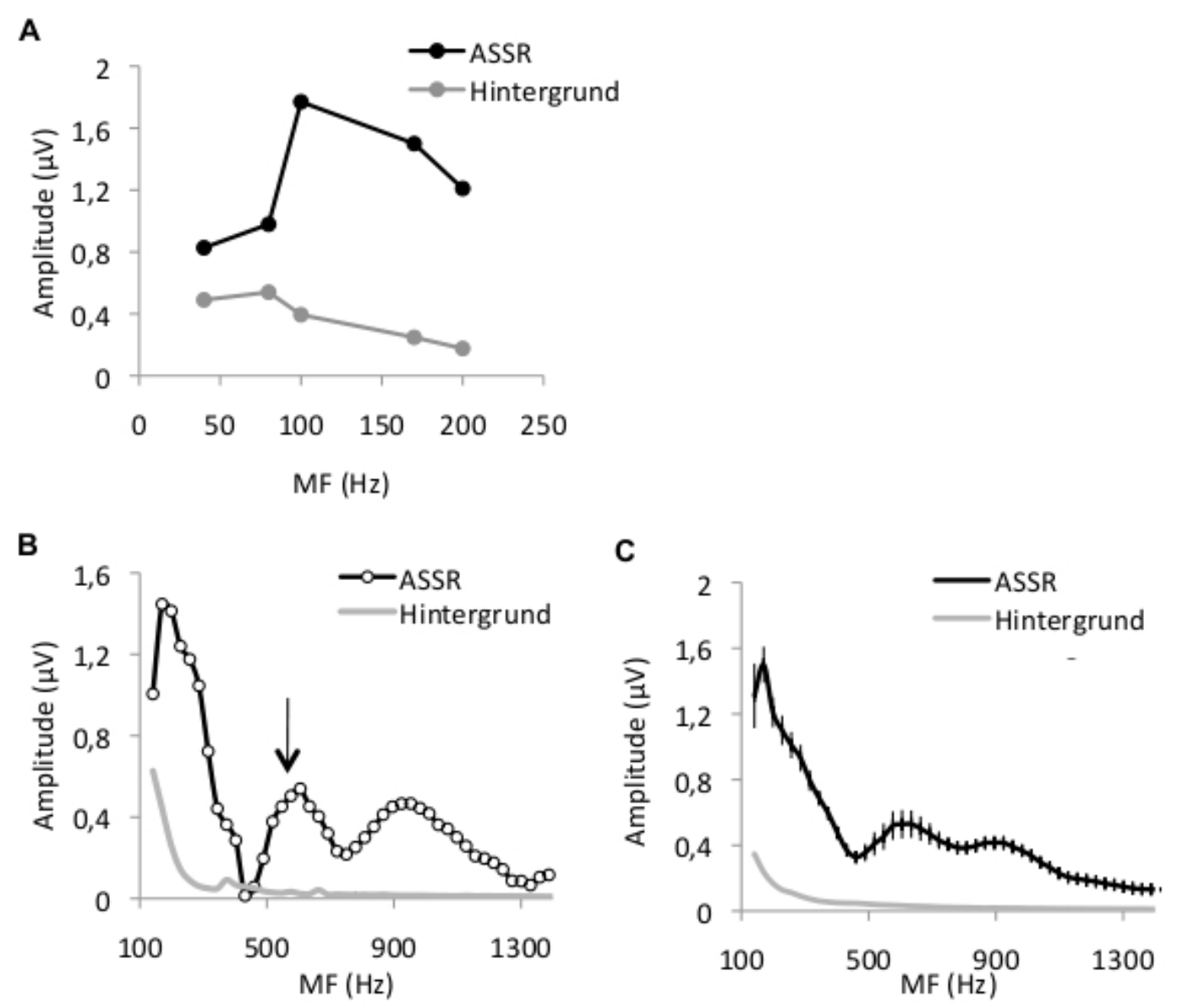

D

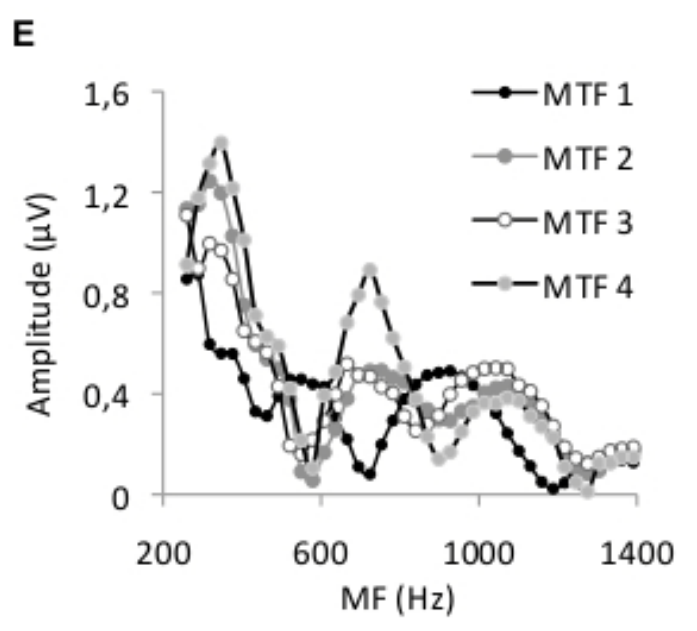

Abb. 10: Modulation Transfer Function (MTF)

(A) Vergleich der absoluten ASSR- und Hintergrundamplituden bei $40 \mathrm{~Hz}, 80 \mathrm{~Hz}, 100 \mathrm{~Hz}$, $170 \mathrm{~Hz}$ und $200 \mathrm{~Hz} \mathrm{MF} \mathrm{(} n=6$ C57/BL6 Tiere). (B) $10 \mathrm{kHz}$ MTF einer repräsentierbaren 8 Wochen alten C57BL/6 Maus bei $80 \mathrm{~dB}$ SPL Intensität. (C) Mittlere MTF aller WT-Tiere ( = 20 Tiere, 32 Ohren insgesamt, davon $7 \mathrm{C57BL} / 6,13 \mathrm{Bsn}{ }^{+/+}$und $13 \mathrm{KCNQ}_{4}^{+/+}$). (D) Mittlere MTF bei $4 \mathrm{kHz}, 7 \mathrm{kHz}, 10 \mathrm{kHz}$ und $15 \mathrm{kHz}$ ( $n=4$ C57/BL6 Tiere). (E) Zeitliche Verschiebung der ASSR-Maxima bei einer repräsentativen 8 Wochen alten C57/BL6 Maus. MTF (2): 60 min nach MTF (1), MTF (3): 130 min nach MTF (1), MTF (4): 243 min nach $\operatorname{MTF}(1)$. 


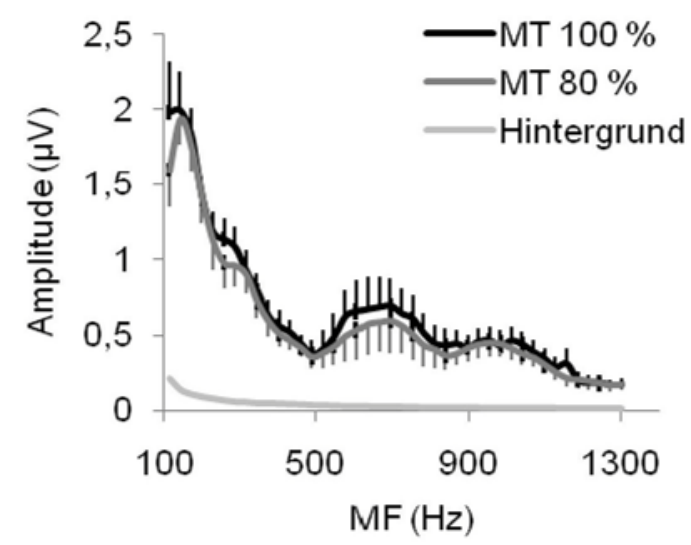

Abb. 11: Vergleich der Modulationstiefe

MTF bei 80 dB SPL Intensität und je 80\% (grau) und 100 \% (schwarz) Modulationstiefe ( $n=8$ C57/BL6 Tiere)

\subsubsection{ASSR-Amplitudenwachstum bei normalhörenden Tieren}

Das Amplitudenwachstum der ASSR wurde als Funktion der Stimulationsintensität aufgetragen und bei unterschiedlichen Modulations- und Trägerfrequenzen untersucht (Abb. 12).

Wie aus der MTF zu vermuten (Abb. 10C), waren in der Amplituden-Wachstumsfunktion die ASSR-Amplituden in der niedrigfrequenten MF-Gruppe $(<200 \mathrm{~Hz}$ ) am größten (Abb. 12B). Bei überschwelliger Stimulation waren die Amplituden signifikant größer als die Amplituden der mittelfrequenten MF-Gruppe (80 dB SPL: $p=0,02 ; 70 \mathrm{~dB}$ SPL: $\mathrm{p}=0,05)$. Ab $60 \mathrm{~dB}$ SPL Stimulation abwärts konnten keine signifikanten Unterschiede zwischen den Amplituden der drei Gruppen gezeigt werden. Im Hörschwellenbereich näherten sich die Kurven sehr stark an.

Die Größe der ASSR-Amplituden war abhängig von der TF (Abb. 12C). Ab einer Intensität über $40 \mathrm{~dB}$ SPL waren die $4 \mathrm{kHz}$ Amplituden signifikant kleiner als die Amplituden der höheren TF ( $p<0,05$ im jeweiligen Vergleich). Die Amplituden der Frequenzen 8 kHz - 16 kHz (Abb. 12C; MF > $200 \mathrm{~Hz}$ ) unterschieden sich statistisch nicht voneinander. 
A

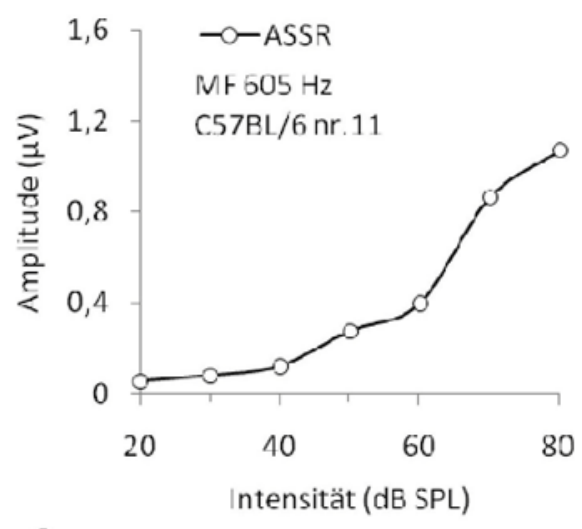

C

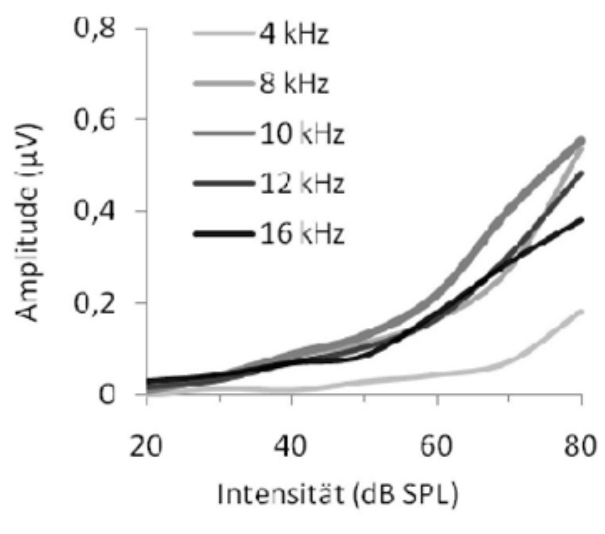

B

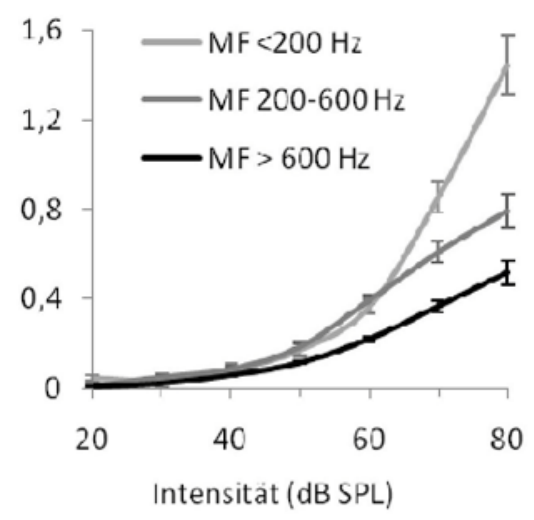

D

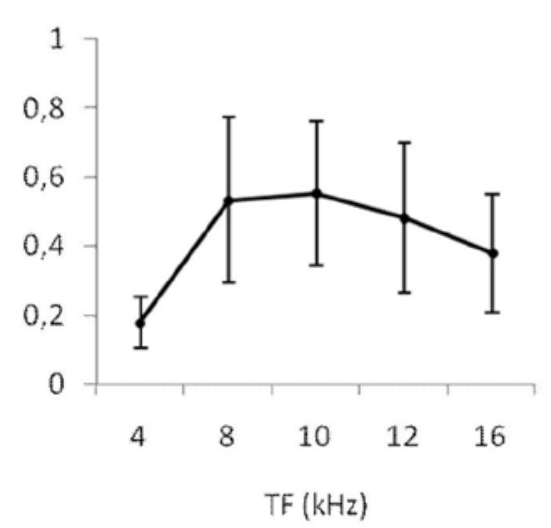

Abb. 12: ASSR-Amplituden-Wachstumsfunktion

(A) Repräsentative Darstellung einer $10 \mathrm{kHz}$ ASSR-Amplituden-Wachstumsfunktion (hintergrundkorrigiert) eines 6 Wochen alten C57/BL6 Tieres. (B) $10 \mathrm{kHz}$ ASSRAmplituden-Wachstumsfunktion (hintergrundkorrigiert) aller WT-Tiere. Für jedes Tier wurden ASSR Hörschwellen in allen MF Bereichen gemessen ( $n=16$ Tiere, 29 Ohren: $3 \mathrm{C} 57 \mathrm{BL} / 6,14 \mathrm{Bsn}+/+$ und $12 \mathrm{KCNQ}_{4}^{+/+}$Ohren). (C) Vergleich der 4-16 kHz ASSRAmplituden-Wachstumsfunktionen (hintergrundkorrigiert) ( $n=5$ C57BL/6 Tiere). Die MF wurde individuell in einem Bereich zwischen 200 und $900 \mathrm{~Hz}$ gewählt. (D) Vergleich der ASSR-Amplitudengrößen in Abhängigkeit von der TF bei $80 \mathrm{dBSPL}$ Stimulation der gleichen Tiere aus (C).

\subsubsection{Hörschwellenbestimmung mittels ASSR und BERA}

Nach Bestimmung der optimalen Modulationsfrequenzen aus der MTF wurde mit mindestens zwei Modulationsfrequenzen die $10 \mathrm{kHz}$ ASSR-Hörschwelle bestimmt. Anschließend wurden diese mit den $10 \mathrm{kHz}$ Tb-BERA- und Klick-Hörschwellen verglichen (Abb. 13). 
ASSR-Hörschwellen, gemessen mit der mittleren (200-600 Hz) und der hohen MFGruppe (200-600 Hz), unterschieden sich $(p=0,38)$ nicht voneinander.

Tb-BERA-Hörschwellen (34,1 dB SPL \pm 1,8 dB SPL) unterschieden sich statistisch nicht ( $\mathrm{p}=0,28)$ von den Hörschwellen der mittelfrequenten MF-Gruppe (31,3 dB SPL \pm 1,8 dB SPL). Die hohe MF-Gruppe (29,1 dB SPL $\pm 2,1 \mathrm{~dB}$ SPL) erzeugte signifikant niedrigere Hörschwellen als die Tb-BERA $(p=0,02)$. Die Klick-Hörschwelle $(30,1 \mathrm{~dB}$ SPL $\pm 1,9 \mathrm{dBSPL}$ ) war statistisch nicht von der mittleren- und hohen MF-Gruppe zu unterscheiden (MF 200-600 Hz: p=0,45; MF > $600 \mathrm{~Hz} p=0,59$ ).

ASSR-Hörschwellen der niedrigen MF-Gruppe unter $200 \mathrm{~Hz}$ (52,2 dB SPL \pm 3,8 dB SPL) waren signifikant höher als die Hörschwellen der anderen MF-Gruppen als auch der TbBERA- und Klick-Hörschwellen (alle $\mathrm{p}<0,01$ ). Zwischen Tb-BERA und Klick-BERA Hörschwelle bestand ein signifikanter Unterschied $(p=0,007)$.

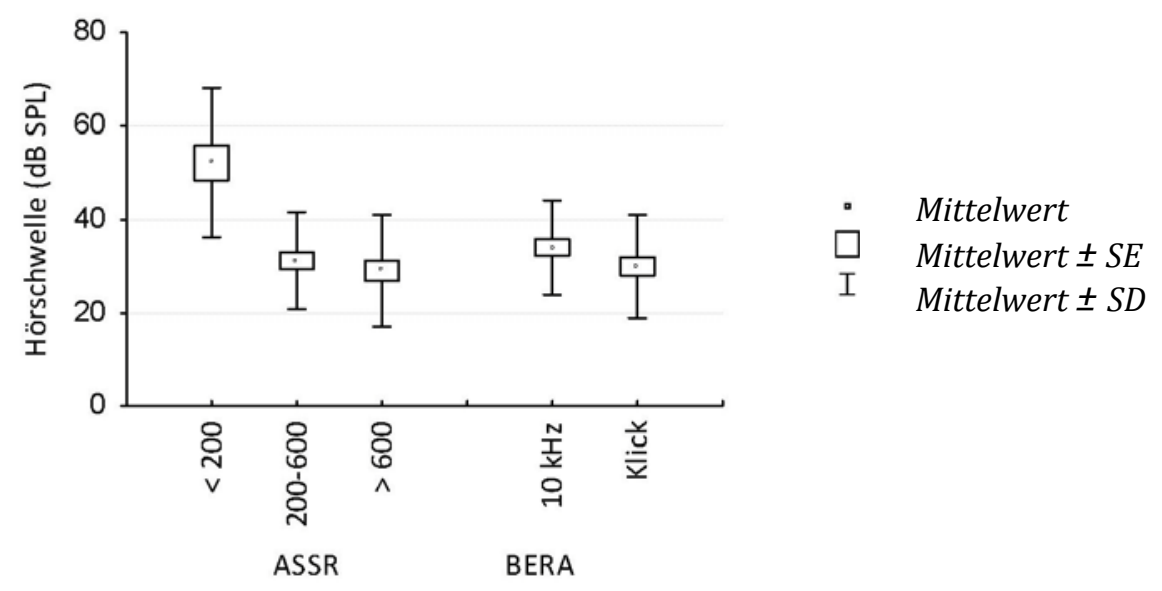

Abb. 13: Box-Plots der ASSR- und Tb-BERA-Hörschwellen der WT-Tiere $10 \mathrm{kHz}$ ASSR (MF <200 Hz, MF 200-600 Hz, MF> 600 Hz) und BERA-Hörschwellen $(10 \mathrm{kHz}$ Tonburst und Klick) aller WT-Tiere ( $n=23$ Tiere, 36 Ohren, davon: 10 C57BL/6 14 Bsn +/+, $12 \mathrm{KCNQ}_{4}^{+/+}$Ohren).

\subsubsection{Statistische und visuelle ASSR Auswertung}

Die statistische Auswertung der FFT mit MATLAB und Microsoft Excel wurde mit der visuell-subjektiven Auswertung des Untersuchers verglichen (Abb.14A). 
Die visuell und statistisch bestimmten ASSR-Hörschwellen bei hörgesunden Tieren der MF-Gruppe unter $200 \mathrm{~Hz}$ unterschieden sich nicht signifikant voneinander $(\mathrm{p}=0,08)$.

In den mittel- und hochfrequenten MF-Gruppen waren die statistisch bestimmten Hörschwellen signifikant niedriger als die visuellen Hörschwellen (MF 200-600 Hz: p = 0,001; MF > $600 \mathrm{Hz:}$ p = 0,002). Die statistischen Hörschwellen der WT-Tiere lagen im Mittel 4,3 dB niedriger als die visuellen Schwellen. Die visuellen ASSR-Hörschwellen der MF-Gruppe unter $200 \mathrm{~Hz}$ waren, wie in Teil 3.1.3, signifikant höher als die Hörschwellen der Gruppen der mittel- $(p=0,004)$ und hochfrequenten $(p=0,003)$ Modulationsfrequenzen. Innerhalb der mittel- und hochfrequenten MF-Gruppen unterschieden sich die visuellen Hörschwellen nicht signifikant voneinander $(p=0,32)$. Die statistisch und visuell bestimmten ASSR-Hörschwellen der hörgesunden und schwerhörigen Tiere korrelierten sehr gut (Abb. 14D: Spearman's $r_{s}=0,93$ ).

Zusätzlich zur bisher durchgeführten Hörschwellenmessung und -auswertung in $10 \mathrm{~dB}$ Schritten wurden Messungen in $3 \mathrm{~dB}$ Schritten durchgeführt (Abb. 14B und C). Ab der ersten Intensität, welche nach der Berechnung mit MATLAB nicht vom Hintergrund zu unterscheiden war, wurden automatisch die nächsthöheren Intensitäten in $3 \mathrm{~dB}$ Schritten geprüft, bis MATLAB einen Unterschied zum Hintergrund nachweisen konnte. Die ASSR-Hörschwellen, ermittelt in $10 \mathrm{~dB}$ und $3 \mathrm{~dB}$ Messschritten, unterschieden sich weder bei den hörgesunden (MF 200-600 Hz: p = 0,12; MF > $600 \mathrm{~Hz}$ : p = 0,23), noch bei den schwerhörigen Tieren (MF 200-600 Hz: $p=0,73$; MF > $600 \mathrm{~Hz}: \mathrm{p}=0,09$ ) signifikant voneinander und korrelierten sehr gut (Abb. 14E: Spearman's $\left.r_{s}=0,91\right)$. 

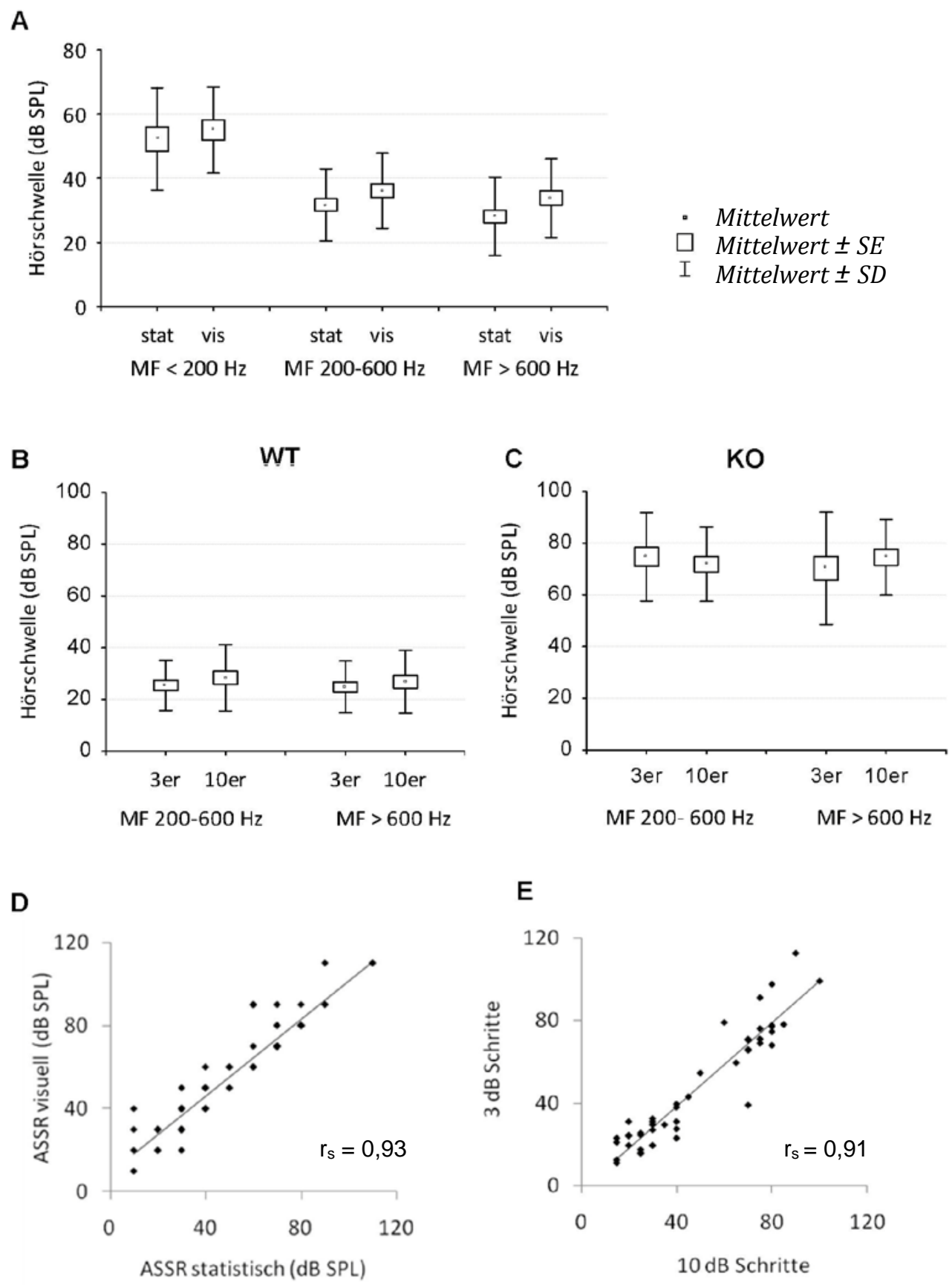

Abb. 14: Box-Plots und Korrelationsdiagramme der statistischen und visuellen ASSRHörschwellen

(A) visuell und statistisch $10 \mathrm{kHz}$ ASSR-Hörschwellen bei hörgesunden Tieren ( $n=18$ Tiere und 27 Ohren, davon 9 Tiere und 9 Ohren C57BL/6, 3 Tiere und 6 Ohren Bsn ${ }^{+/+}$und 6 Tiere und 12 Ohren $\mathrm{KCNQ}_{4}{ }^{+/+}$). (B) $10 \mathrm{kHz}$ ASSR-Hörschwellen der WT-Tiere. Bestimmung in $3 \mathrm{~dB}$ und $10 \mathrm{~dB}$ Schritten ( $\mathrm{n}=16$ Tiere und 25 Ohren, davon $5 \mathrm{KCNQ}_{4}{ }^{+/+}, 7 \mathrm{Bsn}{ }^{+/+}$Tiere und 4 C57/BL6 Tiere). (C) $10 \mathrm{kHz}$ Hörschwellen der KO Tiere ( $n=11$ Tiere und 22 Ohren, davon 6 Tiere Bsn \% und 5 Tiere KCNQ ${ }_{4}^{\%}$. (D) ( $n=49$ Ohren von 4 C57/BL6, 7 Bsn ${ }^{+/+}, 6$ Bsn $\%, 6 \mathrm{KCNQ}_{4}{ }^{+/}$und $6 \mathrm{KCNQ}_{4} \%$ Tieren). (E) Daten aus (B) und (C) 


\subsubsection{ASSR bei experimenteller Schallleitungsschwerhörigkeit}

ASSR-Hörschwellen wurden bei fünf C57BL/6 Tieren im Alter von acht Wochen für ausgewählte Trägerfrequenzen ( $4 \mathrm{kHz}, 8 \mathrm{kHz}, 10 \mathrm{kHz}, 12 \mathrm{kHz}$ und $16 \mathrm{kHz}$ ) bei einer zuvor optimal gewählten MF (200-600 Hz) bestimmt. Es wurden nur Modulationsfrequenzen über $200 \mathrm{~Hz}$ verwendet. Anschließend wurden diese mit ihren Tb-BERA-Hörschwellen verglichen. Nachfolgend wurde bei den gleichen Tieren im Anschluss eine experimentelle Schallleitungsschwerhörigkeit (SLS) durch beidseitiges Versiegeln des äußeren Hörkanals simuliert (Abb. 15).

Tb-BERA-Hörschwellen waren nach der experimentellen SLS bei Frequenzen von 816 kHz im Mittel um 37,5 dB SPL erhöht (8 kHz: + 29 dB SPL, $10 \mathrm{kHz}$ : 37 dB SPL, 12 kHz: + 46,5 dB SPL, 16 kHz: + 38,5 dB SPL). ASSR-Hörschwellen waren im Mittel um 35,6 dB SPL (8 kHz: + 27,5 dB SPL, 10 kHz: + 33 dB SPL, 12 kHz: + 33,5 dB SPL, 16 kHz: $+35,5 \mathrm{~dB}$ SPL) erhöht (Abb. 15A). Bei $4 \mathrm{kHz}$ waren die Hörschwellen nicht erhöht (ASSR: + 0,25 dB SPL, BERA: + $12 \mathrm{~dB}$ SPL nach experimenteller SLS). In der Regressionsanalyse errechnete sich ein Spearman's $r_{s}$ von 0,73.
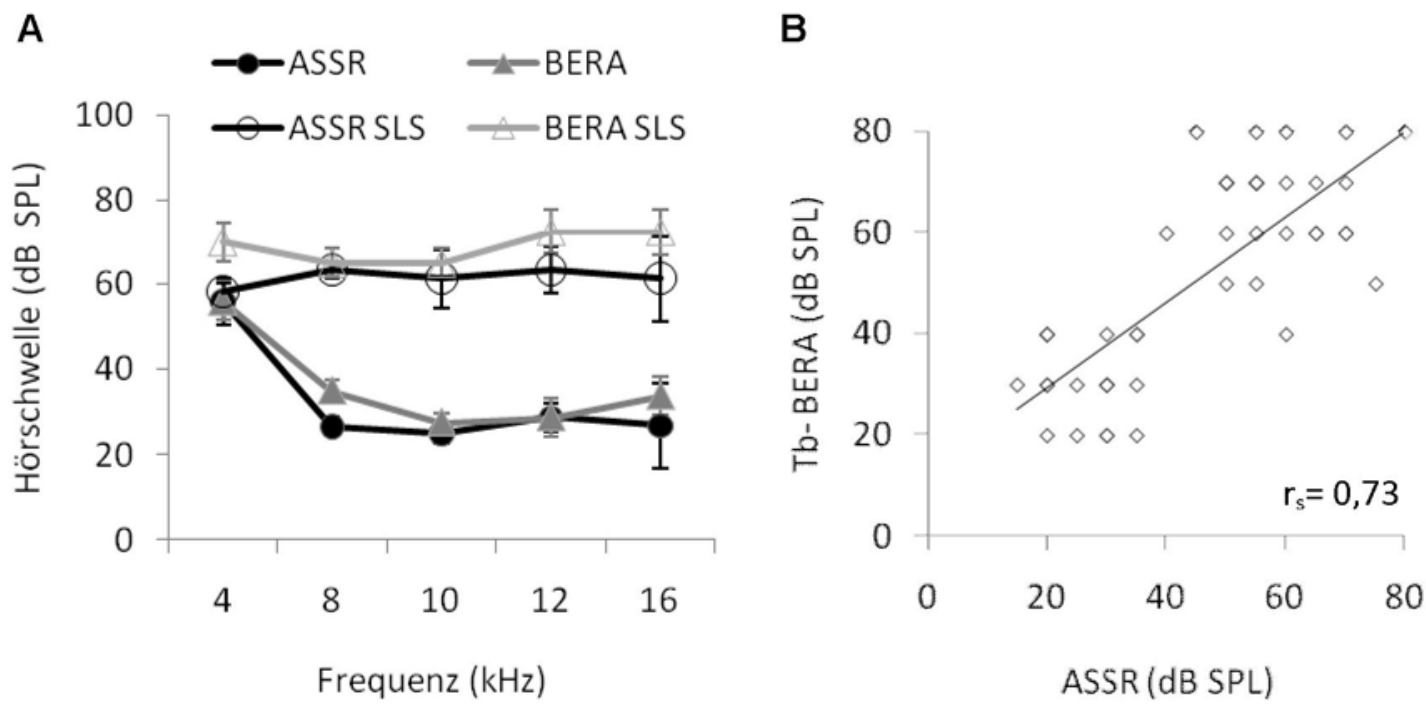

Abb. 15: Experimentelle Schallleitungsstörung (SLS)

(A) ASSR (MF 200-600Hz)- und Tb-BERA-Audiogramme von 5 C57BL/6 Tieren vor und nach experimenteller SLS. (B) Korrelationsdiagramm aller Messungen aus (A) $(n=90$ Einzelmessungen). 


\subsection{ASSR am Mausmodell der SNSH}

Nach den Untersuchungen an normalhörenden Tieren wurden ASSR an zwei Gruppen von Mausmutanten mit bekannter sensorineuraler Schwerhörigkeit (SNSH) gemessen. Analog zum ersten Teil erfolgte eine Gegenüberstellung $\mathrm{zu}$ den transienten Hirnstammpotenzialen sowie im Anschluss ein Vergleich $\mathrm{zu}$ den gewonnenen Erkenntnissen der normalhörenden Tiere.

$\mathrm{KCNQ}_{4} \mathrm{KO}$-Tiere leiden an einem Funktionsverlust der ÄHZ und stellen ein Modell einer SNSH mit einem Defekt des Verstärkersystems dar (Khartkovets et al. 2006). Bassoon Mutanten tragen einen Defekt an den IHZ und leiden an einer fehlerhaften Reizweiterleitung der afferenten Haarzellsynapsen („auditorische Synaptopathie“, Khimich et al. 2005).

\subsubsection{Modulation Transfer Function bei SNSH}

Die MTF der KCNQ 4 WT-Tiere (Abb. 16A: 90 dB SPL Stimulation bei KO-Tieren, $80 \mathrm{~dB}$ SPL Stimulation bei WT-Tieren) zeigte ebenfalls einen zweigipfligen Verlauf mit zwei bis drei Amplitudenmaxima. Nach sehr großen ASSR-Amplituden bei niedrigen Modulationsfrequenzen unter $200 \mathrm{~Hz}$ trat ein Amplitudenminimum bei $180 \mathrm{~Hz}$ auf, es folgte nach einem Minimum bei $430 \mathrm{~Hz}$ ein Anstieg auf ein erstes Maxima bei $605 \mathrm{~Hz}$, sowie ein Zweites bei 985 Hz. Der MTF Verlauf der KO-Tiere folgte dem der WT-Tiere, jedoch waren die Amplituden des ersten ASSR Maximums im Mittel zu 57,3 \% kleiner. Unter der verwendeten MF von $373 \mathrm{~Hz}$ waren die KO Amplitudengrößen signifikant. Bei sehr hohen Modulationsfrequenzen über $1000 \mathrm{~Hz}$ waren die Amplituden der WT- und KO-Tiere nicht voneinander zu unterscheiden.

Bei der Bassoon-Mutante konnten keine ausgeprägten ASSR-Amplituden erzeugt werden (Abb. 16B). Die ASSR trat nur minimal aus dem Hintergrund hervor. Die WTTiere zeigten ebenfalls ein deutliches Amplitudenminimum (518 Hz), aber kein zweites Maximum. 
A

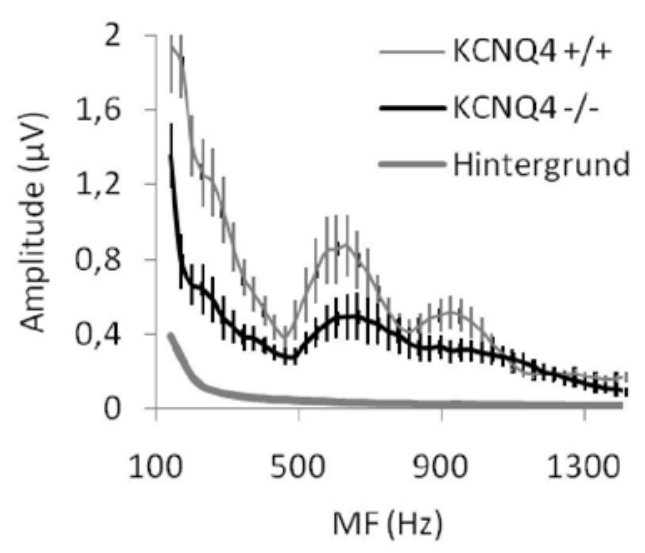

B

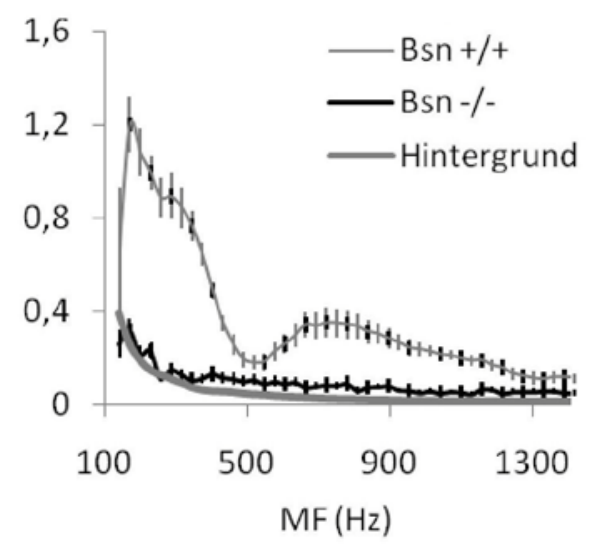

Abb. 16: Modulation Transfer Function (MTF) der KO-Tiere

(A) $M T F$ der $\mathrm{KCNQ}_{4}{ }^{+/+}$(grau, $n=6$ Tiere, 12 Ohren) und $\mathrm{KCNQ}_{4}{ }^{\%}$ Tiere (schwarz; $n=5$ Tiere, 10 Ohren). (B) MTF der Bsn ${ }^{+/+}$(grau, $n=7$ Tiere, 12 Ohren) und Bsn $\%$ Tiere (schwarz, $n=7$ Tiere, 10 Ohren).

\subsubsection{Amplitudenwachstum bei SNSH}

Die Bassoon-Mutanten zeigten ein sehr schwaches Amplitudenwachstum (Abb. 17A). Niedrige Modulationsfrequenzen unter $200 \mathrm{~Hz}$ erzeugten größere ASSR-Amplituden und stärkeres Amplitudenwachstum im überschwelligen Bereich als höhere MFGruppen. Modulationsfrequenzen der niedrigfrequenten MF-Gruppe bildeten im Mittel 31\% größere Amplituden als die Modulationsfrequenzen der mittelfrequenten MFGruppe (90 dB SPL Stimulation). Die ASSR-Amplituden der Bassoon-Mutanten waren das Zehnfache kleiner als die ASSR-Amplituden der gesunden Tiere (MF 200-600 Hz) (Abb. 17C). Zwischen der mittleren MF-Gruppe und der hohen MF-Gruppe bestand bei keiner Stimulationsintensität ein signifikanter Unterschied in der Amplitudengröße.

$\mathrm{KCNQ}_{4} \mathrm{KO}$-Tiere zeigten keinen Unterschied im Amplitudenwachstum zwischen den MFGruppen (Abb. 17B). Die Amplituden der mittelfrequenten MF-Gruppe waren im Vergleich zu den gesunden Tieren 58 \% kleiner (80 dB SPL Stimulation) (Abb. 17D). Im Vergleich zu den WT-Tieren trat bei den $\mathrm{KCNQ}_{4}$ KO-Tieren ab dem Hörschwellenbereich ( $70 \mathrm{~dB}$ SPL) eine Rechtsverschiebung der Kurve auf. Es zeigte sich ein starkes Amplitudenwachstum im Sinne eines audiologischen Recruitmentphänomens (Abb. 17D). 


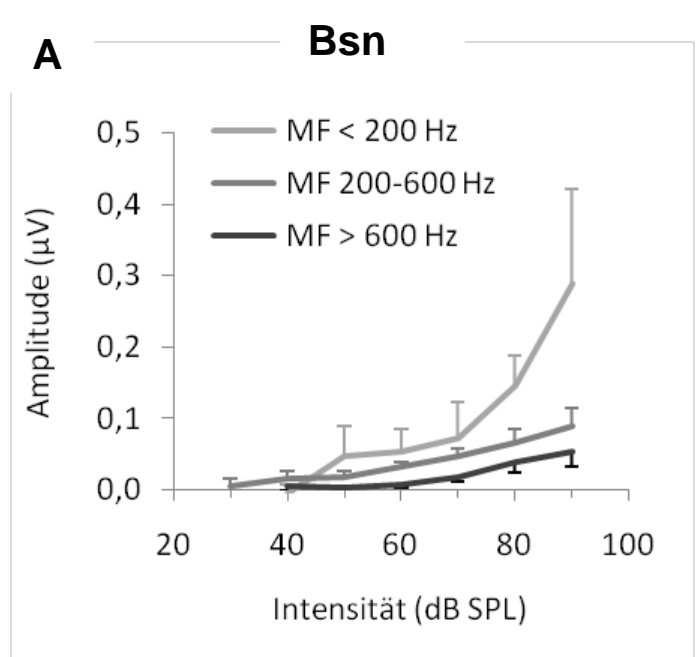

C

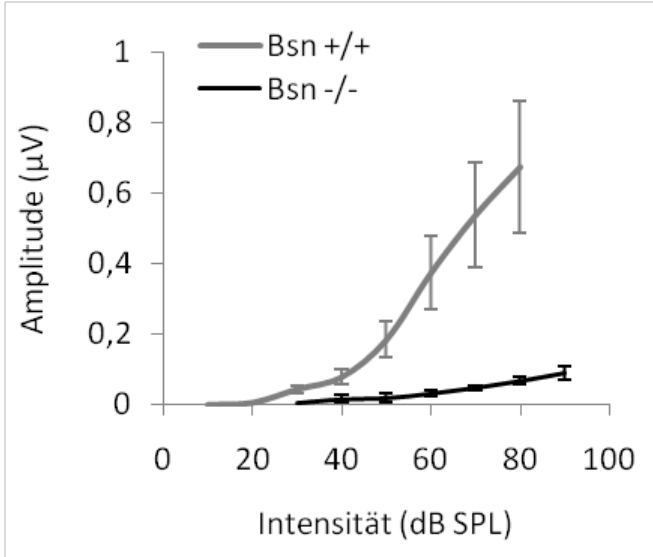

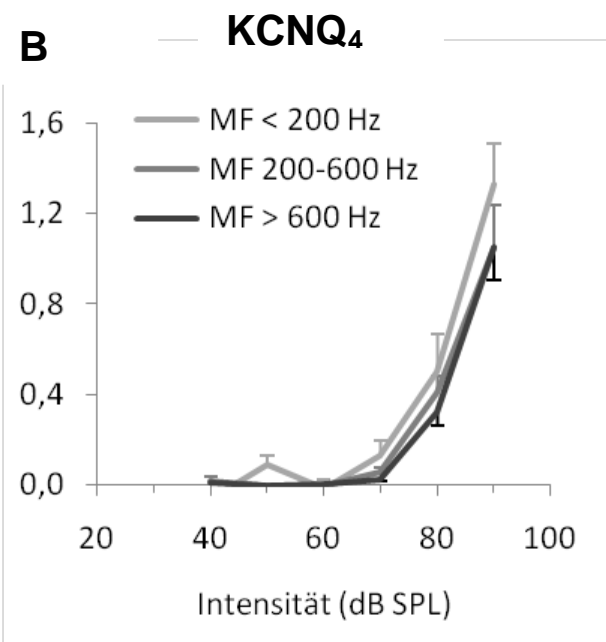

D

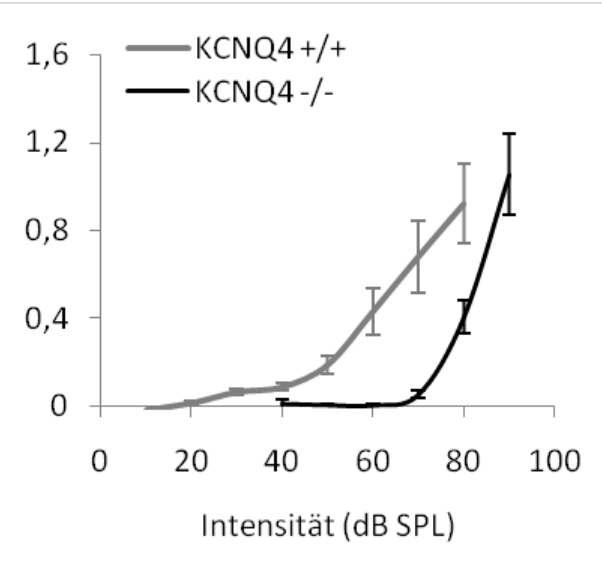

Abb. 17: ASSR-Amplituden-Wachstumsfunktion der SNSH-Tiere

$10 \mathrm{kHz}$ ASSR-Amplituden-Wachstumsfunktion (hintergrundkorrigiert) der (A) Bsn \% ( $n=7$ Tiere, 13 Ohren) und (B) KCNQ $4 \%$ Tiere ( $n=6$ Tiere, 11 Ohren). Für jedes Tier wurden ASSR-Hörschwellen in allen drei MF-Gruppen gemessen. (C) und (D): ASSR Amplitudenwachstum (MF 200-600 Hz) der WT- und KO-Tiere im Vergleich. (C) Bsn +/+ ( $n=7$ Tiere 14 Ohren), Bsn $\%$ (gleiche Daten wie aus 19A) (D) $\mathrm{KCNQ}_{4}{ }^{+/+}(n=6$ Tiere, 11 Ohren), $\mathrm{KCNQ}_{4} \%$ (gleiche Daten wie aus $18 B$ ).

\subsubsection{Hörschwellenvergleich mit ASSR und BERA bei SNSH}

Die gesunden WT-Tiere zeigten keinen statistischen Unterschied zwischen den Hörschwellen der mittel- und hochfrequenten MF-Gruppen (Bsn ${ }^{+/+}: \mathrm{p}=0,26 ; \mathrm{KCNQ}_{4}^{+/+}$: $\mathrm{p}=0,69$ ). Bei den schwerhörigen SNSH-Tieren bestand ebenfalls kein Unterschied zwischen diesen MF-Gruppen (Bsn $\%: p=0,15 ; \mathrm{KCNQ}_{4} \%: \mathrm{p}=0,48$ ). Sowohl die niedrigfrequenten $\quad\left(\mathrm{r}_{\mathrm{s}}=0,85\right) \quad$ (Abb. 18C), als auch die hochfrequenten 
Modulationsfrequenzen $\left(\mathrm{r}_{\mathrm{s}}=0,82\right)$ (Abb. 18D) zeigten gute Korrelationen der ASSR- und Tb- BERA-Hörschwelle.

Die ASSR-Hörschwellen der SNSH-Tiere der niedrigfrequenten MF-Gruppe waren im Vergleich zu der mittelfrequenten MF-Gruppe signifikant höher (Bsn $\%$ : p = 0,04, $\left.\mathrm{KCNQ}_{4} \%: \mathrm{p}=0,04\right)$. Dieser Unterschied bestand nicht im Vergleich $\mathrm{zu}$ den hochfrequenten ASSR-Hörschwellen (Bsn $\%: p=0,07, \mathrm{KCNQ}_{4} \% \mathrm{p}=0,06$ ). Bsn-KO Hörschwellen der niedrigfrequenten MF-Gruppe waren weiterhin signifikant größer als die Tb-BERA- $(p=0,04)$ und Klick-BERA- $(p=0,04)$ Hörschwellen. Die niedrigsten BsnHörschwellen wurden mit der Klick-BERA ermittelt (57,5 dB SPL), welche signifikant niedriger war als alle anderen Messreihen.

$\mathrm{KCNQ}_{4} \mathrm{KO}$-Tiere zeigten keinen signifikanten Unterschied zwischen niedrigfrequenten ASSR-, Tb-BERA- ( $p=0,14$ ) und Klick-BERA-Hörschwellen ( $p=0,36)$ (Abb. 18B). SNSHTiere zeigten geringere Hörschwellenunterschiede, gemessen mit Modulationsfrequenzen unter und über $200 \mathrm{~Hz}$, als die gesunden Vergleichstiere.

Für weitere Vergleiche wurden die ASSR-Hörschwellen der mittel- und hochfrequenten MF-Gruppen gemittelt und als MF-Gruppe über $200 \mathrm{~Hz}$ dargestellt.

Der Hörverlust der schwerhörigen Tiere, gemessenen mit ASSR und Tb-BERA, war vergleichbar (im Mittel über alle Methoden 41,4 dB SPL). Die ASSR-Hörschwelle der gemittelten MF-Gruppe (MF > $200 \mathrm{~Hz}$ ) der Bsn KO-Tiere (74,3 dB SPL) lag 5,5 dB SPL über der mittleren Tb-BERA (65,8 dB SPL) Hörschwelle. Im Vergleich zu den Bsn WTTieren lag in der Bsn KO-Gruppe die ASSR-Hörschwelle um 40,9 dB SPL erhöht und die BERA-Hörschwelle um 31,6 dB SPL erhöht.

Bei den $\mathrm{KCNQ}_{4}$ KO-Tieren lag die ASSR-Hörschwelle der gemittelten MF-Gruppe (74,5 dB SPL) 3,0 dB SPL unter der mittleren Tb-BERA Hörschwelle (77,5 dB SPL). Die ASSR-Hörschwellen lagen im Vergleich zu den $\mathrm{KCNQ}_{4}$ WT-Tieren um 44 dB SPL erhöht. Die Tonburst- BERA-Hörschwelle war um 49,2 dB SPL erhöht. 
A

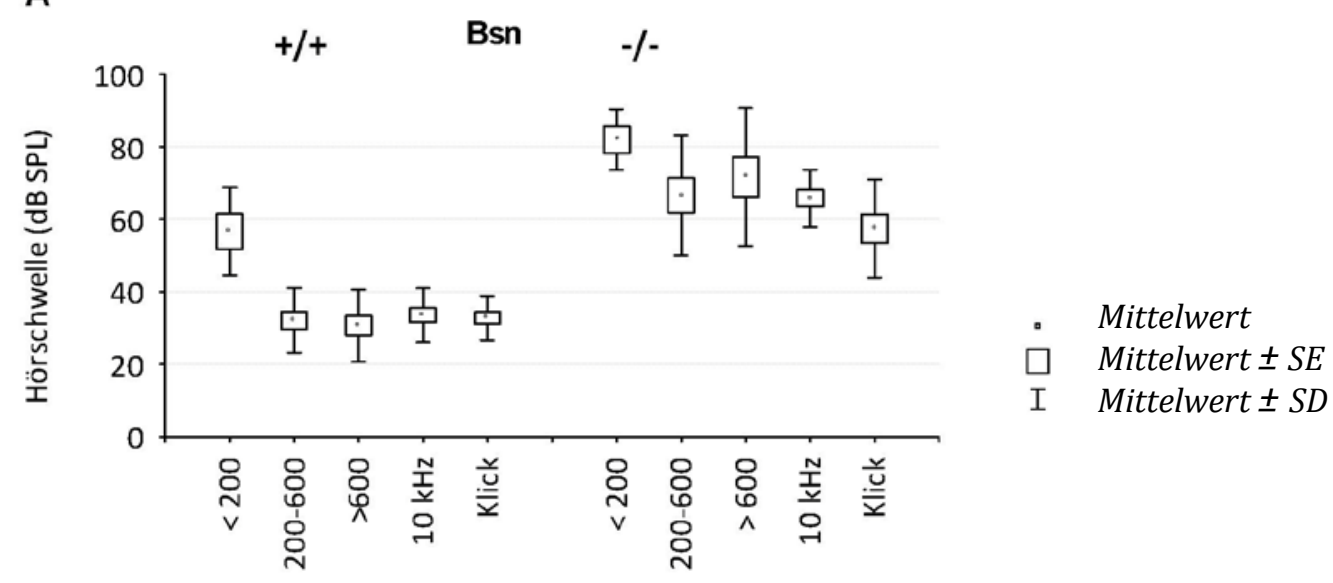

B

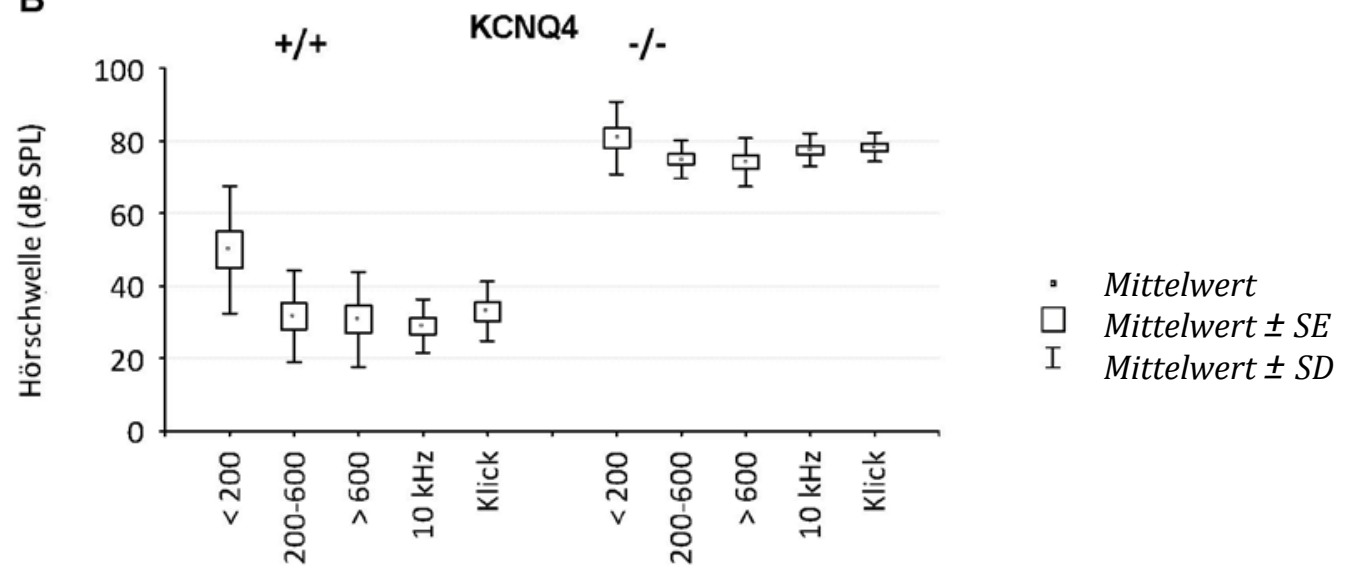

C

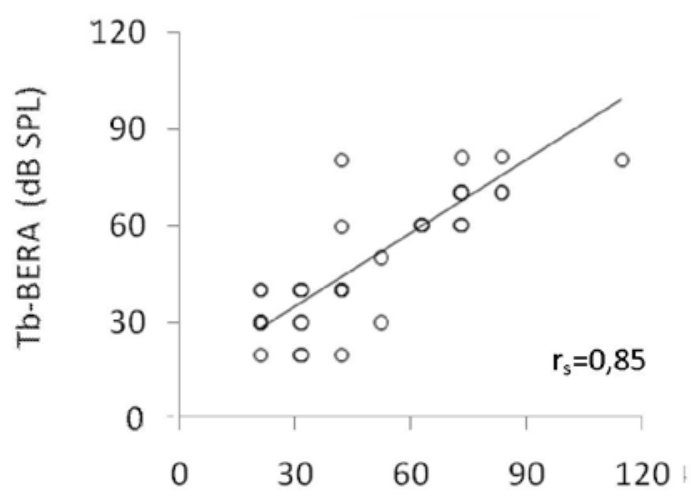

D

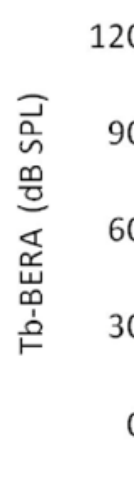

MF $>600 \mathrm{~Hz}$

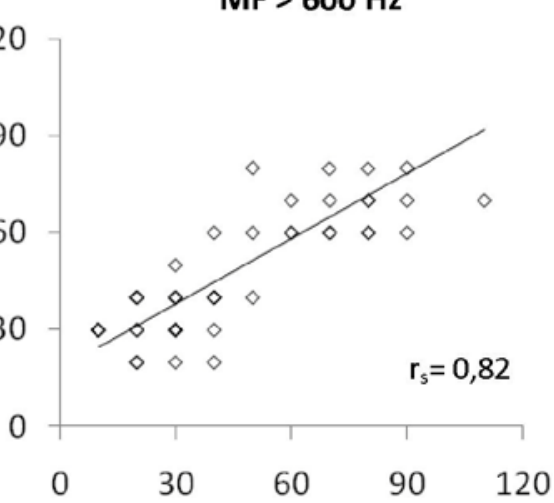

Abb. 18: Box-Plots und Korrelationsdiagramme der ASSR- und BERA-Hörschwellen der SNSH-Tiere

(A) Box-Plots der Bsn ${ }^{++}(n=7$ Tiere, 12 Ohren) und Bsn $\%$ Tiere ( $n=7$ Tiere, 10 Ohren).

(B) Box-Plots der $\mathrm{KCNQ}_{4}{ }^{+/+}\left(n=6\right.$ Tiere, 12 Ohren) und $\mathrm{KCNQ}_{4} \%$-Tiere $(n=5$ Tiere, 10 Ohren). (C) und (D): Korrelationsdiagramme der ASSR- und Tb-BERA-Hörschwellen der Messungen aus (A) und (B). (C) MF von 200- $600 \mathrm{~Hz}$ und (D) MF über $600 \mathrm{~Hz}$. 


\subsection{ASSR, Tb-BERA und DPOAEs zur Differentialdiagnose der SNSH}

Abbildung 19 stellt anhand von ASSR-, Tb-BERA- und DPOAE-Messungen der zwei Mausmodelle ein audiologisches Profil einer SNSH dar. Bei KCNQ 4 KO-Tieren waren DPOAEs trotz hoher Stimulationsintensität nicht nachweisbar. Bei Bassoon Mutanten waren die DPOAEs weiterhin regelrecht nachweisbar.

Die überschwelligen Tb-BERA- und ASSR-Messungen unterschieden sich trotz ähnlicher Hörschwellen grundlegend voneinander. In der Amplituden-Wachstumsfunktion der $\mathrm{KCNQ}_{4}$ KO-Tiere der ASSR und der Tb-BERA war ein steiler Anstieg der Amplitude zwischen 70 dB SPL und 90 dB SPL zu sehen. Teils näherten sich ASSR- und Tb-BERAAmplituden der KCNQ 4 KO-Tiere sogar den Amplitudengrößen der C57BL/6 Tiere an.

Die ASSR-Amplituden der C57/BL6 Tiere waren ein Vielfaches kleiner als die Tb-BERAAmplituden. Selbst im Hörschwellenbereich (20-40 dB SPL) waren die Tb-BERAAmplituden noch im Mittel um das 3,5fache größer. Die KO-Tiere zeigten weniger ausgeprägte Unterschiede. Im Gegensatz zum Amplitudenwachstum der ASSR war ein schwaches Tb-BERA-Amplitudenwachstum der Bsn KO-Tiere vorhanden. Die ASSRAmplituden der Bassoon-Mutanten waren bei allen Intensitäten sehr klein und zeigten kein Wachstum. Im Gegensatz konnte bei den $\mathrm{KCNQ}_{4}$ KO-Tieren kein Unterschied zwischen den ASSR- und Tb-BERA-Amplitudengrößen gezeigt werden. Die Reizantworten der Tb-BERA zeigten keine klaren Jewett-Potenziale, vielmehr fanden sich hier verzögerte und verbreiterte und Potenzialgipfel. Eine Welle I fehlte. 
A

C57BL/6

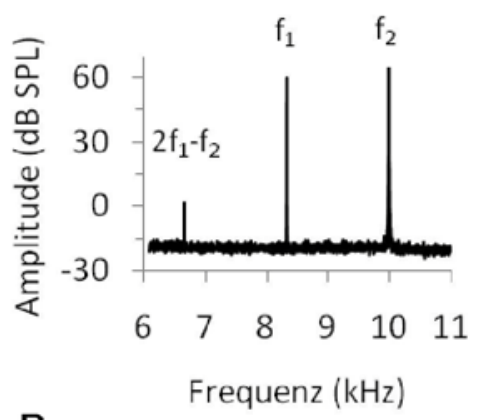

B

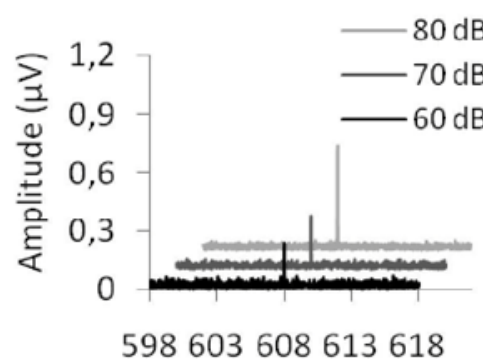

C

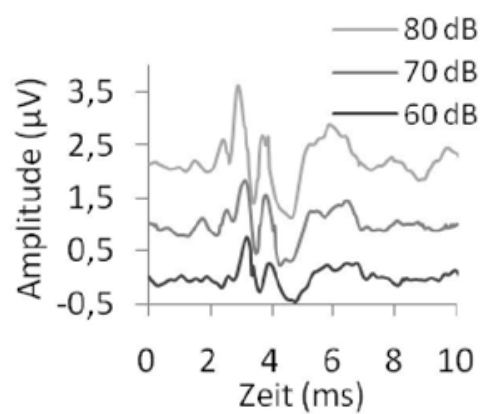

D

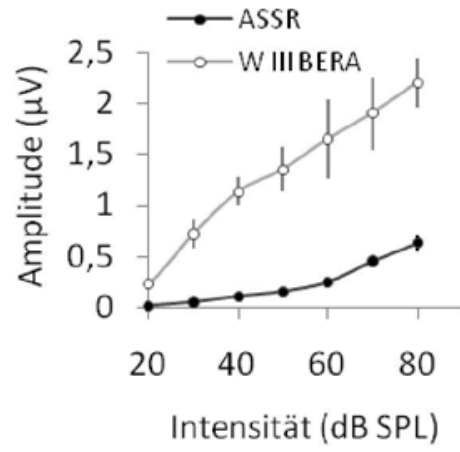

Bsn $^{-1-}$
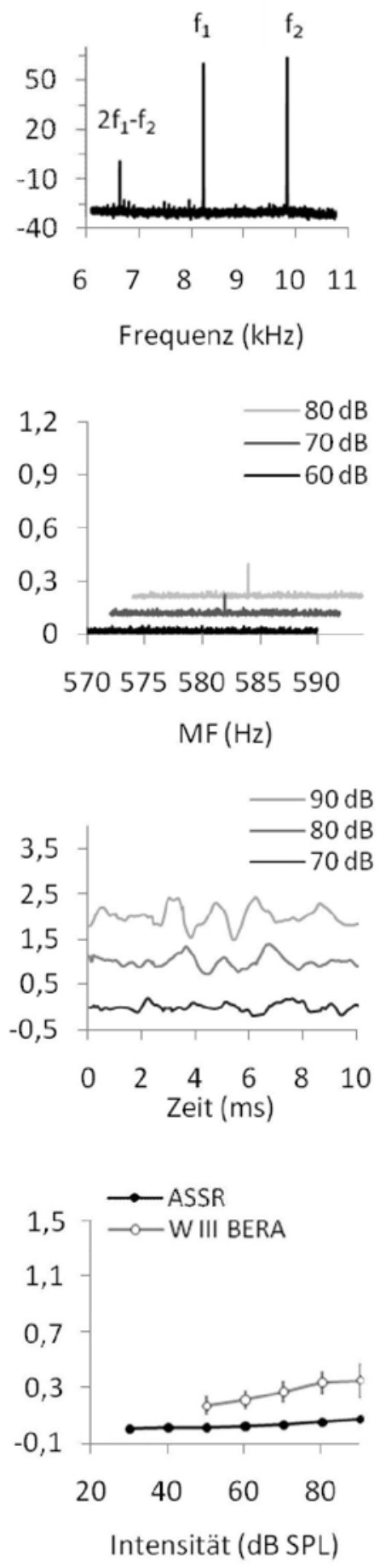

$\mathrm{KCNQ}_{4}{ }^{-1-}$
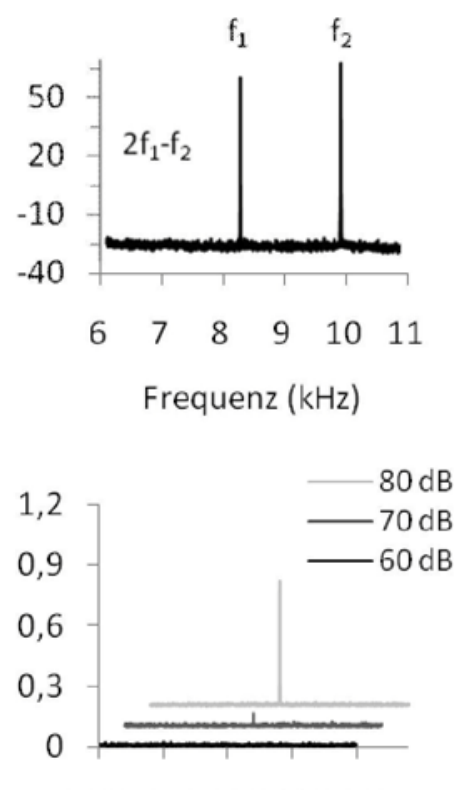

740745750755760

$\mathrm{MF}(\mathrm{Hz})$
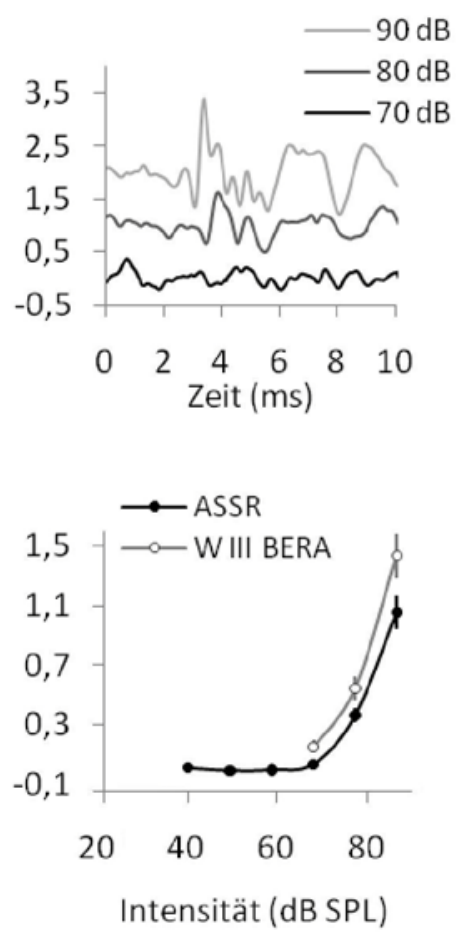

Abb. 19: Profil der sensorineuralen Schwerhörigkeit (SNSH)

(A) DPOAEs als Antwort auf simultane überschwellige Stimulation mit 2 Sinustönen (f1 und f2, $60 \mathrm{~dB} S P L)$ bei repräsentativen Tieren. Man beachte die fehlenden DPOAEs beim $K_{C N Q} \%$ Tier. (B) Repräsentative $10 \mathrm{kHz}$ ASSR bei überschwelliger Stimulation: C57/BL6 (MF $608 \mathrm{~Hz}$ ), Bsn \% (MF $580 \mathrm{~Hz})$ und $\mathrm{KCNQ}_{4} \%$ (MF $752 \mathrm{~Hz}$ ). (C) Tb-BERA-Messungen (10 kHz, Mittelungen von je 1000 Zeitabschnitten) der gleichen Tiere wie in (B). (D) ASSR (gemittelte Amplituden der MF 200-600 Hz und MF > 600Hz) und Tb-BERA (Amplituden der Welle III) Wachstumsfunktionen (C57BL/6 $n=3$ Tiere, 3 Ohren; Bsn $-/-n=7$ Tiere, 13 Ohren; $K_{C N Q} \% n=6$ Tiere, 11 Ohren). 


\subsection{Multifrequente ASSR}

Bisher wurden ASSR als Antwort auf individuelle SAM-Töne mit je einer zugeordneten Modulationsfrequenz beschrieben. Im nachfolgenden Schritt wurden ASSR mit einer multifrequenten Stimulation zur schnelleren frequenzspezifischen Hörschwellenbestimmung erzeugt (John et al. 1998). Zunächst wurden MTFs mit Trägerfrequenzen von $4 \mathrm{kHz}, 7 \mathrm{kHz}, 10 \mathrm{kHz}$ und $15 \mathrm{kHz}$ dargestellt und es wurde nach geeigneten Modulationsfrequenzen in Frequenzbereichen zwischen 200- $400 \mathrm{~Hz}$ und 400- $800 \mathrm{~Hz}$ gesucht. Es wurde ein Stimulus generiert, der vier Trägerfrequenzen der gleichen Intensität enthielt, aber mit je vier unterschiedlichen Frequenzen moduliert wurde. Die gewählten Modulationsfrequenzen stammten aus dem gleichen Maximum einer MTF und lagen mindestens $30 \mathrm{~Hz}$ auseinander (Abb. 20A und B).

Im Hörschwellenvergleich stimmten die multifrequent erzeugten Hörschwellen gut mit ihren zugehörigen monofrequent erzeugten Hörschwellen überein (Abb. 20C multifrequent: 4 kHz: $50 \pm 11$ dB SPL; 7 kHz: $35 \pm 4$ dB SPL; $10 \mathrm{kHz}: 38 \pm 7$ dB SPL; $15 \mathrm{kHz}: 50 \pm 8 \mathrm{~dB}$ SPL). Im Mittel lagen die multifrequenten Hörschwellen 3,25 dB SPL über den monofrequenten Hörschwellen. Im Bereich der höheren Modulationsfrequenzen über $400 \mathrm{~Hz}$ lagen die multifrequenten Hörschwelle im Mittel 1,5 dB unter den monofrequenten Hörschwellen (Abb. 21D multifrequent: $4 \mathrm{kHz}: 38 \pm 4$ dB SPL; $7 \mathrm{kHz:} 20 \pm 0$ dB SPL; $10 \mathrm{kHz}: 18 \pm$ 5,4 dB SPL; $15 \mathrm{kHz}: 25 \pm$ 4,1 dB SPL). Die höhere MF-Gruppe zeigte im Mittel $18 \pm$ 3,3 dB SPL niedrigere Hörschwellen.

Auch bei multifrequenter Stimulation war die Amplitudengröße abhängig von der Trägerfrequenz (Abb. 21). Die kleinsten Amplituden wurden bei $4 \mathrm{kHz}$ erzeugt, mit zunehmender Frequenz nahm die Amplitude zu (vgl. Abb. 12C).

Eine überschwellige multifrequente Stimulation (80 dB SPL) erzeugte kleinere ASSRAmplituden als eine monofrequente Stimulation (Abb.21). Im Hörschwellenbereich war kein Unterschied festzustellen. Bei keiner Frequenz war bei überschwelliger (80 dB SPL), multifrequenter Stimulation ein signifikanter Unterschied zwischen ASSRAmplituden, gemessen mit Modulationsfrequenzen unter $400 \mathrm{~Hz}$ und über $400 \mathrm{~Hz}$ vorhanden. 
A

MF $200-400 \mathrm{~Hz}$

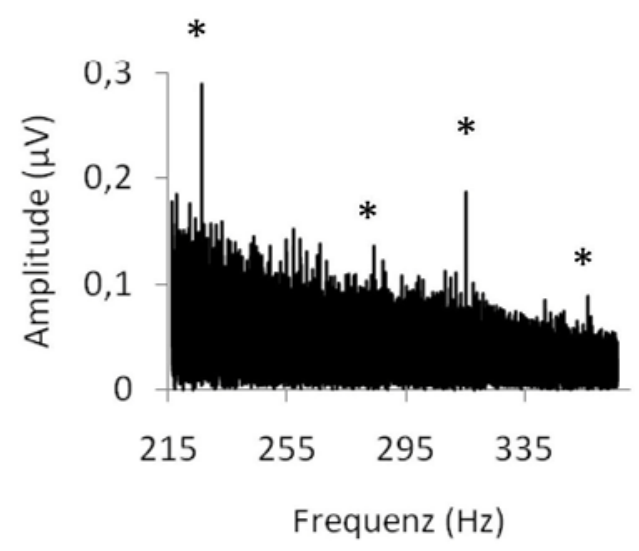

C

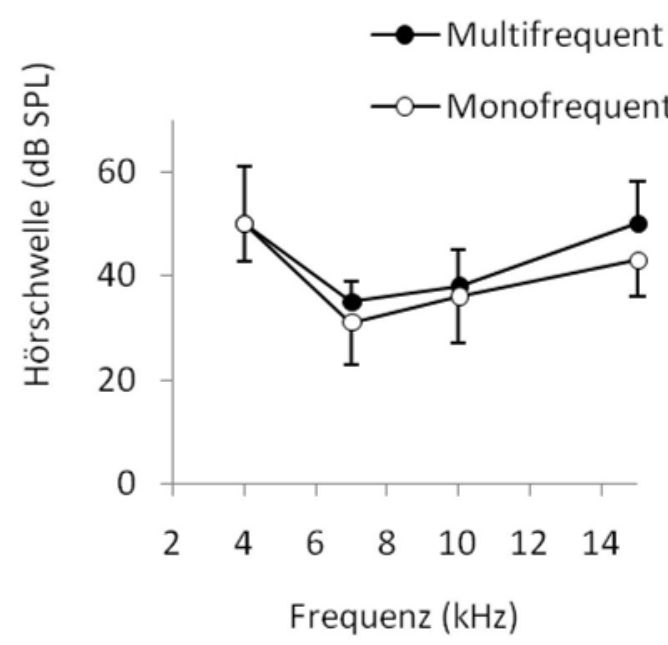

B $\quad$ MF $400-800 \mathrm{~Hz}$

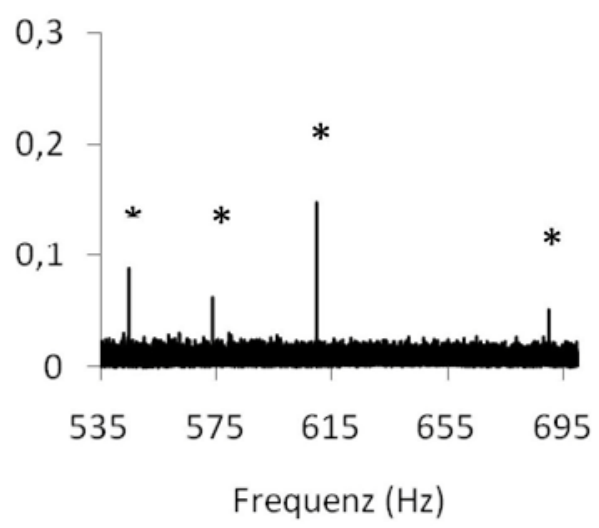

D

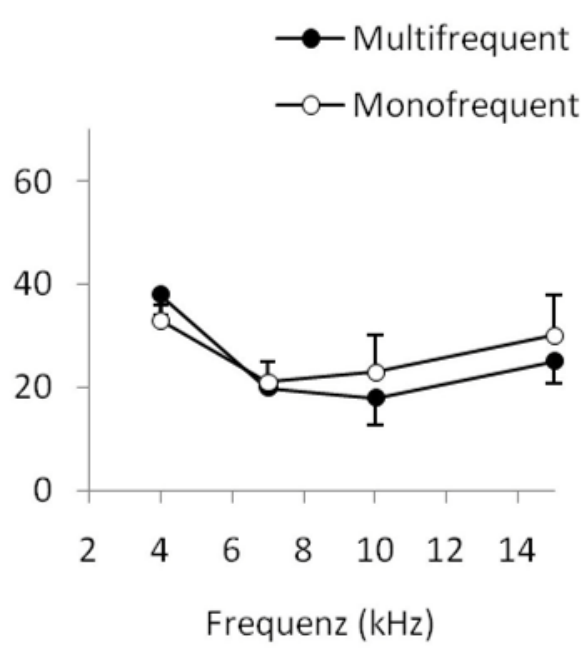

Abb. 20: Multifrequente ASSR

(A) und (B): repräsentatives EEG Spektrum (nach 60 Sekunden Messdauer) einer C57/BL6 Maus bei multifrequenter 60 dB SPL Stimulation (A: MF 200-400 Hz; B: MF 400-800 Hz). Markiert sind die jeweils vier simultanen ASSR. (C) und (D) zeigen die Audiogramme von 4 C57/BL6 Tieren bei mono- und multifrequenter Stimulation. (C: MF 200-400 Hz; B: MF 400-800 Hz). 


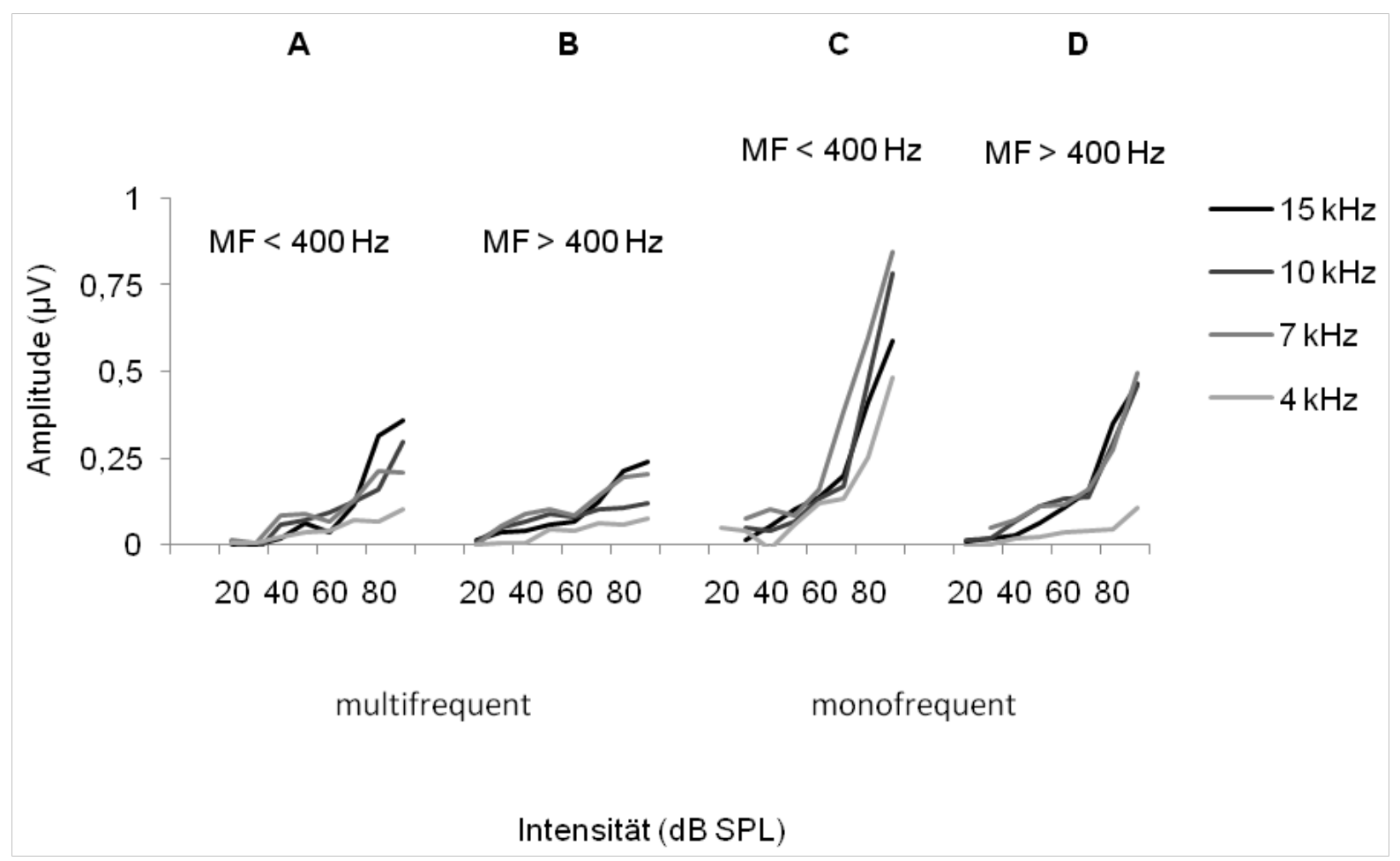

Abb. 21: Amplitudenwachstum bei multifrequenter ASSR

(A) multifrequent, $M F<400 \mathrm{~Hz}$ (B) multifrequent, $M F>400 \mathrm{~Hz}$ (C) monofrequent, $M F<400 \mathrm{~Hz}$ (D) monofrequent, $M F>400 \mathrm{~Hz}(\mathrm{n}=5$ C56/BL6 Tiere). 


\section{Diskussion}

\subsection{Nutzen der ASSR zur audiologischen Untersuchung der Maus}

In dieser Arbeit wurden die frequenzspezifischen ASSR bei der Maus erstmalig charakterisiert und mit der BERA vergleichen. Die Maus spielt eine zentrale Rolle in der Grundlagenforschung der Säugetiere. Bedingt durch eine rasant fortschreitende Erforschung der Genetik der Maus, einer genetischen Standardisierung, günstigen Lebenshaltungskosten und einer kurzen Lebenszeitspanne ist die Maus nicht nur in der Hörforschung, eines der am weitesten verbreiteten Tiermodelle geworden (Steel und Kros 2001, Gao et al. 2004, Ohlemiller 2006). Laufend werden neue Mausmodelle der menschlichen Schwerhörigkeit mit spezifischen Gendefekten zum Verständnis ihrer komplexen Pathologie generiert. Aktuell existieren allein 38 Mausmodelle einer nonsyndromalen Schwerhörigkeit (http://hearingimpairment.jax.org/models.html). Von zunehmendem Interesse ist daher eine Plattform für eine standardisierte auditorische Phänotypisierung von Mäusen, um schrittweise bei gezielten Mutanten die auditorische Funktion zu untersuchen und zu klassifizieren (Brown et al. 2006, Vrijens et al. 2008). Für die Untersuchung der Mauslinien wird daher eine rasche, systematische und objektive Untersuchung der Hörfunktion benötigt. Erste audiologische Typisierungen einer großen Anzahl von Mäusen anhand von BERA (Zheng et al. 1999) und DPOAEs (Martin et al. 2007) zeigen den Bedarf zum effektiven Screenen von Mäusen.

Insbesondere von Nutzen ist die simultane Registrierung mehrerer Frequenzen für ein schnelles Screenen (Herdman et al. 2002). Im Gegensatz zur BERA besteht ein weiterer deutlicher Zeitvorteil durch die automatische statistische Auswertung der ASSR. Zusätzlich kann die weitere Gesamtuntersuchungsdauer mehrerer Tiere durch ein zeitgleiches Handling und Vorbereiten von Tieren, z.B. während der Narkosevorbereitung, reduziert werden. Eine naheliegende Weiterentwicklung der MATLAB Routine wären vollautomatisierte Messreihen, welche z.B. optimale Modulationsfrequenzen aus der MTF auswählen und anwenden. 


\subsection{Etablierung der ASSR-Messungen mit dem TDT-III-System}

Die Erzeugung von mono- und multifrequenten ASSR Stimuli zur Untersuchung der Maus konnte mit dem Tucker-Davis Technologies-System-III gut realisiert werden. Als Grundlage zur effizienten ASSR-Messung wurde zunächst eine MTF zur Ermittlung von geeigneten Modulationsfrequenzen dargestellt. Die MTF zeigte bei normal- und schwerhörigen Tieren MF-Bereiche, welche bei überschwelliger Stimulation signifikant größere Amplituden erzeugten. Ab einer MF von $800 \mathrm{~Hz}$ fiel die Amplitudengröße kontinuierlich ab, blieb jedoch auch bei sehr hohen Modulationsfrequenzen $(1400 \mathrm{~Hz})$ nachweisbar. Eine MTF konnte auch in Studien an anderen Tieren gezeigt werden (Kaninchen: Kuwada et al. 2002, Katze: Synder und Schreiner 1987). Eine Studie am Delfin beschrieb ebenfalls einen zweigipfligen Verlauf der MTF (Finneran et al. 2007) bei hohen Modulationsfrequenzen (100-2000 Hz) und den Nutzen der MTF zur Wahl der Modulationsfrequenz vor Hörschwellenbestimmung. Dobie et al. (1998) zeigten beim Menschen eine MTF mit einem ähnlichen zweigipfligen Verlauf der Amplitude bei sich stetig erhöhender Modulationsfrequenz. Ebenso stellte Picton (2003) in einer retrospektiven Arbeit basierend auf Publikationen von 1984-2003 einen zweigipfligen Verlauf der MTF mit Maxima bei Modulationsfrequenzen um $40 \mathrm{~Hz}$ und 80-90 Hz dar. Ein allgemeiner Erklärungsansatz hierfür wäre, dass höhere Modulationsfrequenzen kleinere Amplituden verursachen, weil diese durch anatomisch tieferliegende Quellen generiert werden (Mauer und Döring 1999, Herdman et al. 2002). Die Entstehung der Minima in der MTF könnte durch ein vermindertes oder verändertes Ansprechen der ASSR Generatoren auf verschiedene Modulationsfrequenzen erklärt werden. Vor allem Interferenzen können zur Potenzialabschwächung führen, wenn Potenziale überlappend von verschiedenden Generatoren entstehen.

Bei Hunden wurden optimale Modulationsfrequenzen von $101 \mathrm{~Hz}$ und $151 \mathrm{~Hz}$ beschrieben (Markessis et al. 2006). Dabei wurden in der Studie nur festgelegte Modulationsfrequenzen von 20-200 Hz mit einem kommerziellen Gerät getestet. Bei Affen wurden optimale Modulationsfrequenzen zwischen 165 und $230 \mathrm{~Hz}$ empfohlen (Burton et al. 1992), jedoch wurden in dieser Arbeit keine Frequenzen über $250 \mathrm{~Hz}$ untersucht. Herdman et al. (2002) beschrieben bis zu fünffach größere Amplituden bei einer Modulationsfrequenz von $39 \mathrm{~Hz}$ als bei $88 \mathrm{~Hz}$. Picton (2003) zeigte, dass Modulationsfrequenzen um $40 \mathrm{~Hz}$ doppelt so große Amplituden hervorrufen als Modulationsfrequenzen um $80 \mathrm{~Hz}$. Einen ähnlich großen Unterschied konnten wir für 
niedrige Modulationsfrequenzen unter $200 \mathrm{~Hz}$ in der mittel- bis hochfrequenten MFGruppe zeigen. In der für die Hörschwellenbestimmmung geeigneten MF-Gruppen waren die Amplitudengrößen sehr ähnlich.

Wiederholte MTF-Messungen am gleichen Tier konnten $\mathrm{zu}$ späteren Untersuchungszeitpunkten Verschiebungen der ASSR-Maxima in niedrigfrequente Bereiche belegen. Eine Veränderung der Narkosetiefe, im Sinne einer flachen Narkose, könnte die Verschiebungen der Minima und Maxima erklären. Beim Mensch ist bekannt, dass die ASSR-Amplitude während tiefer Narkose und im Schlaf (Cohen et al. 1991) abnimmt sowie in Aufwachphasen zunimmt. Veränderungen der Vitalparameter der Maus (Herzfrequenz, Körpertemperatur) wurden nicht beobachtet, jedoch wurde dieses Phänomen nicht systematisch erfasst. Dies wäre Gegenstand für weitere Studien.

Modulationsfrequenzen unter $100 \mathrm{~Hz}$ konnten zwar ASSR erzeugen, jedoch überlagerten niedrigfrequente Frequenzkomponenten des Spontan-Rauschens die ASSR und führten so zu ungünstigen Signal-Rausch Verhältnissen. Vermutlich stellen diese Frequenzanteile Muskelpotenziale, wie z.B. Herzaktionen und physiologische EEGAnteile, dar. Beim Mensch liegt der Hauptfrequenzgehalt des EEGs bei $10 \mathrm{~Hz}$. Picton (2003) ordnet diesen Peak den $\alpha$ - Wellen $(8-13 \mathrm{~Hz})$ des EEGs zu. Da die Hörschwellen der niedrigfrequenten MF-Gruppe unter $200 \mathrm{~Hz}$ signifikant höhere Hörschwellen erzeugten, erachten wir die üblicherweise beim Menschen verwendeten Modulationsfrequenzen von $40 \mathrm{~Hz}$ und $80 \mathrm{~Hz}$ (Galambos et al. 1981, Stapells et al. 1987, Ayoagi 1994) als ungeeignet bei der Maus. Auch beim Menschen ist bekannt, dass niedrige Modulationsfrequenzen größere Amplituden erzeugen (Rickards und Clark 1984, Herdman et al. 2002, Picton et al. 2003). Für sehr niedrige Modulationsfrequenzen ist kein Effekt auf die Hörschwellen beschrieben.

Die statistische Auswertung korrelierte zu der visuellen Auswertung sehr gut, was die Nutzbarkeit der statistischen Auswertung der ASSR bestätigt. Neben der verwendeten Methode existieren weitere Verfahren der statistischen Analyse. Hauptsächlich werden Phasenanalysen und vergleichende Verfahren von ASSR und Hintergrund verwendet (Picton et al. 2001). Ein Goldstandard ist jedoch nicht vorhanden, jede Arbeitsgruppe verfügt über individuelle Kriterien. Für die BERA sind ebenfalls automatisierte Auswertungen der Jewett-Wellen beschrieben. Meist werden vergleichende Verfahren der Antworten, z.B. auch durch MATLAB (Bradley et al. 2005), angewendet. In erster Linie dienen sie als Unterstützung für den Kliniker, ersetzen aber nicht eine zusätzliche 
Auswertung, daher hat sich keine der Methoden durchgesetzt. Eine subjektive Bestimmung der Hörschwelle der Maus ist über konditionierende, verhaltenspsychologische Testverfahren möglich, jedoch sehr aufwendig. Aus diesem Grund blieb ein Vergleich mit einer Reaktionsaudiometrie aus.

Die Hörschwellenbestimmung der ASSR in $3 \mathrm{~dB}$ Schritten zeigte keinen signifikanten Unterschied zu der Detektion in $10 \mathrm{~dB}$ Schritten, benötigte aber zusätzliche Zeit für diese Messungen. Jedoch konnte eine gute Wiederholbarkeit der zuvor bestimmten Hörschwellen in $10 \mathrm{~dB}$ Schritten gezeigt werden. Auch andere Autoren erachten $10 \mathrm{~dB}$ Schritte als ausreichend (Luts et al. 2004).

In dieser Arbeit wurde die Messdauer von 60 Sekunden für jede untersuchte ASSRIntensität eingesetzt. Eine längere Messdauer reduziert die Hintergrundamplituden des EEGs auf Kosten der klinischen Praktikabilität. Für die Untersuchung des Menschen erachten andere Autoren erst eine Messdauer von über 90 Sekunden als ausreichend (Picton et al. 2005, Luts et al. 2004). Ein Konsensus besteht auch hier nicht. Jedoch scheint ein festes Messprotokoll eine entscheidende Rolle zur Vermeidung von signifikanten Fehlerraten zu spielen (Luts et al. 2008).

\subsection{Vergleich der Hörschwellenmessungen der Maus mit dem TDT-III-System}

Die Mausmodelle Bassoon und $\mathrm{KCNQ}_{4}$ ermöglichen einen selektiven Blick auf die funktionellen Schritte kochleärer Funktionen. ASSR-Hörschwellen waren nicht von ihren Tb-BERA Hörschwellen zu unterscheiden, vorausgesetzt, adäquate Modulationsfrequenzen wurden verwendet. Dies betraf hörgesunde Tiere und SNSHTiere, wenn ASSR mit Modulationsfrequenzen über $200 \mathrm{~Hz}$ gemessen wurden. Die Anwendung der ASSR zur Hörschwellenbestimmung mit monofrequenter Stimulation ist sowohl beim Mensch (Aoyagi et al. 1999) als auch bei anderen Spezies (Markessis et al. 2006) beschrieben. Bei den SNSH-Tieren war die Differenz der ASSRHörschwellen zwischen den verschiedenen MF-Gruppen geringer als bei den normalhörenden Tieren. Signifikant niedrigere Klick-Hörschwellen der Bassoon Mutanten können durch die breitbandige Eigenschaft des Stimulus erklärt werden. Audiologisch zeigten sich um $40 \mathrm{~dB}$ erhöhte Hörschwellen in der Tb-BERA, sowie vorhandene OAEs, was DPOAEs, was auch Khimich et al. (2005) zeigen konnten. 
Mono- und multifrequent bestimmte ASSR-Hörschwellen waren nicht voneinander zu unterscheiden. Modulationsfrequenzen unter $400 \mathrm{~Hz}$ zeigten jedoch höhere Hörschwellen als Modulationsfrequenzen über $400 \mathrm{~Hz}$. John et al (1998) fanden heraus, dass niedrige Modulationsfrequenzen beim Mensch ineffizienter zur multifrequenten Hörschwellenbestimmung sind, da bei niedrigen Frequenzen stärkere Interaktionen zwischen einzelnen Frequenzen auftreten. Dies spiegelt sich unter anderem in der Amplitudengröße wieder.

Nach experimenteller Schallleitungsschwerhörigkeit konnte für Frequezen ab $8 \mathrm{kHz}$ kein signifikanter Unterschied zwischen ASSR- und Tb-BERA-Hörschwellen gezeigt werde. Diese exemplarische Darstellung konnte zeigen, dass Modulationsfrequenzen über $200 \mathrm{~Hz}$ auch zur frequenzspezifischen Hörschwellenbestimmung bei einer experimentellen SLS geeignet sind.

\subsection{ASSR zur Differentialdiagnose einer SNSH}

Die Reizantworten der transienten (BERA) und lang anhaltenden (ASSR) Stimuli waren trotz unterschiedlicher Schwerhörigkeitsmechanismen in ähnlicher Art und Weise betroffen. In der Gruppe der SNSH-Tiere wurden die kleinsten ASSR-Amplituden bei Bassoon KO Tieren beobachtet. In der Amplituden-Wachstumsfunktion war annähernd kein Wachstum bei zunehmender Intensität zu beobachten. ASSR Potenziale als Antwort auf SAM-Töne entsprechen wahrscheinlich einem synchronisierten (phasengekoppelten) Feuern von Neuronen des auditorischen Hirnstamms und des Kortex oder eines synchronisiertem Netzwerks von Aktivität des Hirnstamms, Mittelhirns und Kortex. Die synaptische Überleitung im ZNS von Bassoon Mäusen ist durch eine erhöhte Anzahl stiller Synapsen gekennzeichnet, während die aktive Synapse wenige, wenn überhaupt vorhandene, Veränderungen zeigt (Altrock et al. 2003). Die geringen Amplituden können zum einen durch die eingeschränkte synaptische Transmission an den bänderlosen Synapsen der IHZ bei den Bassoon Mutanten erklärbar sein (Khimich et al. 2005). Ebenso könnte auch eine gestörte synaptische Transmission im auditorischen Hirnstamm vorhanden sein. Neben des sehr schwachen ASSR-Amplitudenwachstums fiel ebenfalls eine pathologische Tb-BERA Wachstumsfunktion der Jewett-Welle III auf. Das Fehlen von Bassoon spiegelte sich weiterhin durch verzögerte und verbreiterte Jewett-Wellen wieder. Nicht nur eine 
fehlende Welle I, sondern auch veränderte und verzögerte Jewett-Wellen II-V sprechen für ein Vorkommen von Bassoon entlang der Hörbahn (Khimich et al. 2005).

Tiere mit einer SNSH aufgrund einer fehlenden Verstärkungsfunktion der Basiliarmembranschwingungen als Funktion der ÄHZ (KCNQ 4$)$ waren anhand ihrer Hörschwellen nicht von Bassoon Tieren zu unterschieden. Bei überschwelliger Stimulation zeigten die $\mathrm{KCNQ}_{4}$ KO-Tiere ab der Hörschwelle ein sehr steiles Wachstum der ASSR- und BERA-Amplituden. Dieses elektrophysiologische Phänomen des Recruitments ist auch bei Patienten mit einer SNSH bekannt. Vermutlich stellt das Recruitment einen schnell ansteigenden synaptischen Input durch ausreichend intense Stimuli mit folgender Aktivierung weiterer Spiralganglienneurone dar. Wurden die Haarzellen mit überschwelliger Intensität stimuliert, waren die Amplituden der $\mathrm{KCNQ}_{4}$ KO-Tiere ähnlich groß wie die der normalhörenden Tiere. Dimitrijevic et al. (2002) berichteten sogar über größere ASSR-Amplituden bei Patienten mit sensorineuralen Hörstörungen als bei Normalhörenden. Die Tb-BERA-Hörschwelle der KCNQ 4 KO-Tiere war um $49 \mathrm{~dB}$, die ASSR-Hörschwelle um $44 \mathrm{dBSPL}$ gegenüber der gesunden Vergleichsgruppe erhöht. Kharkovets et al. (2000) zeigten bei 4 Wochen alten Tieren eine Erhöhung der Klick-BERA-Hörschwelle um 55 dB SPL. Kharkovets et al. (2006) konnten bei 3 Wochen alten $\mathrm{KCNQ}_{4}$ KO-Tieren noch vorhandene, aber reduzierte DPOAEs nachweisen. In dieser Arbeit waren bei 6-8 Wochen alten Tieren keine DPOAEs mehr darstellbar, was für den Verlust der Funktionsfähigkeit der ÄHZ spricht.

Gesunde Tiere und Bassoon KO-Tiere zeigten signifikant größere Tb-BERA als ASSRAmplituden. ASSR-Stimuli erregen durch ihre frequenzspezifische Eigenschaft die Kochlea schmalbandiger, andererseits ist eine Vergleichbarkeit schwierig, da die Potenziale unterschiedlich generiert und registriert werden. Aufgrund des Recriutment Phänomens war bei den $\mathrm{KCNQ}_{4}$ KO Tieren keine Differenz zwischen ASSR und BERA bezüglich der Amplitudengröße vorhanden. Die Analyse der überschwelligen ASSR- und BERA-Potenzialantworten kann somit auch zur Differenzierung der Pathomechanismen eines an SNSH erkrankten Tieres beitragen. Oft werden die ASSR lediglich als Methode zur Hörschwellenbestimmung genutzt mit der Begründung, dass sie keine Hinweise auf den Entstehungsort der Hörstörung zulassen. Bei speziellen Pathomechanismen jedoch können die Tb-BERA und die ASSR, zusammen mit den DPOAEs helfen, die vorliegenden Mechanismen einer SNSH voneinander abzugrenzen. So ist nicht nur die Hörschwelle entscheidend, vielmehr kann das Gesamtprofil diagnostische Hinweise über die Form 
der hereditären Schwerhörigkeit geben. Ein ähnlicher Ansatz wurde bereits mit TbBERA und DP-Gramm anhand der Bronx-Waltzer Maus verfolgt (Inagaki et al. 2006).

\subsection{Ausblick}

Für die Zukunft bleibt abzuwarten, wie sich die ASSR im Bereich der experimentellen Audiologie bei der Maus etabliert. Nach den Erfahrungen mit der individuell konfigurierbaren psychoakustischen Messstation Tucker-Davis Technologies-III mit detaillierter Einsicht in Aufbau und Funktionsweise, ergab sich die Möglichkeit an jedem Schritt der Stimulusgeneration, - präsentation und -aufzeichnung Einfluss zu nehmen. Aufgrund des sehr aufwendigen Verfahrens wird die Anwendung von frei konfigurierbaren und flexiblen Messplattformen in der Zukunft eine zunehmende Rolle spielen (Van Dun et al. 2008). Ein vereinfachter Messaufbau, basierend auf Soundkarten (Mühler et al, 2005) zum Screenen von Mäusen wäre anwenderfreundlicher, kostengünstiger und ausreichend. Die Ergebnisse der Arbeit zeigten, dass zum Screenen ASSR-Messungen ohne vorherige MTF-Messungen bei fest definierten Modulationsfrequenzen akzeptabel wären (z.B. $600 \mathrm{~Hz}$ ). Die exakte Höhe der Modulationsfrequenz (mittel- oder hochfrequent) spielt für diese Fragestellung eine untergeordnete Rolle, da sich im Hörschwellenbereich die ASSR-Amplitudengrößen nicht signifikant unterscheiden.

Systematische Untersuchungen zu den Ursachen der Variabilität der MTF könnten weiterhin Einflüsse der ASSR-Generatoren auf die Potenziale aufdecken. Denkbar sind Faktoren wie Körpertemperatur oder Narkosetiefe, da beim Mensch bekannt ist, dass $40 \mathrm{~Hz}$ Potenziale durch die Narkosetiefe beeinflusst werden (Plourde et al. 2008).

Eine simultane Registrierung von ASSR und DPOAEs mit einem amplitudenmodulierten Primärton f $f_{1}$ (Oswald et al. 2006, Purcell et al. 2003) wäre eine technische Erweiterung zum SAM-Ton und würde eine weitere Zeitersparnis bedeuten. Für visuell evozierte Potenziale der Elektroretinographie wäre ein ähnliches Prinzip mit einem SAM-Lichtreiz denkbar 


\section{Zusammenfassung}

Die vorliegende Arbeit widmet sich dem Vergleich zweier objektiver Hörtests an gesunden und schwerhörigen Mäusen zur Differenzierung der ursächlichen Pathomechanismen einer sensorineuralen Schwerhörigkeit (SNSH). Einer SNSH liegen sowohl Pathologien im Innenohr als auch am Hörnerv zugrunde. Eine klare Zuordnung der phänotypischen Ausbildung der Hörstörung zu einem spezifischen Defekt ist heute noch nicht realisiert. Anhand zweier definierter SNSH-Mausmodelle (Bassoon und $\mathrm{KCNQ}_{4}$ ) wurde der Nutzen der Auditory Steady-State Responses (ASSR) evaluiert.

Zunächst wurden die ASSR-Messungen erstmalig bei normalhörenden Tieren etabliert und beschrieben. ASSR bei der Maus waren innerhalb von drei Modulationsfrequenzbereichen (unter $200 \mathrm{~Hz}$, von 200- $600 \mathrm{~Hz}$ und über $600 \mathrm{~Hz}$ ) stabil zu erzeugen. Die ASSR-Hörschwellen wurden mit den Hörschwellen der Brainstem Evoked Response Audiometry (BERA) verglichen. Sowohl die subjektiv-visuellen als auch die statistisch-objektiven ASSR-Hörschwellen waren nicht von ihren zugehörigen BERA-Hörschwellen zu unterscheiden.

Im folgenden Teil der Arbeit wurden ASSR- und BERA-Messungen am Mausmodell der SNSH durchgeführt. Tiere mit einem Defekt des Verstärkersystems der äußeren Haarzellen $\left(\mathrm{KCNQ}_{4} \mathrm{KO}\right)$ und Tiere mit einem Defekt der synaptischen Schallkodierung der inneren Haarzellen (Bassoon KO) wurden untersucht. Die ASSR-Hörschwellen beider Gruppen waren mit den BERA-Hörschwellen vergleichbar. Beide Mutanten zeigten einen Anstieg der ASSR- und BERA-Hörschwellen um etwa $40 \mathrm{~dB}$ SPL im Vergleich zu den hörgesunden Tieren gleichen Alters. Tiere, welche an einem Defekt des Verstärkersystems litten, zeigten einen steilen Anstieg der ASSR- und BERA-Amplituden ab dem Hörschwellenbereich. Dieses Recruitmentphänomen stellt vermutlich eine starke Aktivierung synchroner, neuronaler Aktivität über die Hörschwelle hinaus dar. Im Gegensatz zeigte die Gruppe der Tiere mit defekter synaptischer Übertragung ein fehlendes Amplitudenwachstum bei zunehmender Stimulationsintensität, was für eine gestörte Transmitterübertragung an den bänderlosen Synapsen spricht.

Zusammenfassend ließ sich feststellen, dass die ASSR als bekannte elektrophysiologische Methode eine schnelle, frequenzspezifische und objektive Methode zur Hörschwellenbestimmung der Maus darstellt. Zusammen mit der BERA und den Otoakustischen Emissionen gelang es, ein audiologisches Profil der 
sensorineuralen Schwerhörigkeit zu erstellen, welches zur Differentialdiagnose einer SNSH beitragen kann. 


\section{Literaturverzeichnis}

Altrock WD, Tom Dieck S, Sokolv M, Meyer AC, Sigler A, Brakebusch C, Fassler R, Richter K, Boeckers TM, Gundelfinger ED (2003): Functional inactivation of a fraction of excitatory synapses in mice deficient for the active zone protein bassoon. Neuron 37, 787-800

Angenstein F, Hilfert L, Zuschratter W, Altrock WD, Niessen HG, Gundelfinger ED (2008): Morphological and metabolic changes in the cortex of mice lacking the functional presynaptic active zone protein bassoon: a combined 1H-NMR spectroscopy and histochemical study. Cereb Cortex $\underline{18}, 890-7$

Aoyagi M, Kiren T, Kim Y, Suzuki Y, Fuse T, Koike Y (1993): Hear Res 65, 253-61. Optimal modulation frequency for amplitude-modulation following response in young children during sleep.

Aoyagi M, Kiren T, Furuse H, Fuse T, Suzuki Y, Yokota M, Koike Y (1994): Pure-tone threshold prediction by $80-\mathrm{Hz}$ amplitude-modulation following response. Acta Otolaryngol Suppl $\underline{511}, 7-14$

Aoyagi M, Suzuki Y, Yokota M, Furuse H, Watanabe T, Ito T (1999): Reliability of 80-Hz amplitude-modulation-following response detected by phase coherence . Audiol Neurootol $\underline{4}, 28-37$

Arnold S, Burkard R (2002): Inner hair cell loss and steady-state potentials from the inferior colliculus and auditory cortex of the chinchilla. J Acoust Soc Am 112, 590599

Batra R, Kuwada S, Meher VL (1986): The frequency-following response to continuous tones in humans. Hear Res $\underline{21}, 167-177$

Behrend O, Brand A, Kapfer C, Grothe B (2002): Auditory response properties in the superior paraolivary nucleus of the gerbil. J Neurophysiol $\underline{87}$, 2915-28

Beisel KW, Nelson NC, Delimont DC, Fritzsch B (2000): Longitudinal gradients of KCNQ4 expression in spiral ganglion and cochlear hair cells correlate with progressive hearing loss in DFNA2. Brain Res Mol Brain $\underline{82}$ 137-49.

Bradley AP, Wilson WJ (2005): Automated analysis of the auditory brainstem response using derivative estimation wavelets. Audiol Neurootol 10, 6-21 
Brandt A, Striessing J, Moser T (2003): CaV1.3 channels are essential for development and presynaptic activity of cochlea inner hair cells. J Neurosci 23 10832-10840

Brandt A, Khimich D, Moser T (2005): Few CaV1.3 channels regulate the exocytosis of a synaptic vesicle at the hair cell ribbon synapse J Neurosci $\underline{25,11577-11585}$

Brown SD, Hancock JM, Gates H (2006): Understanding Mammalian Genetic Systems: the challenge of phenotyping in the mouse. PLoS Genet 2 , 1131-1137

Buchwald JS, Huang C (1975): Far-field acoustic response: origins in the cat. Science 189, 382-384

Burton MJ, Cohen LT, Rickards FW, McNally KI, Clark GM (1992): Steady-state evoked potentials to amplitude modulated tones in the monkey. Acta Otolaryngol 112 , 745-751

Canale A, Lacilla M, Cavalot AL, Albera R (2006): Auditory steady-state responses and clinical applications. Eur Arch Otorhinolaryngol 263, 499-503

Cheatham MA, Zheng J, Huynh KH, Du GG, Gao J, Zuo J, Navarrete E, Dallos P (2005) Cochlear function in mice with only one copy of the prestin gene. J Physiol $\underline{569} 229$ $-241$

Cohen LT, Rickards FW, Clark GM (1991): A comparison of steady-state evoked potentials to modulated tones in awake and sleeping humans. J Acoust Soc Am $\underline{90}$, 2467-2479

Cone-Wesson B, Rickards F, Poulis C, Parker J, Tan L, Pollard J (2002): The auditrory steady-state response: Clinical observations and applications in infants and children. J Am Acad Audiol 13,-270-282

Coucke P, van Camp G, Djoyodiharjo B, Smith SD, Frants RR, Padberg GW, Darby JK, Huizing EH, Cremers CW, Kimberling WJ (1994): Linkage of autosomal dominant hearing loss to the short arm of chromosome 1 in two families. N Engl J Med 331 , $425-431$

Coucke PJ, Van Hauwe P, Kelley PM, Kunst H, Schatteman I, Van Velzen D, Meyers J, Ensink RJ, Verstreken M, Van Camp G (1999): Mutations in the KCNQ4 gene are responsible for autosomal dominant deafness in four DFNA2 families. Hum Mol Genet $\underline{8}, 1321-1328$

Dau T, Wegner O, Mellert V, Kollmeier B (2000): Auditory brainstem responses with optimized chirp signals compensating basilar-membrane dispersion. J Acoust Soc Am $\underline{3}, 1530-1540$ 
De Leenheer EM, Ensink RJ, Kunst HP, Marres HA, Talebizadeh Z, Declau F, Smith SD, Usami S, Van de Heyning PH, Cremers CW (2002): DFNA2/KCNQ 4 and its manifestations. Adv Otorhinolaryngol $\underline{61}, 41-6$

Delmaghani S, del Castillo FJ, Michel V, Leibovici M, Aghaie A, Ron U, Van Laer L, Ben-Tal N, Van Camp G, Petit C (2006): Mutations in the gene encoding pejvakin, a newly identified protein of the afferent auditory pathway, cause DFNB59 auditory neuropathy. Nat Genet 38, 770-778

Dick O, tom Dieck S, Altrock WD, Ammermüller J, Weiler R, Garner CC, Gundelfinger ED, Brandstätter JH (2003): The presynaptic active zone protein bassoon is essential for photoreceptor ribbon synapse formation in the retina. Neuron $\underline{37}$, 775-786

Dimitrijevic A, John MS, van Roon P, Picton TW (2001): Human auditory steady-state responses to tones independently modulated in both frequency and amplitude. Ear Hear $\underline{22}, 100-111$

Dimitrijevic A, John MS, Van Roon P, Purcell DW, Adamonis J, Ostroff J, Nedzelski JM, Picton TW (2002): Estimating the audiogram using multiple auditory steady-state responses. J Am Acad Audiol 13, 205-224

Dobie RA, Wilson MJ (1996):A comparison of $t$ test, $F$ test, and coherence methods of detecting steady-state auditory-evoked potentials, distortion-product otoacoustic emissions, or other sinusoids. J Acous Soc Am 100, 2236-2245

Dobie RA, Wilson MJ (1998): Low-level steady-state auditory evoked potentials: effects of rate and sedation on detectability. J Acoust Soc Am 104, 3482-3488

Dolphin WF, Mountain DC (1992): The envelope following response: Scalp potentials elicited in the mongolian gerbil using sinusoidally AM acoustic signals. Hear Res 58, 70-78

Finneran JJ, London HR, Houser DS (2007): Modulation rate transfer functions in bottlenose dolphins (Tursiops truncatus) with normal hearing and high-frequency hearing loss. J Comp Physiol A $\underline{193}$, 835-843

Fullerton BC, Kiang NY (1990): The effect of brainstem lesions on brainstem auditory evoked potentials in the cat. Hear Res $\underline{49}$, 363-390

Galambos R, Makeig S, Talmachoff PJ (1981): A 40-Hz auditory potential recorded from the human scalp. Proc Natl Acad Sci USA 78, 2643-2647

Gao J, Wu X, Zuo J (2004): Targeting hearing genes in mice.Brain Res Mol Brain Res 132, 192-207 
Ghiglieri V, Picconi B, Sgobio C, Bagetta V, Barone I, Paillè V, Di Filippo M, Polli F, Gardoni F, Calabresi P (2009): Epilepsy-induced abnormal striatal plasticity in Bassoon mutant mice. Eur J Neurosci 29, 1979-1993

Glaser EM, Suter CM, Dasheiff R, Goldberg A (1976): The human frequency-following response: its behavior during continuous tone and tone burst stimulation. Electroencephalogr Clin Neurophysiol 40, 25-32

Glowatzki E, Fuchs PA (2002): Transmitter release at the hair cell ribbon synapse. Nat Neurosci $\underline{5}, 147-154$

Griesinger CB, Richards CD, Ashmore JF (2005): Fast vesicle replenishment allows indefatigable signalling at the first audiory synapse. Nature $435,212-215$

Griffiths SK, Chambers RG (1991): The amplitude modulation-following response as an audiometric tool. Ear Hear 4 , 235-241

Gross M, Finckh-Krämer U, Spormann-Lagodzinski ME (1999): Deutsches Zentralregister für kindliche Hörstörungen. Bilanz nach den erten zwei Jahren. Dt Ärztebl 95, 45-50

Gross M, Lange K, Spormann-Lagodzinski ME (2001): Angeborene Erkrankungen des Hörvermögens bei Kindern. Teil 2: Genetische Hörstörungen. HNO $\underline{49}$, 602-617

Herdman AT, Stapells DR (2001): Thresholds determined using the monotic and dichotic multiple auditory steady-state response technique in normal-hearing subjects. Scand Audiol 30, 41-49

Herdman AT, Stapells DK (2003): Auditory steady-state response thresholds of adults with sensorineural hearing impairments.Int J Audiol 42, 237-248

Herdman AT, Picton TW, Stapells DR (2002): Place specifity of multiple auditory steadystate responses. J Acoust Soc Am 112, 1569-1582

Hildebrand MS, Tack D, McMordie SJ, DeLuca A, Hur IA, Nishimura C, Huygen P, Casavant TL, Smith RJ (2008): Audioprofile-directed screening identifies novel mutations in KCNQ4 causing hearing loss at the DFNA2 locus. Genet Med 10, 797-804

Hoke M und Hoke ES: Wandel in Diagnostik und Therapie: Auditorische, Reiz-und Ereigniskorrelierte Potentiale und Magnetfelder in der audiologischen Diagnostik. In: Koch U, Theissing J, Hrsg. HNO-Heilkunde, Kopf- und Hals- Chirurgie im Wandel. Springer Verlag, Berlin, Heidelberg, New York 1997, 175-217 
Hudspeth AJ, Corey DP (1997): Sensitivity, polarity, and conductance change in the response of vertebrate hair cells to controlled mechanical stimuli. Proc Natl Acad Sci U S A $74,2407-2411$

Inagaki M, Kon K, Suzuki S, Kobayashi N, Kaga M, Nanba E (2006): Characteristic findings of auditory brainstem response and otoacoustic emission in the Bronx waltzer mouse. Brain Dev 28, 617-624

Janssen T: Otoakustische Emissionen; in: Praxis der Audiometrie. Lehnhardt E, Laszig R, Hrsg, Thieme Verlag Stuttgart 2001, 79 - 107

Japaridze G, Shakarishvili R, Kevanishvili Z (2002): Auditory brainstem, middle-latency, and slow cortical responses in multiple sclerosis. Acta Neurol Scand 106, 47-53.

Jeng FC, Abbas PJ, Brown CJ, Miller CA, Nourski KV, Robinson BK (2008): Electrically Evoked Auditory Steady-State Responses in Guinea Pigs Audiol Neurootol $\underline{13}$, 161171

Jentsch TJ (2000): Neural $\mathrm{KCNQ}_{4}$ potassium channels: Physiology and role in disease. Nat Rev Neurosci 1, 21-30

Jerger J, Chmiel R, Frost JD Jr, Coker N (1986): Effect of sleep on the auditory steady state evoked potential.Ear Hear $\underline{7}, 240-245$

Jewett DL, Romano MN, Williston JS (1970): Human auditory evoked potentials: possible brain stem components detected on the scalp. Science 167, 1517-1518

John MS, Picton TW (2000): Human auditory steady-state responses to amplitudemodulated tones: phase and latency measurements. Hear Res $\underline{141}$ 57-79

John MS, Lins OG, Boucher BL, Picton TW (1998): Multiple auditory steady-state responses (MASTER): stimulus and recording parameters. Audiology 37, 59-82

John MS, Dimitrijevic A, van Roon P, Picton TW (2001): Multiple auditory steady-state responses to AM and FM stimuli. Audiol Neurootol $\underline{6}$, 12-27

Kalatzis V, Petit C (1998): The fundamental and medical impacts of recent progress in research on hereditary hearing loss. Hum Mol Genet Z 1589-1597

Kemp DT (1978): Stimulated acoustic emissions from within the human auditory system. J Acoust Soc Am 64, 1386-1391

Kileny P (1981): The frequency specificity of tone-pip evoked auditory brain stem responses. Ear Hear $\underline{2}, 270-275$

Kharkovets T, Hardelin JP, Safieddine S, Schweizer M, El-Amraoui A, Petit C, Jentsch TJ (2000): $\mathrm{KCNQ}_{4}$, a $\mathrm{K}^{+}$channel mutated in a form of dominant deafness, is expressed 
in the inner ear and the central auditory pathway. Proc Natl Acad Sci USA 978, 4333-4338

Kharkovets T, Dedek K, Maier H, Schweizer M, Khimich D, Nouvian R, Vardanyan V, Lewer R, Moser T, Jentsch TJ (2006): Mice with altered $\mathrm{KCNQ}_{4} \mathrm{~K}^{+}$channels implicate sensory outer hair cells in human proggressive deafness. EMBO J 25 , 642-652

Khimich D, Nouvian R, Pujol R, Tom Dieck S, Egner A, Gundelfinger ED, Moser T (2005): Hair cell synaptic ribbons are essential for synchronous auditory signaling. Nature 434, 889-894

Kiren T, Aoyagi M, Furuse H, Koike Y (1994): An experimental study on the generator of amplitude-modulation following response. Acta Otolaryngol Suppl $\underline{511}$, 28-33

Kros CJ, Ruppersberg JP, Rüsch A (1998) Expression of a potassium current in inner hair cells during development in mice. Nature $\underline{394}, 281-284$

Kubisch C, Schroeder BC, Friedrich T, Lutjohann B, El-Amraoui A, Marlin S, Petit C, Jentsch TJ (1999): $\mathrm{KCNQ}_{4}$, a novel potassium channel expresses in sensory outer hair cells, is mutated in dominant deafness. Cell $\underline{96,437-446}$

Kuwada S, Batra R, Maher VL (1986): Scalp potentials of normal and hearing-impaired subjects in response to sinusoidally amplitude-modulated tones. Hear Res $\underline{21}, 179$ 192.

Kuwada S, Anderson JS, Batra R, Fitzpatrick DC, Teissier N, D'Angelo WR (2002): Sources of the scalp-recorded amplitude-modulation following response. J Am Acad Audiol $13,188-204$

Lacas-Gervais S, Guo J, Strenzke N, Scarfone E, Kolpe M, Jahkel M, De Camilli P, Moser T, Rasband MN, Solimena M (2004): BetaIVSigma1 spectrin stabilizes the nodes of Ranvier and axon initial segments. J Cell Biol 166, 983-990

Lehnhardt E, Laszig R: Praxis der Audiometrie. Thieme Verlag, Stuttgart 2001, 83

Lenzi D, Runyeon JW, Crum J, Ellisman MH, Roberts WM (1999): Synaptic Vesicle Populations in Saccular Hair Cells Reconstructed by Electron Tomography. J Neurosci $\underline{19}, 119-132$

Levi EC, Folsom RC, Dobie RA (1993): Amplitude-modulation following response (AMFR): effects of modulation rate, carrier frequency, age, and state. Hear Res $\underline{68}$, $42-52$ 
Levine RA, Gardner JC, Fullerton BC, Stufflebeam SM, Carlisle EW, Furst M, Rosen BR, Kiang NY (1993): Effects of multiple sclerosis brainstem lesions on sound lateralization and brainstem auditory evoked potentials. Hear Res $\underline{68}$, 73-88

Liberman MC, Gao J, He DZ, Wu X, Jia S, Zuo J (2002): Prestin is required for electromotility of the outer hair cells and for the cochlear amplifier. Nature 4,300 304

Lins OG, Picton TW (1995): Auditory steady-state responses to multiple simultaneous stimuli Electroencephalogr Clin Neurophysiol 96, 420-432

Lins OG, Picton TW Boucher BL, Durieux-Smith A, Champagne SC, Moran LM, PerezAbalo MC, Martin V, Savio G. (1996): Frequency-specific audiometry using steadystate responses. Ear Hear 17, 81-96

Luts $\mathrm{H}$, Wouters J (2004): Hearing assessment by recording multiple auditory steadystate responses: the influence of test duration. Int J Audiol $\underline{8}, 471-478$

Luts H, Van Dun B, Alaerts J, Wouters J (2008): The influence of the detection paradigm in recording auditory steady-state responses. Ear Hear $\underline{4}$, 638-650

Mäkelä JP, Karmos G, Molnár M, Csépe V, Winkler I (1990): Steady-state responses from the cat auditory cortex. Hear Res $\underline{45}, 41-50$

Marcotti W, Kros CJ (1999):Developmental expression of the potassium current $I_{K, n}$ contributes to maturation of mouse outer hair cells. J Physiol $\underline{520}$, 653-660

Marcus DC, Wu T, Wangemann P, Kofuji P (2002): KCNJ10 (Kir4.1) potassium channel knockout abolishes endocochlear potential. Am J Physiol Cell Physiol 282, 403-407.

Markessis E, Poncelet L, Colin C, Coppens A, Hoonhorst I, Deggouj N, Deltenre P (2006): Auditory steady-state evoked potentials (ASSEPs): a study of optimal stimulation parameters for frequency-specific threshold measurement in dogs. Clin Neurophysiol 117, 1760- 1771

Martin GK, Vazquez AE, Jimenez AM, Stagner BB, Howard MA, Lonsbury-Martin BL (2007): Comparison of distortion product otoacoustic emissions in 28 inbred strains of mice. Hear Res $\underline{243}, 59-72$

Mauer G, Döring WH: Generators of amplitude modulation following response (AMFR). Paper presented at the 16th meeting of the International Evoked Response Audiometry Study Group, Tromso, Norway 1999

Melcher JR, Kiang NY (1996): Generators of the brainstem auditory evoked potential in the cat. III:Identified cell populations. Hear Res $\underline{93}$, 52-71. 
Melcher JR, Knudson IM, Fullerton BC, Guinan JJ Jr, Norris BE, Kiang NY (1996a): Generators of the brainstem auditory evoked potential in cat. I. An experimental approach to their identification.Hear Res 93, 1-27

Melcher JR, Guinan JJ Jr, Knudson IM (1996b): Generators of the brainstem auditory evoked potential in the cat. II. Correlating lesion sites with waveformchanges. Hear Res $\underline{93}$ 28-51

Meyer AC, Frank T, Khimich D, Hoch G, Riedel D, Chapochnikov NM, Yarin YM, Harke B, Hell SW, Egner A, Moser T (2009): Tuning of synapse number, structure and function in the cochlea. Nat Neurosci $\underline{12}, 44-53$.

Möller AR, Jannetta P, Bennett M, Möller MB (1981): Neural generators of brainstem evoked potentials. Results from human intracranial recordings. Ann Otol Rhinol Laryngol 90, 591-596

Morton NE (1991): Genetic epidemiology of hearing impairment. Ann NY Acad Sci $\underline{630}$, 16-31

Moser T, Beutner D (2000): Kinetics of exocytosis and endocytosis at the cochlear inner hair cell afferent synapse of the mouse. Proc Natl Acad Sci U S A 97, 883-888

Mühler R, Ziese M, von Specht H (2005): Registrierung von auditory steady-state responses (ASSR) mit Laborsystemen. Z Audiol 44 , 20-30

Müller M, v Hünerbein K, Hoidis S, Smolders JW (2005): A physiological place-frequency map of the cochlea in the CBA/J mouse. Hear Res $\underline{202}$, 63-73

Nie (2008): $\mathrm{KCNQ}_{4}$ mutations associated with nonsyndromic progressive sensorineural hearing loss. Curr Opin Otolaryngol Head Neck Surg 16, 441-444

Nouvian R, Göttingen:persönliche Mitteilung und Darstellung, 2006

Nouvian R, Beutner D, Parsons TD, Moser T (2006): Structure and function of the hair cell ribbon synapse. J Membr Biol 209, 153-165.

Ohlemiller KK (2006): Contributions of mouse models to understanding of age- and noise-related hearing loss. Brain Res 1091, 89-102

Oliver D, Knipper M, Derst C, Fakler B (2003): Resting potential and submembrane calcium concentration of inner hair cells in the isolated mouse cochlea are set by KCNQ-type potassium channels. J Neurosci 23, 2141-2149

Oswald JA, Rosner T, Janssen T (2006): Hybrid measurement of auditory steady-state responses and distortion product otoacoustic emissions using an amplitudemodulated primary tone. J Acoust Soc Am 119, 3886-3895 
Pantev C, Lütkenhöner B, Hoke M, Lehnertz K. (1986): Comparison betweeen simultaneously recorded auditory-evoked magnetic fields and potentials elicited by ipsilateral, contralateral and binaural tone burst stimulation. Audiology $25,54-$ 56

Parkinson NJ, Olsson CL, Hallows JL, McKee-Johnson J, Keogh BP, Noben-Trauth K, Kujawa SG, Tempel BL (2001): Mutant beta-spectrin 4 causes auditory and motor neuropathies in quivering mice. Nat Genet 29, 61-65

Petit C, Levilliers J, Hardelin JP (2001): Molecular genetics of hearing loss. Annu Rev Genet $\underline{35}, 589-646$

Pickles JO, Corey DP (1992): Mechanoelectrical transduction by hair cells. Trends Neurosci 15, 254-259

Picton TW, Hillyard SA, Krausz HI, Galambos R (1974): Electroencephalogr Human auditory evoked potentials. I. Evaluation of components. Clin Neurophysiol $\underline{36}, 181$

Picton TW, Ouellette J, Hamel G, Smith AD (1979): Brainstem evoked potentials to tonepips in notched noise. J Otolaryngol $\underline{8}, 289-314$

Picton TW, Dimitrijevic A, John MS, Van Roon P (2001): The use of phase in the detection of auditory steady-state responses. Clin Neurophysiol $\underline{112}$ 1698-1711

Picton TW, John MS, Dimitijevic A, Purcell D (2003): Human auditory steady-state responses. Int J Audiol 42, 177-219

Picton TW, Dimitijevic A, Perez-Abalo M, van Roon P (2005): Estimating audiometric thresholds using auditory steady-state responses. J Am Acad Audiol 16, 143-156

Platzer J, Engel J, Schrott-Fischer A, Stephan K, Bova S, Chen H, Zheng H, Striessnig J (2000): Congenital deafness and sinoatrial node dysfunction in mice lacking class D L-type $\mathrm{Ca}^{2+}$ channels. Cell $\underline{102}, 89-97$

Plourde G, Garcia-Asensi A, Backman S, Deschamps A, Chartrand D, Fiset P, Picton TW (2008): Attenuation of the 40-hertz auditory steady state response by propofol involves the cortical and subcortical generators. Anaesthesiology 108, 233-242

Purcell DW, John MS, Picton TW (2003): Concurrent measurement of distortion product otoacoustic emissions and auditory steady state evoked potentials. Hear Res $\underline{176}$, 128-141

Regan D (1966): Some characteristics of average steady-state and transient responses evokes by modulated light. Electroencephalogr Clin Neurophysiol 20, 238-248 
Regan D: Human brain electrophysiology: evoked potentials and evokes magnetic fields in science and medicine. Elsevier Science, New York 1989

Reyes SA, Lockwood AH, Salvi RJ, Coad ML, Wack DS, Burkard RF (2005): Mapping the $40-\mathrm{Hz}$ auditory steady-state response using current density reconstructions. Hear Res $\underline{204}, 1-15$

Richter K, Langnaese K, Kreutz MR, Olias G, Zhai R, Scheich H, Garner CC, Gundelfinger ED (1999): Presynaptic cytomatrix protein bassoon is localized at both excitatory and inhibitory synapses of rat brain. Comp Neurol 408, 437-448

Rickards FW, Clark GM: Steady state evoked potentials to amplitude modulated tones. In: Nodar RH, Barber C, Hrsg. Evoked Potentials II. Butterworth Publishers, Boston $1984,163-168$

Rocha-Sanchez SM, Morris KA, Kachar B, Nichols D, Fritzsch B, Beisel KW (2007): Developmental expression of $\mathrm{KCNQ}_{4}$ in vestibular neurons and neurosensory epithelia. Brain Res $\underline{1139}, 117-125$

Ross B, Draganova R, Picton TW, Pantev C (2003): Frequency specificity of 40-Hz auditory steady-state responses. Hear Res 186, 57-68

Roux I, Safieddine S, Nouvian R, Grati M, Simmler MC, Bahloul A, Perfettini I, Le Gall M, Rostaing P, Hamard G, Triller A, Avan P, Moser T, Petit C (2006): Otoferlin, defective in a human deafness form, is essential for exocytosis at the auditory ribbon synapse. Cell 127, 277-289.

Ryan A, Dallos P (1975): Effect of absence of cochlear outer hair cells on behavioral auditory threshold. Nature $\underline{253}, 44-46$

Scherf RL, Brokx J, Wuyts FL, Van de Heyning PH (2006): The ASSR: Clinical application in normal-hearing and hearing-impaired infants and adults, comparison with the click evoked ABR and pure-tone audiomery. Int J Audiol 45, 281-286

Scherg M, von Cramon D (1985a):Two bilateral sources of the late AEP as identified by a spatio-temporal dipole model. Electroencephalogr Clin Neurophysiol 62, 32-44

Scherg M, von Cramon D (1985b): Electroencephalogr Clin Neurophysiol 62, 290-299

Schmidt GN, Müller J, Bischoff P (2008): Measurement of the depth of anaesthesia. Anaesthesist $\underline{57}, 9-30$

Schmitz F, Königstorfer A, Südhof TC (2000): RIBEYE, a component of synaptic ribbons: a protein's journey through evolution provides insight into synaptic ribbon function. Neuron $\underline{28}, 857-872$ 
Schoch S, Gundelfinger ED (2006): Molecular organization of the presynaptic active zone. Cell Tissue Res $\underline{326}$, 379-391

Schoonhoven R, Boden CJ, Verbunt JP, de Munck JC (2001): A whole head MEG study of the amplitude-modulation-following response: phase coherence, group delay and dipole source analysis. Clin Neurophysiol 114, 2096-2106

Selyanko AA, Hadley JK, Wood IC, Abogadi3e FC, Jentsch TJ, Brown DA (2000): Inhibition of KCNQ1-4 potassium channels expressed in mammalian cells via M1 muscarinic acetylcholine receptors. J Physiol $\underline{522}$, 349-355

Shen Z, Marcus DC, Sunose H, Chiba T \& Wangemann P (1997): $I_{s K}$ channel in strial marginal cell: Voltage-dependence, ion selectivity, inhibition by 293B and sensitivity to clofilium. Audit Neurosci $\underline{3}, 215-230$

Sininger YS, Abdala C, Cone-Wesson B (1997): Auditory threshold sensitivity of the human neonate as measured by the auditory brainstem response. Hear Res 104 27-38

Sohn W (2001): Schwerhörigkeit in Deutschland. Repräsentative HörscreeningUntersuchung bei 2000 Probanden in 11 Allgemeinpraxen. Z Allg Med 77 143-147

Spiwoks-Becker I, Maus C, tom Dieck S, Fejtová A, Engel L, Wolloscheck T, Wolfrum U, Vollrath L, Spessert R (2009): Active zone proteins are dynamically associated with synaptic ribbons in rat pinealocytes. Cell Tissue Res $\underline{333}, 185-95$

Stapells DR, Makeig S, Galambos R (1987): Auditory steady-state responses: threshold prediction using phase coherence. Electroencephalogr Clin Neurophysiol $\underline{67}, 260-$ 270

Stapells DR, Oates P (1997): Estimation of the pure-tone audiogram by the auditory brainstem response: a review. Audio \& Neurootol $2,257-280$

Starr A, Zaaroor M (1990): Eighth nerve contributions to cat auditory brainstem responses (ABR). Hear Res $\underline{48}$, 151-160

Steel KP, Kros CJ (2001): A genetic approach to understanding auditory function. Nat Genet 27,143-149

Sterling P, Matthews G (2005): Structure and function of ribbon synapses. Trends Neurosci 28, 20-29

Strenzke N, Pauli-Magnus D, Meyer A, Brandt A, Maier H, Moser T (2008): Update on physiology and pathophysiology of the inner ear. HNO $\underline{56}, 27-37$ 
Stürzebecher E, Cebulla M, Wernecke KD (1996): Objective Response Detection in the Frequency Domain: Comparison of Several q-Sample Tests. Audiol Neurootol 4, 211

Swanepoel DW, Erasmus H (2007): Auditory steady-state responses for estimating moderate hearing loss. Eur Arch Otorhinolaryngol 264,755-759

Synder RL, Schreiner CE (1987): Auditory neurophonic responses to amplitude modulated tones: transfer functions and forward masking. Hear Res $\underline{31}$, 79-91

Szalda K, Burkard R (2005): The effects of nembutal anesthesia on the auditory steadystate response (ASSR) from the inferior colliculus and auditory cortex of the chinchilla. Hear Res 203, 32-44

tom Dieck S, Sanmarti- Vila L, Langnaese K, Richter K, Kindler S, Soyke A, Wex H, Smalla KH, Garner CC, Gundelfinger ED (1998): Bassoon, a novel zinc-finger CAG/ glutamine-repeat protein selectively localized at the active zone of presynaptic nerve terminals. J Cell Biol $\underline{142}, 499-509$

van Camp G, Smith RJH: Hereditary Hearing Loss Homepage. URL: http://webh01.ua.ac.be/hhh/

Van Dun B, Verstraeten S, Alaerts J, Luts H, Moonen M, Wouters J (2008): A flexible research platform for multi-channel auditory steady-state response measurements. J Neurosci Method 169, 239-248

van der Reijden CS, Mens LH, Snik AF (2006): Frequency-specific objective audiometry: tone-evoked brainstem responses and steady-state responses to $40 \mathrm{~Hz}$ and $90 \mathrm{~Hz}$ amplitude modulated stimuli. Int J Audiol 45, 40-45

Vander Werff KR, Brown CJ (2002): Comparison of auditory steady-state response and auditory brainstem response thresholds in children. J Am Acad Audiol 13, 227-235

Vrijens K, Van Laer L, Van Camp G (2008): Human hereditary hearing impairment: mouse models can help to solve the puzzle. Hum Genet $124,325-48$

Wangemann P (2006): Supporting sensory transduction: Cochlear fluid homeostasis and the endocochlear potential. J Physiol $\underline{576}, 11-21$

Winter C, tom Dieck S, Boeckers TM, Bockmann J, Kämpf U, Sanmartí-Vila L, Langnaese K, Altrock W, Stumm M, Gundelfinger ED (1999): The presynaptic cytomatrix protein Bassoon: sequence and chromosomal localization of the human BSN gene. Genomics 57, 389-397 
Yang CH, Chen HC, Hwang CF (2008): The prediction of hearing thresholds with auditory steady-state responses for cochlear implanted children. Int J Pediatr Otorhinolaryngol $\underline{72}, 609-617$

v Békésy G (1928): Zur Theorie des Hörens: Die Schwingungsform der Basilarmembran. Phys Z 29, 793-810

v Békésy G: Experiments in Hearing. McGraw Hill, New York 1960

Zheng J, Shen W, He DZ, Long KB, Madison LD, Dallos P (2000): Prestin is the motor protein of the cohlear outer hair cells. Nature 405,149-155

Zheng QY, Johnson KR, Erway LC (1999): Assessment of hearing in 80 inbred strains of mice by ABR threshold analyses. Hear Res 130, 94-107

Zhou R, Assouline JG, Abbas PJ, Messing A, Gantz BJ (1995): Anatomical and physiological measures of auditory system in mice with peripheral myelin deficiency. Hear Res $\underline{88}$, 87-97 


\section{Danksagung}

Mein Dank gilt Prof. Dr. T. Moser für die Bereitstellung des interessanten Themas sowie für die außerordentlich gute und angenehme Betreuung. Insbesondere während der Verfassung der Publikation und der Fertigstellung der Dissertation ein großer Dank für die vielfältige Kritik und Diskussionbereitschaft.

Ich danke Gerhard Hoch für die hervorragende technische Betreuung, die vielen geduldigen Erklärungen und Hilfestellungen. Ohne ihn wäre die Durchführung der Arbeit nicht möglich gewesen.

Ebenfalls geht ein großer Dank an alle die 2007 zur Publikation der Arbeit beigetragen haben. Insbesondere Gerhard Hoch und Dr. Nicola Strenzke haben durch viele Diskussionen und Anmerkungen einen großen Anteil hieran geleistet. Vielen Dank für theoretischen und praktischen Rat und Tat zu jeder Zeit!

Bei Dr. Thomas Jentsch, Zentrum für Molekulare Neurobiologie in Hamburg, und Dr. Susanne tom Dieck, Max-Planck Institut für Hirnforschung in Frankfurt am Main, möchte ich mich für die Bereitstellung eines Teils der Versuchstiere bedanken.

Ebenso danke ich Christian Rüdiger für die Mitarbeit und stets hilfsvolle Unterstützung und Margitta Köppler für die durchgeführten PCR Analysen

Bei Brigitte Higazi möchte ich mich für das Korrekturlesen während der Endphase der Arbeit bedanken sowie für die vielen kleinen organisatorischen Hilfestellungen. 
-72 - 